\title{
SATELLITE REMOTE SENSING OF GLOBAL RAINFALL USING PASSIVE MICROWAVE RADIOMETRY
}
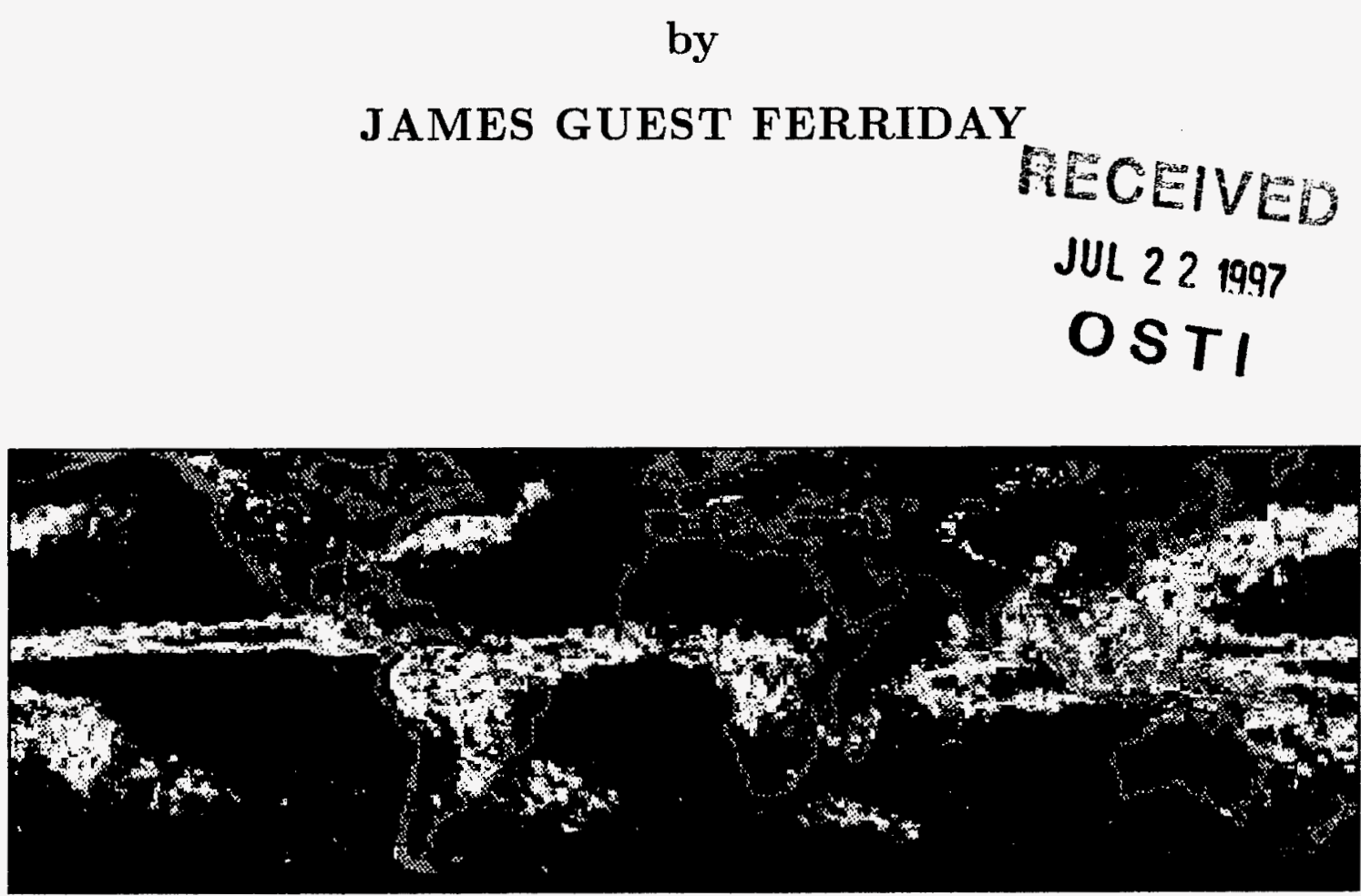

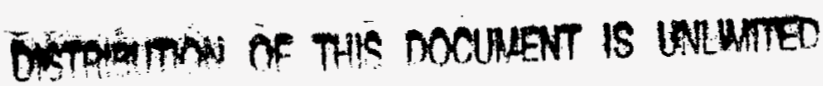

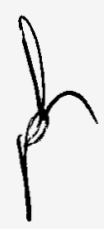

MASTER

Colorado Center for Astrodynamics Research University of Colorado Boulder, Colorado 


\section{DISCLAIMER}

This report was prepared as an account of work sponsored by an agency of the United States Government. Neither the United States Government nor any agency thereof, nor any of their employees, makes any warranty, express or implied, or assumes any legal liability or responsibility for the accuracy, completeness, or usefulness of any information, apparatus, product, or process disclosed, or represents that its use would not infringe privately owned rights. Reference berein to any specific commercial product, process, or service by trade name, trademark, manufacturer, or otherwise does not necessarily constitute or imply its endorsement, recommendation, or favoring by the United States Government or any agency thereof. The views and opinions of authors expressed herein do not necessarily state or reflect those of the United States Government or any agency thereof. 
SATELLITE REMOTE SENSING OF GLOBAL RAINFALL USING PASSIVE MICROWAVE RADIOMETRY

by

JAMES GUEST FERRIDAY

B.S., University of Colorado, 1989

M.S., University of Colorado, 1991

\author{
A thesis submitted to the \\ Faculty of the Graduate School of the \\ University of Colorado in partial fulfillment \\ of the requirements for the degree of \\ Doctor of Philosophy \\ Department of Aerospace Engineering Sciences


The Government reserves for itself and others acting on its behalf a royalty free, nonexclusive, irrevocable, world-wide license for govermental purposes to publish, distribute, translate, duplicate, exhibit, and perform any such data copyrighted by the contractor. 
This thesis for the Doctor of Philosophy degree by

James Guest Ferriday

has been approved for the

Department of

Aerospace Engineering Sciences

by
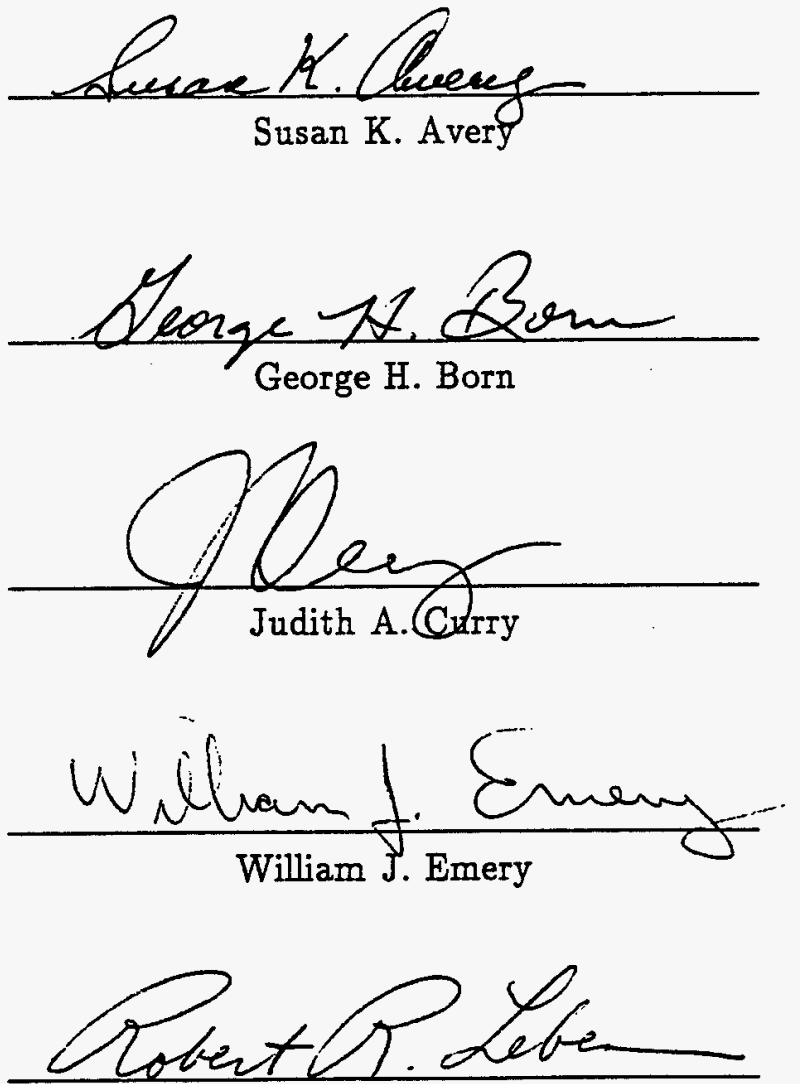

Robert R. Leben

Date November 8, 1994 
Ferriday, James Guest (Ph.D., Aerospace Engineering Sciences)

Satellite Remote Sensing of Global Rainfall Using Passive Microwave Radiometry

Thesis directed by Professor Susan K. Avery

\begin{abstract}
Global rainfall over land and ocean is estimated using measurements of upwelling microwaves by a satellite passive microwave radiometer. Radiative transfer calculations through a cloud model are used to parameterize an inversion technique for retrieving rain rates from brightness temperatures measured by the Special Sensor Microwave/Imager (SSM/I). The rainfall retrieval technique is based on the interaction between multi-spectral microwave radiances and millimeter sized liquid and frozen hydrometeors distributed in the satellite field-of-view. The rain rate algorithm is sensitive to both hydrometeor emission and scattering while being relatively insensitive to extraneous atmospheric and surface effects. Separate formulations are used over ocean and land to account for different background microwave characteristics and the algorithm corrects for inhomogeneous distributions of rain rates within the satellite field-of-view.

Estimates of instantaneous and climate scale rainfall are validated through comparisons with modeled clouds, surface radars, rain gauges and alternative satellite estimates. The accuracy of the rainfall estimates is determined from a combination of validation comparisons, theoretical sampling error calculations, and modeled sensitivity to variations in atmospheric and surface radiative properties. An error budget is constructed for both instantaneous rain rates and climate scale global estimates. At a one degree resolution, the root mean square errors in instantaneous rain rate estimates are $13 \%$ over ocean and $20 \%$ over land. The root mean square errors in global rainfall totals over a four month period are found to be $46 \%$ over ocean and $63 \%$ over land.
\end{abstract}


Global rainfall totals are computed on a monthly scale for a three year period from 1987 to 1990 . The time series is analyzed for climate scale rainfall distribution and variability. Monthly rainfall patterns over the northwestern Atlantic Ocean exhibit a strong correlation between increased rainfall and the warmer waters of the Gulf Stream. Over northern Africa, a rain edge detection technique is applied to a monthly time series to track the propagation of heavy convective rainfall associated with the ITCZ as it moves latitudinally across the Sahel. Finally, variability in global seasonal rainfall observed during the El Niño Southern Oscillation shows that the variability of climate scale rainfall is equal in magnitude to the mean rainfall itself. The most prominent global change associated with El Niño is a shift in the heaviest rainfall from the western to the central and eastern Pacific Ocean. 


\section{Acknowledgements}

I am grateful to all who have helped along the way. Special thanks to Susan Avery for her guidance and patience as my thesis advisor. Susan has offered expertise in remote sensing using both radar and passive microwave systems and has contributed to the analysis of the global rainfall climatology. Robert Chase was the first to encourage me to pursue research in remote sensing and provided the initial opportunity. George Born has time and again offered assistance and guidance during my time at the Colorado Center for Astrodynamics Research. Christian Kummerow of the NASA Goddard Space Flight Center introduced me to the beam filling problem and provided radar and cloud model data as well as a radiative transfer solver. Kelly Luetkemeyer developed the distributed information system used for data processing and analysis and has applied his expertise to all aspects of the research. Wesley Berg developed the software for processing the SSM/I data and has contributed helpful suggestions and valuable advice. Robert Leben directed the numerical analysis used in the study of the Gulf Stream. Judy Curry has led study groups in precipitation remote sensing and shared her knowledge of rainfall remote sensing during the development of the rainfall retrieval algorithm. Bill Emery has taught data analysis and remote sensing systems courses providing the background for this study and has improved this dissertation. Each of these individuals has influenced my graduate research and will be fondly remembered.

This research was sponsored in part by NASA WetNet grant NAGW-1960 and in part by the U.S. Department of Energy, under appointment to the Graduate Fellowships for Global Change administered by Oak Ridge Institute for Science and Education. 


\section{DEDICATION}

To my parents, David and Virginia, and brother, David. 


\section{CONTENTS}

\section{Chapter}

1 RAINFALL REMOTE SENSING ................... 1

1.1 Observational requirements . . . . . . . . . . . . . 1

1.2 Rainfall monitoring techniques . . . . . . . . . . . . . 2

1.3 Rainfall retrieval using $\operatorname{SSM} / \mathrm{I} \ldots \ldots \ldots \ldots$

2 PASSIVE MICROWAVE THEORY . . . . . . . . . . . 6

2.1 Cloud modeling . . . . . . . . . . . . 6

2.2 Radiative transfer theory . . . . . . . . . . . . . 9

$2.3 \mathrm{SSM} / \mathrm{I}$ description $\ldots \ldots \ldots \ldots \ldots$

2.4 Calculations of upwelling microwave radiances . . . . . . 10

2.5 Global brightness temperature maps . . . . . . . . . . 15

3 RAINFALL ESTIMATION USING SSM/I . . . . . . . . . . 22

3.1 Algorithm formulation . . . . . . . . . . . . 22

3.2 Rain screening . . . . . . . . . . . . . 23

3.3 Rain rate calculation . . . . . . . . . . . . . 29

3.4 Algorithm sensitivity analysis ... . . . . . . . . 34

3.5 Algorithm implementation ................. . 40

4 ALGORITHM VALIDATION AND ERROR BUDGET . . . . . . . 47

4.1 Characterization of errors . . . . . . . . . . . 47

4.2 Intercomparison of rainfall detection procedures over land . . 50

4.3 Comparison to a dynamical cloud model . . . . . . . . . 57

4.4 Comparison with surface radar . . . . . . . . . . . . 64

4.5 Algorithm intercomparison programs . . . . . . . . . 71 
4.6 Validation of monthly global rainfall totals . . . . . . . . 75

4.7 Calculation of an error budget $\ldots \ldots \ldots$. . . . . . 90

4.7.1 Errors in instantaneous estimates .......... 90

4.7.2 Errors in monthly estimates . . . . . . . . . . 92

5 CLIMATE SCALE RAINFALL ANALYSIS $\ldots \ldots \ldots$

5.1 Rainfall climatology . . . . . . . . . . . . . . . . . 97

5.2 Global changes in rainfall associated with ENSO . . . . . . 107

5.3 Coupling of rainfall and sea surface temperature over the Gulf Stream ......................... 110

5.4 Rain edge detection over the African Sahel . . . . . . . . . 119

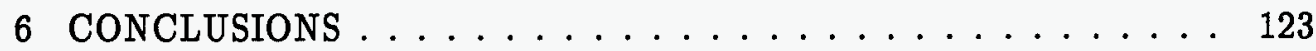

Bibliography ............................ 126 


\section{TABLES}

Table

2.1 Parameters used in the cloud model for theoretical radiative trans-

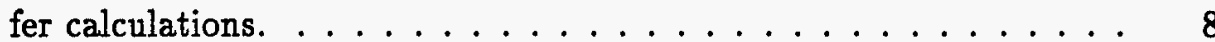

4.1 Coordinate locations of surface precipitation radar sites used in comparisons with coincident SSM/I overpasses. . . . . . . . 65

4.2 Times (UTC) for nine precipitation radar scans used in comparisons with coincident SSM/I overpasses. . . . . . . . . 65

4.3 Statistics calculated from a comparison of the SSM/I algorithm and the Global Precipitation Climatology Center continental raingauge database using monthly total rainfall between $60^{\circ} \mathrm{N}$ and $60^{\circ} \mathrm{S}$ latitude for the period of August through November, 1987 at a resolution of $2.5^{\circ} \ldots \ldots \ldots \ldots \ldots \ldots$

4.4 Statistics calculated from a comparison of the SSM/I ocean algorithm and the Morrissey and Greene Pacific Atoll Raingage Data Set using $2.5^{\circ}$ resolution monthly totals for the period August through November, $1987, \ldots \ldots \ldots \ldots \ldots$

4.5 Statistics calculated from a comparison of the SSM/I land algorithm and the Global Precipitation Climatology Center continental raingauge database using monthly rainfall totals at $1^{0}$ resolution for the period August through November, 1987. . . . . . . . 
4.6 Statistics calculated from a comparison of the SSM/I ocean algorithm and the Legates/Willmott (L/W) precipitation climatology using monthly oceanic precipitation totals at $1^{0}$ resolution for the period August through November, 1987. . . . . . . . . . .

4.7 Statistics calculated from a comparison of the SSM/I ocean algorithm and rainfall totals from SSM/I by Berg using monthly precipitation totals at $1^{0}$ resolution for the period August through November, $1987 . \ldots \ldots \ldots \ldots \ldots \ldots$

4.8 SSM/I rainfall algorithm errors calculated from comparisons with alternative rainfall data. The GCEM and Radar errors are for instantaneous area averaged rainfall retrievals and the GPCC and Legates Willmott errors are for global four month means. . . . .

4.9 Theoretical error budget for global rainfall monthly means at one degree resolution. The theoretical temporal and diurnal sampling errors are estimated for the SSM/I orbital characteristics. The algorithm error is taken from the instantaneous rms differences between SSM/I and the GCEM and radar data. . . . . . . . . 94 


\section{FIGURES}

Figure

2.1 Model of liquid and ice phase hydrometeor content normalized by surface rain rate and distributed through altitude. . . . . . . 8

2.2 Theoretical horizontally polarized brightness temperatures as a function of cloud model rain rate over the ocean. . . . . . . . . 12

2.3 Theoretical vertically polarized brightness temperatures as a function of cloud model rain rate over the ocean. . . . . . . . . . 13

2.4 Theoretical brightness temperatures as a function of rain rate over land. ............................ 14

2.5 SSM/I $19 \mathrm{GHz}$ horizontally polarized brightness temperature for May 1,1988 gridded to one degree resolution. . . . . . . . . . 17

2.6 SSM/I $37 \mathrm{GHz}$ horizontally polarized brightness temperature for May 1,1988 gridded to one degree resolution . . . . . . . . . 18

2.7 SSM/I $85 \mathrm{GHz}$ horizontally polarized brightness temperature for May 1,1988 gridded to one degree resolution. . . . . . . . . . 19

2.8 SSM/I $19 \mathrm{GHz}$ brightness temperature polarization difference for May 1,1988 gridded to one degree resolution. . . . . . . . . . 20

$2.9 \mathrm{SSM} / \mathrm{I} 37 \mathrm{GHz}$ brightness temperature polarization difference for May 1,1988 gridded to one degree resolution. . . . . . . . . . . 21

3.1 Theorectically calculated polarization difference at SSM/I frequencies over an ocean surface with increasing rain rate. $\ldots \ldots \ldots 25$ 
3.2 Zonal (top) and meridional (bottom) averages of vertically polarized $19 \mathrm{GHz}$ brightness temperatures calculated separately over land and ocean from SSM/I data on August 2, 1987. . . . . . .

3.3 Zonal (top) and meridional (bottom) averages of $19 \mathrm{GHz}$ brightness temperature polarization difference calculated separately over land and ocean from SSM/I data on August 2, 1987. . . . . . .

3.4 Zonal (top) and meridional (bottom) averages of $37 \mathrm{GHz}$ brightness temperature polarization difference calculated separately over land and ocean from SSM/I data on August 2, 1987. . . . . . .

3.5 Formulation of the SSM/I land rain rate algorithm: the $T_{b}$ are linearly combined, corrected for beam filling, and plotted as a function of cloud model rain rate. A regression line is fit through the $T_{b}$ points providing the slope and bias used to invert actual measured $T_{b}$ to rain rates. $\ldots \ldots \ldots \ldots \ldots$

3.6 Formulation of the SSM/I land rain rate algorithm: the $T_{b}$ are linearly combined, corrected for beam filling, and plotted as a function of cloud model rain rate. A regression line is fit through the $T_{b}$ points providing the slope and bias used to invert actual measured $T_{b}$ to rain rates. $\ldots \ldots \ldots \ldots \ldots$

3.7 Theoretical sensitivity of the ocean rainfall algorithm to cloud liquid water, water vapor and ice. $\ldots \ldots \ldots \ldots$

3.8 Theoretical sensitivity of the land rainfall algorithm to cloud liquid water, water vapor and ice.

3.9 Theoretical sensitivity of the ocean rainfall algorithm to surface temperature.

3.10 Theoretical sensitivity of the land rainfall algorithm to surface temperature. 
3.11 Theoretical sensitivity of the ocean rainfall algorithm to surface freezing level.

3.12 Theoretical sensitivity of the land rainfall algorithm to surface freezing level. ...................

3.13 Algorithm for estimating rain rate from SSM/I brightness temper-

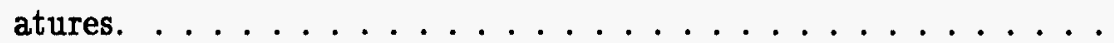

3.14 Rain rates $(\mathrm{mm} / \mathrm{hr})$ during a United Kingdom mid-latitude depression derived from F11 SSM/I data on 08/23/92 at 06:53 UTC. .

3.15 Hurricane Andrew rain rates $(\mathrm{mm} / \mathrm{hr}$ ) derived from SSM/I F11 data on $08 / 27 / 92$ at 22:35 UTC.

3.16 Rain rates $(\mathrm{mm} / \mathrm{hr})$ during TOGA-COARE derived from F11 SSM/I data on $02 / 06 / 93$ at $07: 24$ UTC.

3.17 Rainfall total for the month of August, 1987, derived from SSM/I data. An average of all rain rate observations within each one degree grid point is used to compute the monthly total. . . . . .

4.1 Normalized fraction of SSM/I pixels within each one degree grid box which are flagged as possibly raining by the McFarland Neale Calibration-Validation screening algorithm. .........

4.2 Normalized fraction of SSM/I pixels within each one degree grid box which are flagged as possibly raining by the Spencer polarization corrected temperature scattering based screening algorithm.

4.3 Normalized fraction of SSM/I pixels within each one degree grid box which are flagged as possibly raining by the Grody screening

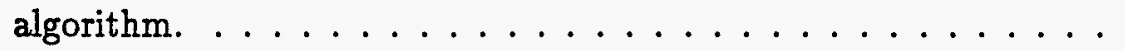

4.4 Normalized fraction of SSM/I pixels within each one degree grid box which are flagged as possibly raining by the Ferriday SSM/I screening algorithm. 
4.5 Goddard Cummulus Ensemble Model shaded with a ray tracing technique showing the outline of the cloud where the rain rate is 5 $\mathrm{mm} / \mathrm{hr} \ldots \ldots \ldots \ldots \ldots \ldots \ldots \ldots \ldots \ldots \ldots \ldots \ldots \ldots \ldots \ldots \ldots \ldots$

4.6 Surface rain rates from an area average of the Goddard Cumulus Ensemble Model. . . . . . . . . . . . . . . . . 60

4.7 Rain rates estimated by the ocean rainfall algorithm from simulated SSM/I brightness temperatures upwelling through the GCEM. .

4.8 A comparison of surface rain rates from the Goddard Cumulus Ensemble Model (GCEM) with rain rates estimated by the application of the SSM/I ocean algorithm to brightness temperatures simulated through the model. . . . . . . . . . . .

4.9 Histograms of the rain rates from the surface level of the Goddard Cumulus Ensemble Model and from ocean rainfall algorithm estimates using simulated upwelling brightness temperatures through

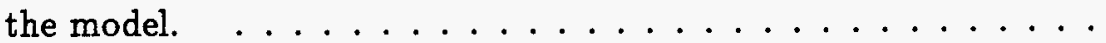

4.10 Coincident rain rates estimated from SSM/I and the Darwin, Australia precipitation radar for February 11,1988 at 21:18 UTC.

4.11 Coincident rain rates estimated from SSM/I and the Cape Canaveral, Florida precipitation radar for December 11,1988 at 23:44 UTC.

4.12 Coincident rain rates estimated from SSM/I and the Oklahoma City, Oklahoma precipitation radar for July 13, 1987 at 01:20 UTC.

4.13 Rain rate distributions from precipitation radars at Darwin, Australia, Cape Canaveral, Florida and Oklahoma City, Oklahoma with estimates from coincident SSM/I overpasses. . . . . . .

4.14 Rainfall total for August through November, 1987, from the Global Precipitation Climatology Center. Continental raingauge measurements are interpolated to a global grid. 
4.15 Rainfall total for August through November from the Legates \& Willmott shipboard and terrestrial raingauge climatology. . . . . 80

4.16 Rainfall total for August through November, 1987, reported by Berg (1994). A modified version of the Hughes algorithm is applied to SSM/I data over the oceans and a lognormal distribution is used to estimate monthly totals. $\ldots \ldots \ldots \ldots \ldots$

4.17 Rainfall total for August through November, 1987, from the Ferriday SSM $/$ I algorithm. . . . . . . . . . . .

4.18 Distributions of total global continental precipitation for August through November, 1987 from estimates by the SSM/I algorithm and a raingage areal average by GPCC. . . . . . . . . .

4.19 Meridionally (top) and zonally (bottom) averaged distributions of total global continental precipitation for August through November, 1987 from estimates by the SSM/I algorithm and a raingauge average by GPCC. . . . . . . . . . . . .

4.20 Distributions of total global oceanic precipitation for August through November, 1987 from estimates by the SSM/I algorithm and a shipboard climatology by Legates and Willmott.

4.21 Meridionally (top) and zonally (bottom) averaged distributions of total global oceanic precipitation for August through November, 1987 from estimates by the SSM/I algorithm and a shipboard raingauge climatology by Legates and Willmott. . . . . . . . .

4.22 Distributions of total global oceanic precipitation for August through November, 1987 from estimates by the SSM/I algorithm and SSM/I

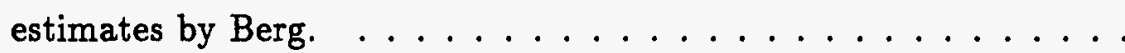


4.23 Meridionally (top) and zonally (bottom) averaged distributions of total global oceanic precipitation for August through November, 1987 from estimates by the SSM/I algorithm and SSM/I estimates

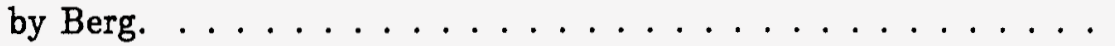

5.1 Rainfall total for September-October-November, 1987, estimated from SSM/I.

5.2 Rainfall total for December-January-February, 1987-1988 estimated from SSM $/$ I. . . . . . . . . . . . . . . . . 99

5.3 Rainfall total for March-April-May, 1988, estimated from SSM/I. . 100

5.4 Rainfall total for June-July-August, 1988, estimated from SSM/I. . 101

5.5 Rainfall total for September-October-November, 1988, estimated from SSM $/$ I. . . . . . . . . . . . . . . . . . . 102

5.6 Rainfall total for December-January-February, 1988-1989, estimated

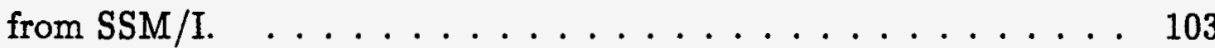

5.7 Rainfall total for March-April-May, 1989, estimated from SSM/I. . 104

5.8 Rainfall total for June-July-August, 1989, estimated from SSM/I. . 105

5.9 Rainfall total for September-October-November, 1989, estimated

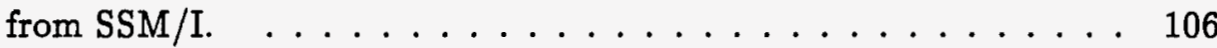

5.10 Estimated rainfall difference (SON 1987 - SON 1988) . . . . . 109

5.11 Monthly rainfall over the Gulf Stream derived from SSM/I in $1988 . \quad 113$

5.12 Monthly Gulf Stream sea surface temperatures in 1988 after Reynolds. 114

5.13 Percent of variance explained by the ordered eigenvectors corresponding to the covariance fields of rainfall and sea surface temperature determined from singular value decomposition. . . . . . 115

5.14 Modes one and two of Gulf Stream rainfall variability coupled with sea surface temperature. . . . . . . . . . . . . . 116 
xviii

5.15 Modes one and two of Gulf Stream sea surface temperature variability coupled with rainfall. . . . . . . . . . 117

5.16 Temporal amplitudes of modes one (upper) and two (lower) of the singular value decomposition of rainfall and sea surface temperatures over the Gulf Stream. . . . . . . . . . . . . . 118

5.17 Monthly rainfall in Northern Africa estimated from SSM/I during 1988.

5.18 Northern boundary of the ITCZ rainfall over Africa during 1988. . 122 


\section{CHAPTER 1}

\section{RAINFALL REMOTE SENSING}

\subsection{Observational requirements}

Rainfall plays an important role in the hydrologic and energy cycles of the Earth system. Rainfall is part of the Earth's transport mechanism for distributing energy and water between the ocean, land and atmosphere. Solar energy absorbed in the equatorial oceans is transported into the atmosphere through evaporation and then released as latent heat energy during raindrop condensation. This energy contributes to the atmospheric circulation which in turn carries water vapor poleward. The latent heat released at higher latitudes acts to reduce the Earth's latitudinal temperature gradient. Many large scale atmospheric dynamical features such as the Hadley cell and the Walker circulation are driven in part by the energetics of the rainfall process.

In addition to the influences within the atmosphere, rainfall interacts with ocean and land surfaces. The freshwater flux associated with rainfall alters the ocean salinity and buoyancy, which in turn affects vertical mixing, skin temperature and radiation to space. Over land the rainfall distribution controls the biological system, affecting soil moisture, potential evapotranspiration and sustainable leaf area. Climate scale changes in terrestrial rainfall cause ecotone migration and redistribution on a global scale.

Rainfall is a component of the Earth system that directly affects the livability of the planet. The variability of tropical monsoons brings cycles of both drought and flooding in India and Asia and cycles of drought, crop failure, and famine in the African Sahel. Rainfall variability in the United States has resulted in the recent 
long term drought in the Southwest and severe flooding in the Midwest. The impact of the natural variability of rainfall is accompanied by the prospect of long term global climate change. A consensus report on equilibrium climate models predicts that if $\mathrm{CO}_{2}$ is doubled over the next hundred years the globe will warm by $1.5^{\circ} \mathrm{C}$ to $4.5^{\circ} \mathrm{C}$ and that rainfall will decrease in North America by as much as 0.7 meters per year (Mitchell 1990). The continuous observation of global rainfall is especially important considering the critical role that rainfall plays in the quality of human life and the nature of the Earth system.

\subsection{Rainfall monitoring techniques}

Despite the scientific and human significance of an understanding of global rainfall, only recently has the capability for global monitoring been realized. It is not feasible to collect sufficient information from radar and raingauges on the ground, especially over the ocean. Because rainfall is so highly variable in time and space it was not until the introduction of Earth orbiting satellites that the distribution of planetary rainfall was first monitored. Satellite estimates of rainfall were first derived from visible and infrared instruments using cloud top temperature and cloud optical properties to indirectly infer underlying rain rates (Adler and Negri 1988; Arkin and Meisner 1987; Negri et al. 1988). Although the accuracies achieved by the visible and infrared techniques suffered from the indirect relationship between cloud properties and rainfall (McConnell and North 1987), valuable tropical rainfall climatologies were derived using visible and infrared data (Arkin and Ardanuy 1989; Garcia 1985).

With the advent of passive microwave radiometers, including the Electrically Scanning Microwave Radiometer (ESMR), the Scanning Multichannel Microwave Radiometer (SMMR) on the Nimbus and Seasat satellites, and the Special Sensor Microwave/Imager (SSM/I) on the Defense Meteorological Satellite Program (DMSP) satellites, more accurate rainfall retrievals were achieved. Upwelling passive 
microwave radiances directly interact with raindrops through attenuation and scattering while remaining virtually unattenuated by clouds (Wilheit and Chang 1980). The $19 \mathrm{GHz}$ channel of the ESMR instrument on Nimbus-5 was used to infer precipitation rates over the ocean based on the functional relationship between rain rate and increases in measurable upwelling brightness temperature resulting from raindrop emissions (Wilheit 1986). Over the ocean, which has a relatively low emission when viewed at an oblique angle, emission based algorithms are effective until the rain rates reach about $20 \mathrm{~mm} / \mathrm{hr}$. At this point, brightness temperatures saturate and begin to decrease as the rain layer becomes optically thick.

In addition to the raindrop emission at lower microwave frequencies, large liquid and frozen hydrometeors scatter radiances at higher frequencies. At the 37 GHz SMMR channel and the 37 and $85 \mathrm{GHz}$ SSM/I channels, rain and ice scatter and depolarize upwelling radiances. The scattering of the SMMR $37 \mathrm{GHz}$ measurements was used to retrieve rain rates in convective storms (Spencer 1986), and the SSM/I $85 \mathrm{GHz}$ channel was used to retrieve precipitation over land and ocean (Spencer et al. 1989). Although scattering techniques are not especially sensitive to low rain rates where raindrops are smaller and ice content may be minimal, scattering algorithms can detect rainfall over land surfaces, with higher resolutions and for higher rain rates than emission algorithms. The lower frequency $(19 \mathrm{GHz})$ and higher frequency (85 $\mathrm{GHz}$ ) channels were combined by Liu and Curry (1992) to formulate an algorithm sensitive to both emission and scattering, thus taking advantage of both regimes at once. Methods for utilizing passive microwave radiometric measurements to retrieve vertical rain rate profiles have been developed by Kummerow et al. (1989), Olson (1989), and Mungai and Smith (1988).

Although significant progress has been demonstrated for computing global monthly rainfall composites over the ocean (Arkin and Ardanuy 1989; Berg and Chase 1992; Berg and Avery 1994; Prabhakara et al. 1992; Wilheit et al. 1991), 
global rainfall estimates must be greatly improved before climate changes can be distinguished from natural variability (Simpson 1988). With an operational deployment of SSM/I instruments on Defense Meteorological Satellites, it is now possible to develop and validate algorithms for monitoring global rainfall over both land and ocean. Although rainfall estimates from SSM/I have been shown to compare favorably with ground based observations, continued algorithm development is needed to further reduce rainfall estimation errors (Adler et al. 1993; Liu and Curry 1992; Grody 1991; Spencer et al. 1989).

Validation studies of passive microwave algorithms usually claim an accuracy of only about a factor of two (Simpson 1988). The accuracies are inconsistent over variable land backgrounds and for non-conventional raincloud types such as the "warm rain" over the tropical oceans and orographic rain over western India (Lee et al. 1991; Kniveton et al. 1993; Barrett et al. 1994). The results of the intercomparisons of current SSM/I rainfall algorithms reveal significant differences in rainfall estimates. These differences result from a variety of theoretical approaches utilized in algorithm development. There are differences in treating the attenuation and scattering in the signal, separating rainfall response from surface variability, accounting for rainfall inhomogeneity in the radiometer field-of-view, and distinguishing between warm rain events and non-precipitating cloud liquid water (Wilheit et al. 1994). The nonlinear relationship between measured radiances and rain rates, when coupled with rain rate variability within the instantaneous instrument field-of-view, contributes to a retrieval underestimation commonly referred to as the beam filling error (Ferriday and Kummerow 1992; North and Nakamoto 1989). Variations in surface properties and cloud structure contribute additional challenges to estimation algorithms when applied to the global environment (Kummerow et al. 1989; Grody 1991). 


\subsection{Rainfall retrieval using SSM/I}

In order to produce accurate global maps of rainfall, a new technique is developed to estimate rain rates using passive microwave measurements from SSM/I (Ferriday and Avery 1994). Measured multi-spectral brightness temperatures are inverted to retrieve rain rates based on theoretical radiative transfer calculations through a surface-cloud model. The algorithm is sensitive to both emission and scattering, accounts for variable rainfall distributions within the radiometer field-ofview and is relatively insensitive to variations in surface and atmospheric background effects. Furthermore, the algorithm is very simple in form and structured to be readily implemented by investigators using SSM/I data.

An error budget is calculated for both instantaneous and time averaged rain rates. The uncertainties are estimated from a combination of validation comparisons, theoretical sampling error calculations and sensitivities to variations in cloud model composition. Using the algorithm, a time series of global rainfall is computed from F8 SSM/I data for the period August, 1987 through December, 1989. The global maps are analyzed for rainfall distribution and variability. The relationship between rainfall and sea surface temperatures over the Gulf Stream is investigated. The latitudinal rainfall edge over northern Africa is tracked to determine the temporal variability of the northern migration of the intertropical convergence zone over the Sahel. Finally, global rainfall variability is monitored during an El Niño Southern Oscillation event. 


\section{CHAPTER 2}

\section{PASSIVE MICROWAVE THEORY}

\subsection{Cloud modeling}

Passive microwave rainfall remote sensing is based on distinguishing the rainfall signature in upwelling radiance measured by a spaceborne radiometer from the effects of the underlying surface and atmospheric cloud liquid water, water vapor and ice. The development of the SSM/I rainfall algorithm begins with a description of microwave radiative transfer theory applied to a physical model detailing both the underlying surface and atmospheric composition. The model specifies the amount and distribution of atmospheric and surface components that strongly infiuence upwelling microwave radiance. The quantity of water vapor and molecular oxygen are modeled using a constant path integrated value while liquid and ice hydrometeors, cloud liquid water, and temperature are vertically distributed. Underlying surface parameters such as temperature and emissivity are coupled to the atmospheric parameters to form a cloud model system. Theoretical calculations of radiances upwelling through the model form the basis of estimating the underlying rain rate using actual satellite brightness temperature measurements.

In general, cloud models specify either a plane-parallel, horizontally infinite cloud distribution or a vertically structured horizontally finite cloud distribution. There are two basic approaches for modeling horizontally infinite, plane-parallel clouds. In one basic modeling approach, rain is constrained to below the freezing level and ice to above the freezing level (Spencer et al. 1983). In a more realistic approach, vertical layers containing mixed distributions of rain, cloud liquid water, and ice particles are modeled (Wu and Weinman 1984; Liu and Curry 1992). In 
more complicated models, numerous atmospheric profiles representing different rain event types are used in a retrieval scheme (Kummerow et al. 1989).

The cloud model used in this study is a vertically structured, plane-parallel, horizontally infinite representation of a raining atmosphere similar to Wu and Weinman (1984) and Liu and Curry (1992). Vertical hydrometeor profiles, including raindrops, ice particles and cloud liquid water are specified from $0-14 \mathrm{~km}$ in a series of homogeneous layers. The model represents rain cloud conditions typical of stratiform rain at low rain rates and convective rain at higher rain rates. Raindrops are found exclusively below the freezing level for low rain rates, but as rain rate increases, raindrops are included in layers above the freezing level. Ice particles, modeled as aspherical frozen rain drops, are distributed above the freezing level.

The distribution of hydrometeors within each layer is shown for liquid and ice in Figure 2.1. The rain rate is constant from the surface to $4 \mathrm{~km}$. A layer of cloud liquid water is also included from 4-6 km. Ice and supercooled water drops compose mixed layers between 4 and $8 \mathrm{~km}$. The rain rate decreases while ice increases linearly with altitude in this mixed layer. Ice content at $8 \mathrm{~km}$ is $1 / 2$ the surface rain rate, and above $8 \mathrm{~km}$, decreases linearly with height. The cloud top height increases linearly with surface rain rate from 8 to $12 \mathrm{~km}$. Table 2.1 lists the parameters used in the model which are independent of rain rate. The temperature profile has a freezing level at $4 \mathrm{~km}$ and a lapse rate of $6.5 \mathrm{~K} / \mathrm{km}$, corresponding to pseudo adiabatic conditions. Humidity is held constant at $90 \%$ through all layers. The model includes cloud liquid water with a density ranging from 0-0.2 $\mathrm{gm} / \mathrm{m}^{3}$ near and below the freezing level. The boundary conditions include a contribution of downwelling radiation from space of $2.7 \mathrm{~K}$ and a constant surface temperature of $288 \mathrm{~K}$. The emissivity of the land surface is held constant at 0.95 and the ocean is treated as a specular surface. 
Table 2.1. Parameters used in the cloud model for theoretical radiative transfer calculations.

\begin{tabular}{|l|l|}
\hline Surface Temperature & $288 \mathrm{~K}$ \\
\hline Land emissivity & 0.95 \\
\hline Humidity & $90 \%$ \\
\hline Lapse Rate & $-6.5 \mathrm{~K} / \mathrm{km}$ \\
\hline Max Cloud Height & $14 \mathrm{~km}$ \\
\hline Cloud Liquid Water & $0-0.2 \mathrm{~g} / \mathrm{m}^{3}$ \\
\hline Space background & $2.7 \mathrm{~K}$ \\
\hline
\end{tabular}

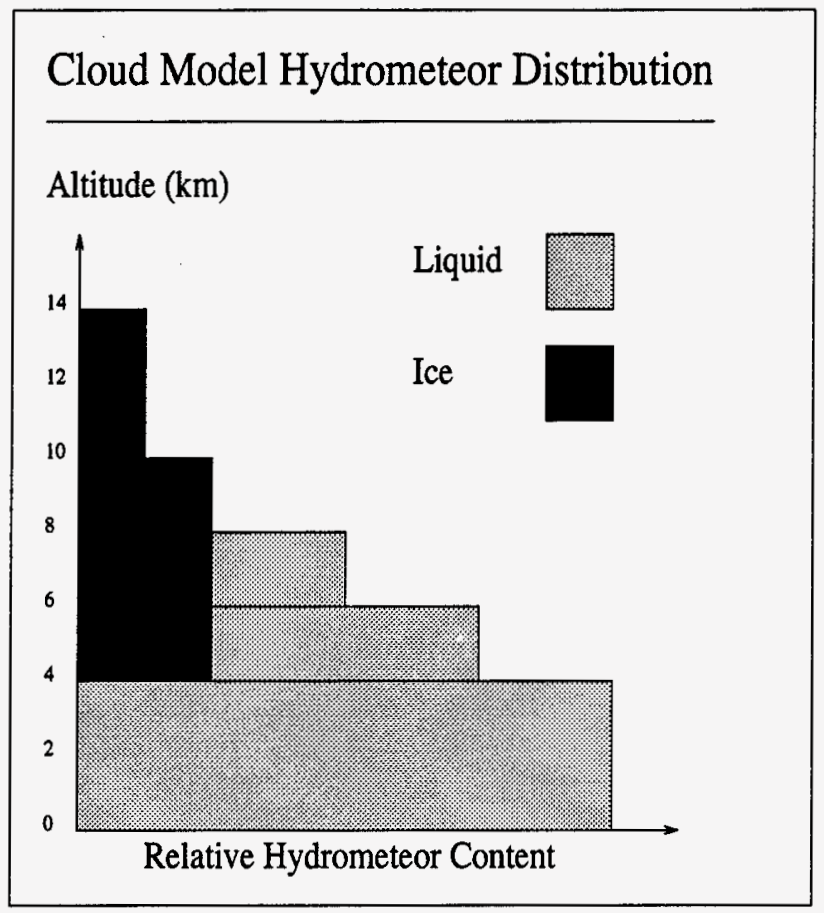

Figure 2.1. Model of liquid and ice phase hydrometeor content normalized by surface rain rate and distributed through altitude. 


\subsection{Radiative transfer theory}

Equations which describe the theoretical transfer of microwave radiances through a horizontally infinite, plane-parallel vertically structured atmosphere form the basis for calculations of upwelling radiances measurable by SSM/I. The basic equation for the differential radiant intensity can be written as

$$
-\mu \frac{d I(\tau, \mu)}{d \tau}=-I(\tau, \mu)+J(\tau, \mu)
$$

where $I(\tau, \mu)$ is the radiant intensity at optical depth $\tau$ and $\mu=\cos (\theta)$, where $\theta$ is the zenith angle. The source function $J$ is defined as

$$
J(\tau, \mu)=[1-\alpha(\tau)] \cdot B(\tau)+\frac{\alpha(\tau)}{2} \int_{0}^{2 \pi} p\left(\tau, \mu ; \mu^{\prime}\right) I\left(\tau, \mu^{\prime}\right) d \mu^{\prime}
$$

in which $B(\tau)$ is the Planck function, $\alpha$ is the single scattering albedo and $p$ is the single scattering phase function. The equation for $\tau$, the extinction optical depth at any point in the medium is

$$
\tau(z)=\int_{z}^{z^{*}} k_{\text {ext }}\left(z^{\prime}\right) d z^{\prime}
$$

where $k_{\text {ext }}$ is the extinction coefficient, $z^{*}$ is the cloud top altitude and $z$ is the altitude in kilometers (Olson 1989).

The radiant intensity can be expressed in more conventional units as the brightness temperature, which is the thermodynamic temperature of a blackbody emitting an equivalent intensity. At microwave frequencies the Rayleigh-Jeans approximation replaces the Planck function (Liou 1980) for blackbody emission,

$$
B_{\nu}(T)=\left[\frac{2 k_{B o l t z} \nu^{2}}{c^{2}}\right] T
$$

where $T$ is the thermodynamic temperature of the blackbody, $c$ is the speed of light, $\nu$ is the radiation frequency, and $k_{B o l t z}$ is the Boltzman constant $\left(1.38 \times 10^{16} \mathrm{erg} / \mathrm{K}\right)$. The brightness temperature as a function of intensity is then

$$
T_{b}=\left[\frac{c^{2}}{2 k_{B o l t z} \nu^{2}}\right] I .
$$




\subsection{SSM/I description}

Calculations of upwelling radiances are desired for frequencies sampled by the Special Sensor Microwave/Imager (SSM/I), a passive microwave radiometer providing the data base for retrieving global rainfall. The SSM/I is built by Hughes Aircraft Company (HAC) under the direction of the Naval Space Systems Activity (NSSA) and the Air Force Space Division (AFSD) (Hollinger et al. 1987). The SSM/I is carried aboard the Defense Meteorological Satellite Program (DMSP) Block 5D-2, F8, F10 and F11 spacecraft. It serves as an oceanographic and meteorological sensor providing data for the extraction of environmental parameters such as ocean wind speeds, ice concentrations, land surface cover, precipitable water, cloud liquid water and rain rates.

The F8 spacecraft is in a circular, sun-synchronous, near-polar orbit at an altitude of $833 \mathrm{~km}$ (Wentz 1989). The orbital period is 102.0 minutes yielding 14.1 full orbits each day. Each scan covers $12.5 \mathrm{~km}$ of ground track with a $1400 \mathrm{~km}$ swath width. Seven channels measure upwelling radiance at $19.35,22.235,37.0$, and 85.5 GHz. All channels except the vertically polarized $22.235 \mathrm{GHz}$ channel are dual polarized. Along the swath, 128 radiometric samples are obtained at two $85.5 \mathrm{GHz}$ channels, and 64 samples are obtained on alternating scans by the remaining channels. The spatial resolution of the SSM/I channels varies inversely with frequency from $60 \mathrm{~km}$ at $19.35 \mathrm{GHz}$ to $15 \mathrm{~km}$ at $85.5 \mathrm{GHz}$. Global SSM/I coverage yields approximately 40 million measurements. With the launch of F10 and F11 the DMSP began operational support of a constellation of at least three spacecraft with SSM/I instruments.

\subsection{Calculations of upwelling microwave radiances}

Theoretical upwelling brightness temperatures $\left(T_{b}\right)$ corresponding to each of the SSM/I channels are calculated as a function of rain rate. Radiative transfer 
calculations are made using a one dimensional Eddington approximation (Kummerow 1987) in which the phase function and intensity distribution of the upwelling microwave radiance are expanded as

$$
p=1+3 g\left[\cos \theta \cos \theta^{\prime}+\sin \theta \sin \theta^{\prime}\right]
$$

where $p$ is the phase function, $g$ is the asymmetry factor for single scattering, $\theta$ and $\theta^{\prime}$ are the incident and outgoing scattering angles, and

$$
I=I_{0}+I_{1} \cos \theta
$$

in which $I$ is the radiant intensity.

These expressions for $p$ and $I$ are then substituted into the radiative transfer equation (2.1) which becomes,

$$
d I_{0} / d z=-k_{\text {ext }}+(1-\alpha g) I_{1}
$$

The Eddington approximation requires that $k_{\text {ext }}, \alpha$ and $g$ are constant within each computational layer. These parameters are calculated using Mie theory (Liou 1980). Both raindrops and ice particles are modeled as spherical hydrometeors homogeneously distributed in each computational layer as described by the MarshallPalmer dropsize distribution (Marshall and Palmer 1949).

The extinction and single scatter albedo coefficients are calculated from an empirical power-function model as

$$
k=K R^{\kappa}
$$

where $k$ is the extinction coefficient, $K$ and $\kappa$ are constants and $R$ is the rain rate and

$$
a=A R^{\alpha}
$$

where $a$ is the single scatter albedo coefficient and $A$ and $\alpha$ are constants.

Theoretical upwelling brightness temperatures for SSM/I channels are calculated as a function of rain rate. Brightness temperatures are calculated separately over ocean and land surfaces. Horizontally polarized brightness temperatures are 
plotted in Figure 2.2 as a function of rain rate over the ocean and vertically polarized ocean brightness temperatures are shown in Figure 2.3. The form of the curves represents contributions from both emission and scattering associated with liquid and frozen hydrometeors. For a non-raining case, the temperatures are dependent primarily on surface emission.

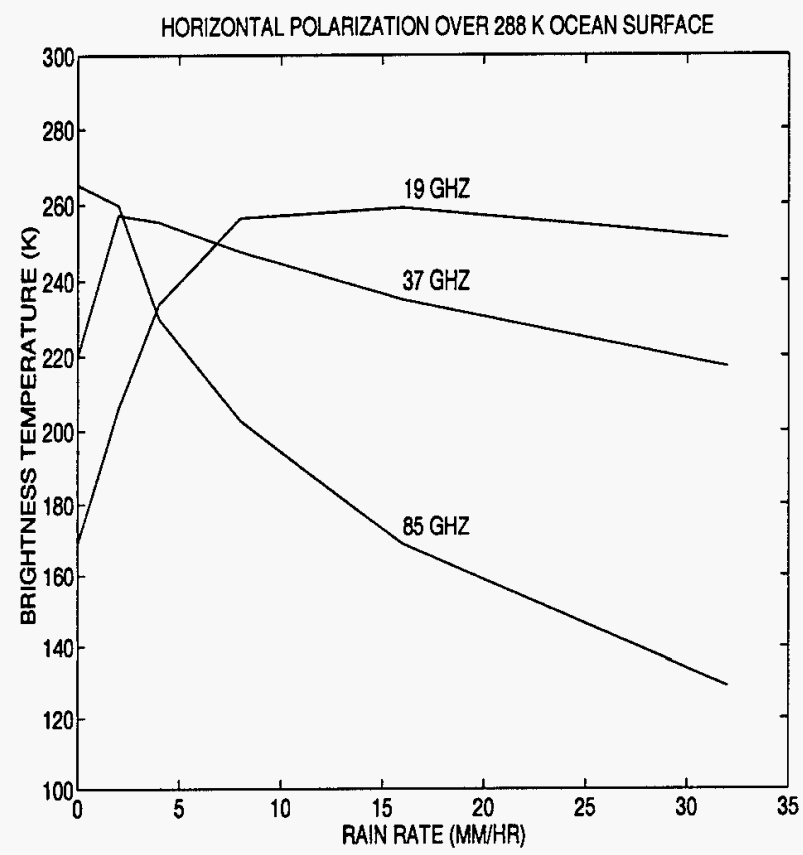

Figure 2.2. Theoretical horizontally polarized brightness temperatures as a function of cloud model rain rate over the ocean.

The relationship between brightness temperature $\left(T_{b}\right)$ and rain rate (RR) over ocean begins with an increase of the lower frequency $T_{b}$ with rain rate until a saturation temperature is reached. The saturation is followed by a slight decrease in $T_{b}$ with further rain rate increases. The initial $T_{b}$ increase is due to absorption and emission by liquid rain drops which level off when the drop layers become optically thick. Contributions from scattering by ice aloft and emission from colder drops at higher altitudes depress temperatures at the highest rain rates. The $19 \mathrm{GHz}$ signal is highly polarized at low rain rates because the ocean acts as a specular surface 
when viewed at an oblique angle such as with the SSM/I. The signal becomes unpolarized at high rain rates because of the randomly polarized attenuation produced by raindrops and scattering by ice.

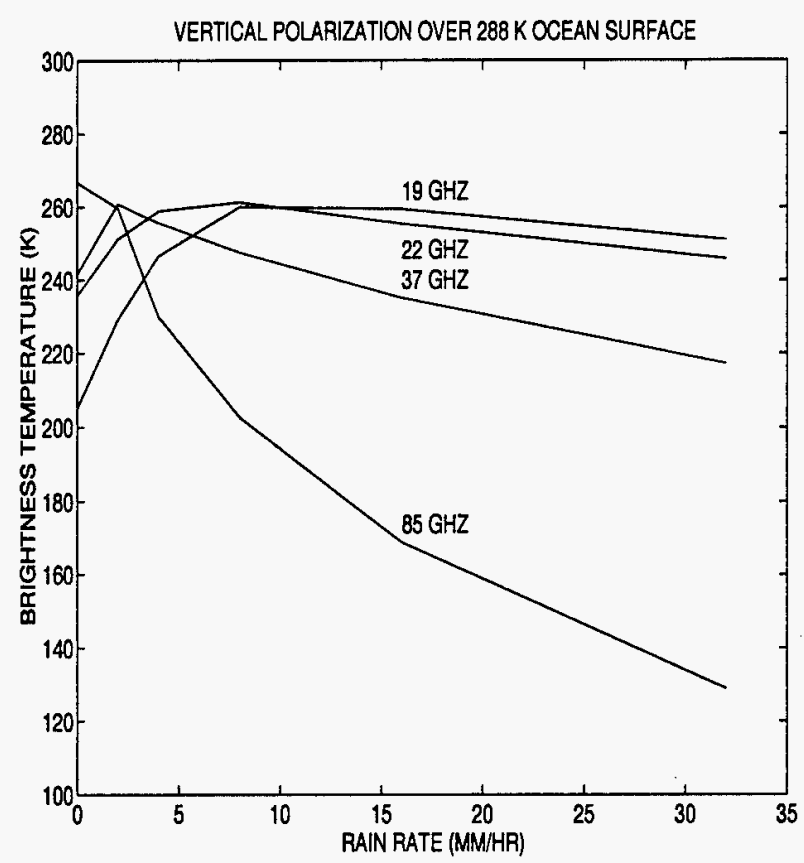

Figure 2.3. Theoretical vertically polarized brightness temperatures as a function of cloud model rain rate over the ocean.

At $85 \mathrm{GHz}$, the $T_{b}$ exhibit a pronounced depression beginning at low rain rates which continues without saturation to rain rates of $35 \mathrm{~mm} / \mathrm{hr}$. The no-rain $T_{b}$ are higher than those from the lower frequency channels because the emissivity of the ocean surface increases with frequency in this regime. The marked drop in $T_{b}$ with rain rate at $85 \mathrm{GHz}$ is due primarily to significant scattering by ice hydrometeors above the freezing level in raining clouds. Not all rain clouds contain ice, especially stratiform systems, so the model used in this study contains appreciable ice only at higher rain rates. The $85 \mathrm{GHz}$ channels are less polarized than lower frequency channels because polarization decreases with frequency for an obliquely viewed ocean surface. The attenuation of $T_{b}$ with rain rate at $37 \mathrm{GHz}$ contains a mixture of the 
characteristics outlined for 19 and $85 \mathrm{GHz}$. At low rain rates the $T_{b}$ increase is due to rain drop emission, but at higher rain rates the signal is depressed by scattering from ice particles.

The calculations of $T_{b}$ upwelling over land, which is treated as a Lambertian emitter (Liou 1980), are shown in Figure 2.4. The emissivity of land is highly dependent on surface moisture, texture and composition. Because modeling of land surface emissivity is beyond the scope of this study, a constant emissivity is adopted for both vertical and horizontal polarizations yielding one set of $T_{b}$ curves. Because the land background has a much higher emissivity than the ocean, rainfall emission is precluded. The primary signal associated with increasing rain rates is the decrease in $T_{b}$ associated with scattering most noticeable at $85 \mathrm{GHz}$. The scattering signal does not saturate even at a rain rate of $35 \mathrm{~mm} / \mathrm{hr}$.

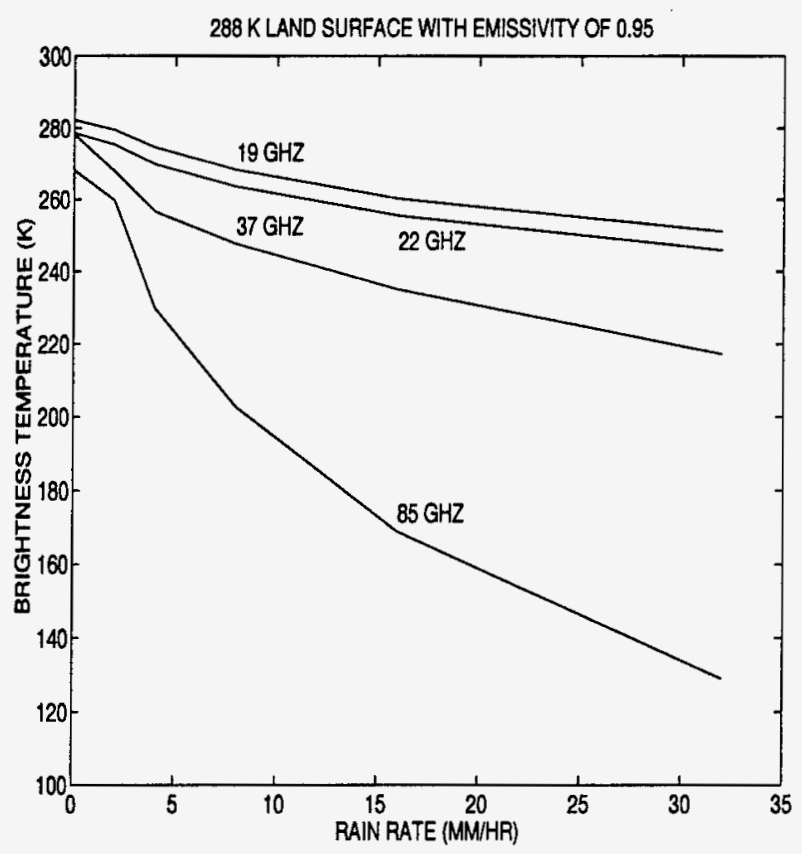

Figure 2.4. Theoretical brightness temperatures as a function of rain rate over land. 


\subsection{Global brightness temperature maps}

The general characteristics of the SSM/I $T_{b}$ and polarization differences are presented in a series of images from one day of data collection over the globe. Figures 2.5-2.7 depict $T_{b}$ with a frequency and polarization of $19 \mathrm{~h}, 37 \mathrm{~h}, 85 \mathrm{~h}$, respectively. Figure 2.8 shows the $19 \mathrm{GHz}$ polarization difference and Figure 2.9 shows the $37 \mathrm{GHz}$ polarization difference. The data were collected on May 01, 1988 by the F8 SSM/I during a 24 hour period. An average measurement is calculated within each grid point at a resolution of one degree latitude and longitude. The data outages, appearing as diamond shapes spanning across the image, result from the criss-crossing of instrument scans during ascending and descending orbits. The orbit precesses so that the entire globe is sampled every few days within the polar orbit inclination limits. The F8 orbit is sun synchronous with a local equatorial ascending crossing time of 6:12 am. Microwave radiances measurable by SSM/I are emitted by the Earth's surface and attenuated and scattered by the intervening atmosphere so that both day and night temperatures can be composited into a daily image.

The general characteristics exhibited by the maps of measured brightness temperature can be described relative to the lower frequency and higher frequency channels. The lower frequency channels have a lower resolution, are more highly polarized, and are attenuated most significantly by liquid hydrometeors and precipitable water. The higher frequency channels have higher resolution, are less polarized and are attenuated primarily by scattering from atmospheric frozen hydrometeors. The horizontally polarized channels have lowered brightness temperatures over moist and flooded land surfaces and over the ocean due to a reduced emissivity. The global $T_{b}$ maps emphasize the radiative principles demonstrated by the theoretical calculations of upwelling radiances measurable by SSM/I presented in section 2.4. The global $T_{b}$ maps collectively show the latitudinal temperature gradient with bright temperatures near the equator that decrease with increasing latitude. The higher 
emissivity of the land surface for both polarization measurements is seen in all the maps. The higher polarization of the ocean is evident in the reduced horizontal polarized brightness temperatures, especially at $19 \mathrm{GHz}$. The strong convection in the equatorial intertropical convection zone (ITCZ) gives rise to extremely large amounts of rainfall. The attenuation and scattering resulting from this intense band of equatorial rainfall is visible as increases in the lower frequency channels and reduced temperatures in the higher frequency channels. Over land the $19 \mathrm{GHz}$ horizontal channel is relatively homogeneous. The scattering and polarized $T_{b}$ at $85 \mathrm{GHz}$ resulting from lowered emissivity by ice and snow is evident in Figure 2.7 over the Himilayas and Antarctica. 


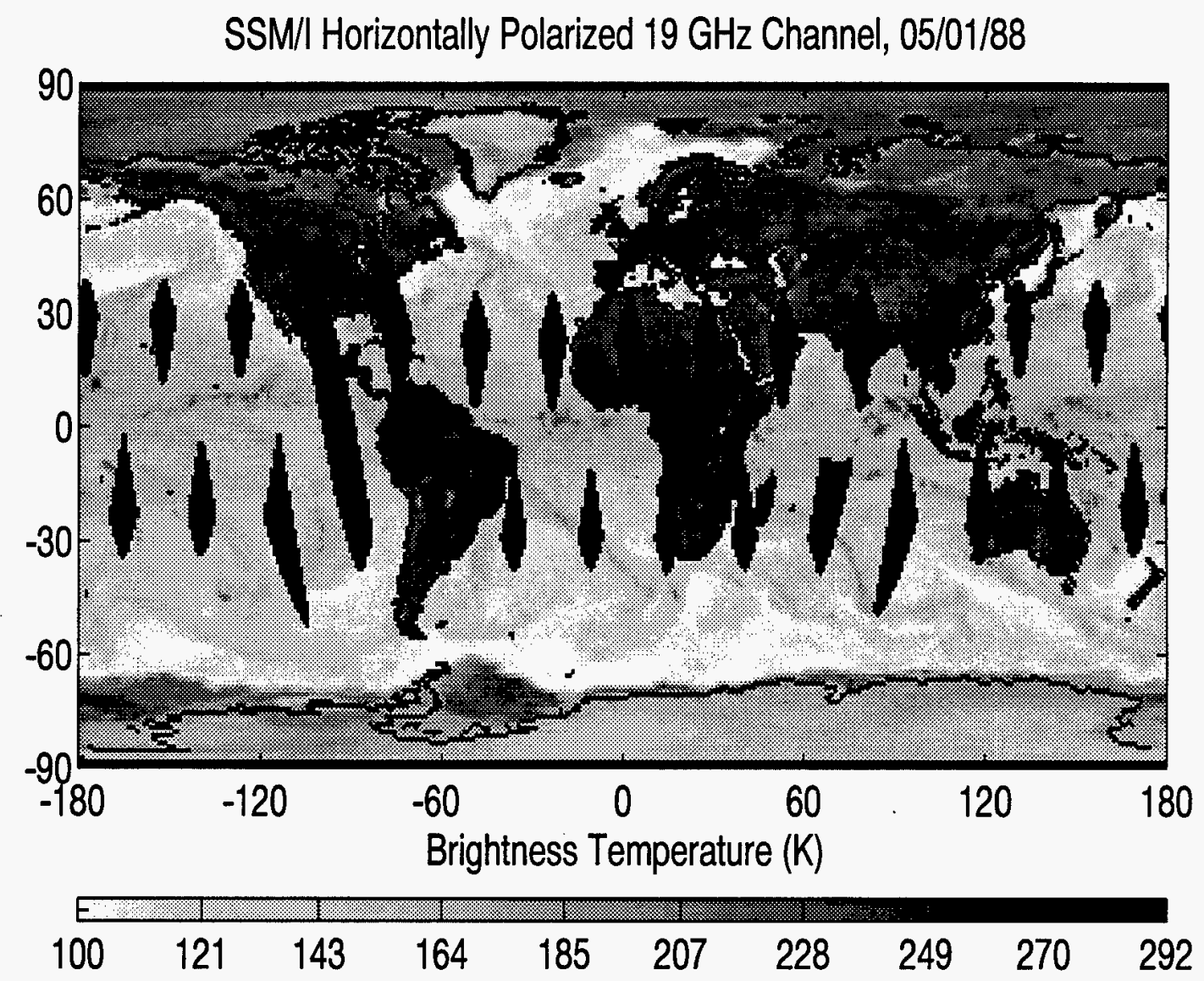

Figure 2.5. SSM/I $19 \mathrm{GHz}$ horizontally polarized brightness temperature for May 1, 1988 gridded to one degree resolution. 
SSM/I Horizontally Polarized $37 \mathrm{GHz}$ Channel, 05/01/88

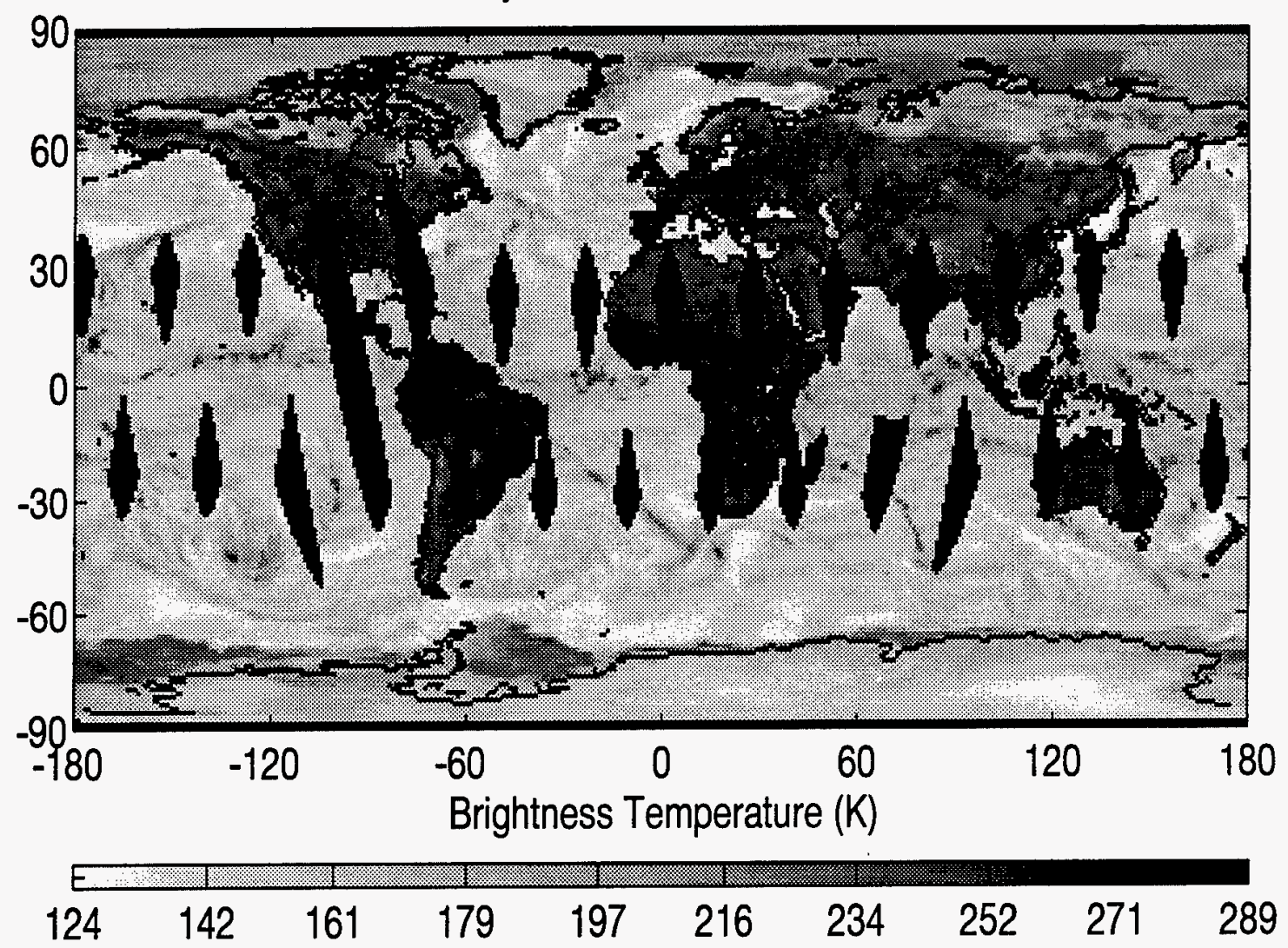

Figure 2.6. SSM/I $37 \mathrm{GHz}$ horizontally polarized brightness temperature for May 1, 1988 gridded to one degree resolution 


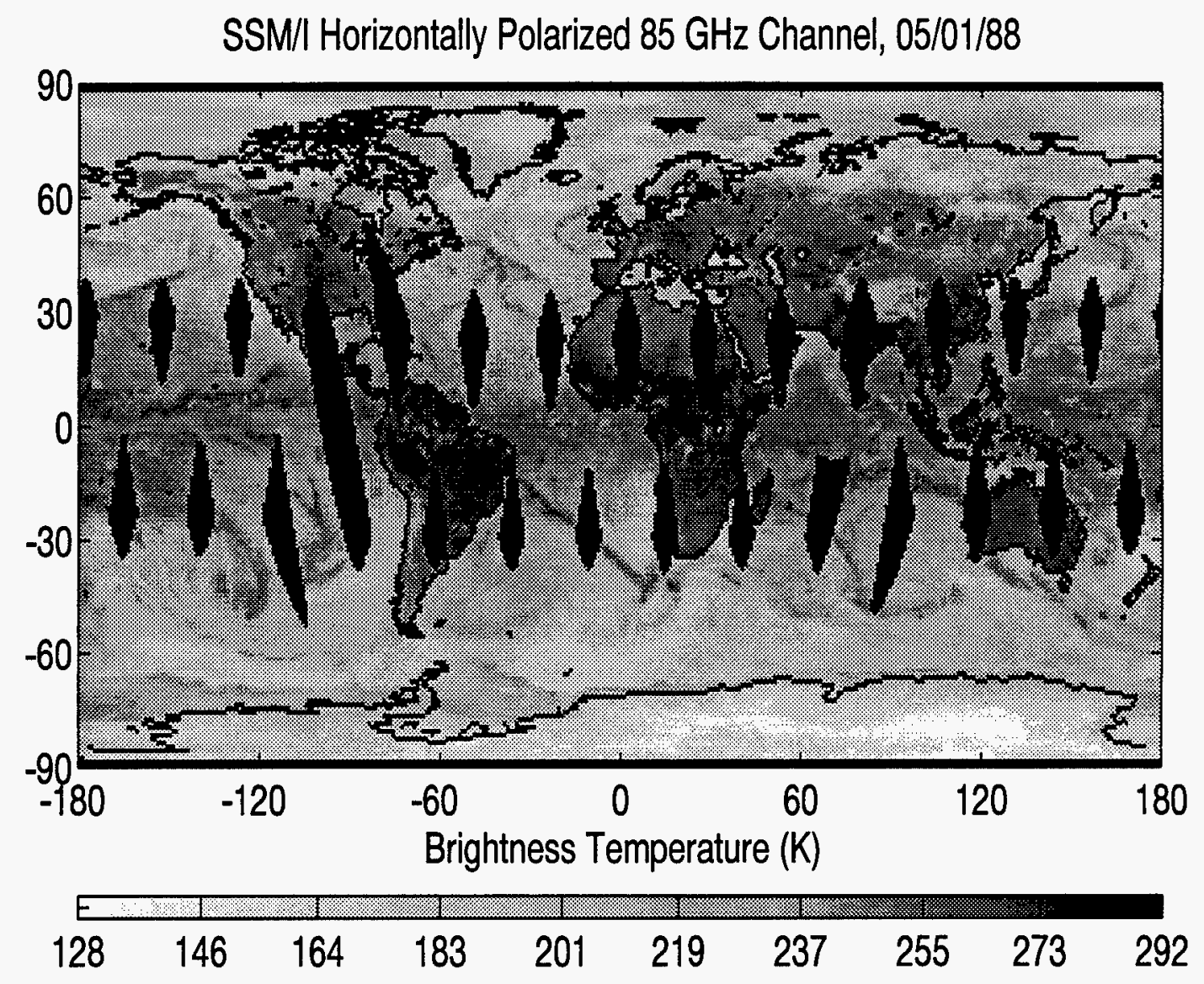

Figure 2.7. SSM/I $85 \mathrm{GHz}$ horizontally polarized brightness temperature for May 1, 1988 gridded to one degree resolution. 
SSM/l $19 \mathrm{GHz}$ V-H Polarization Difference, 05/01/88

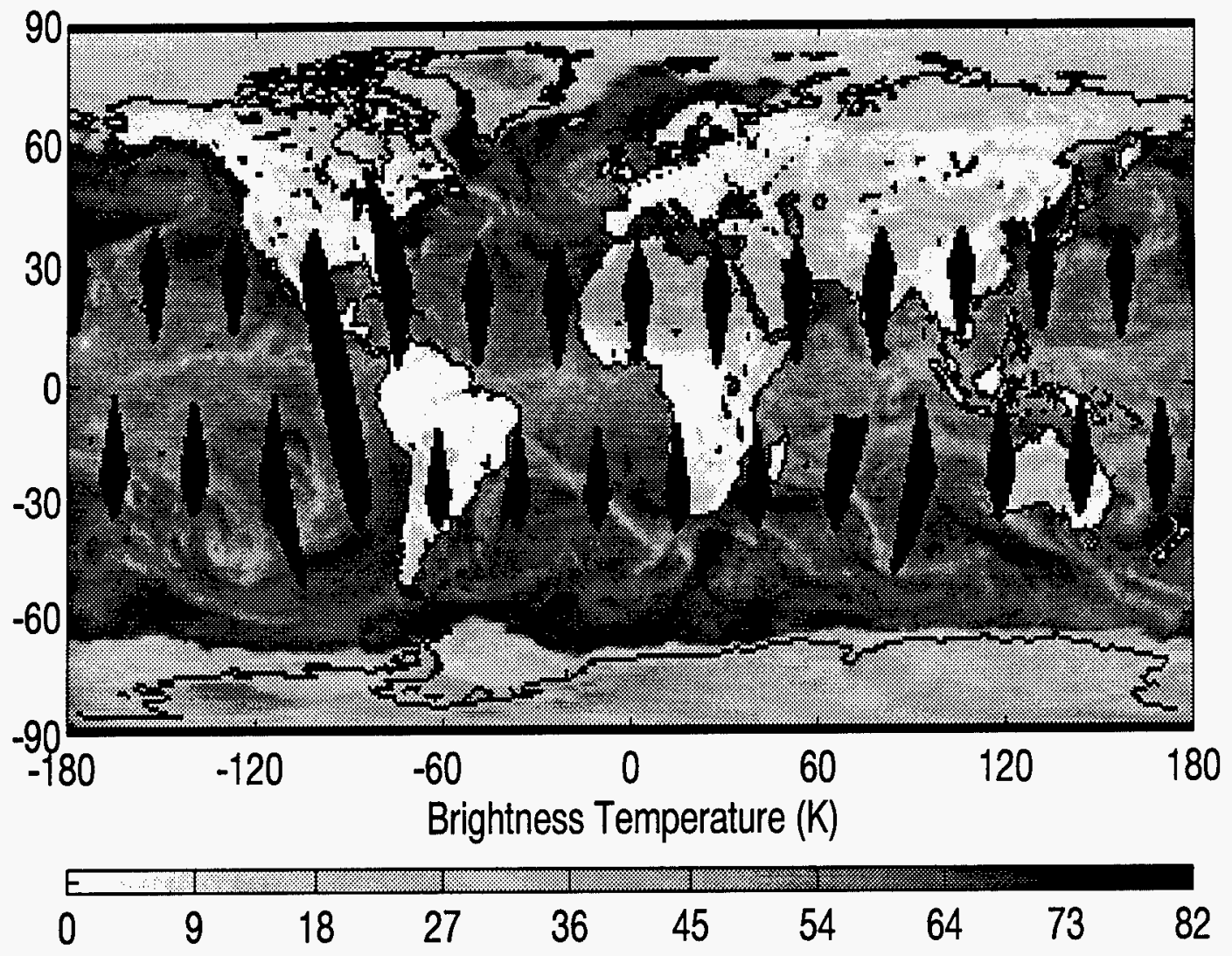

Figure 2.8. SSM/I $19 \mathrm{GHz}$ brightness temperature polarization difference for May 1,1988 gridded to one degree resolution. 
SSM/ $37 \mathrm{GHz}$ V-H Polarization Difference, 05/01/88

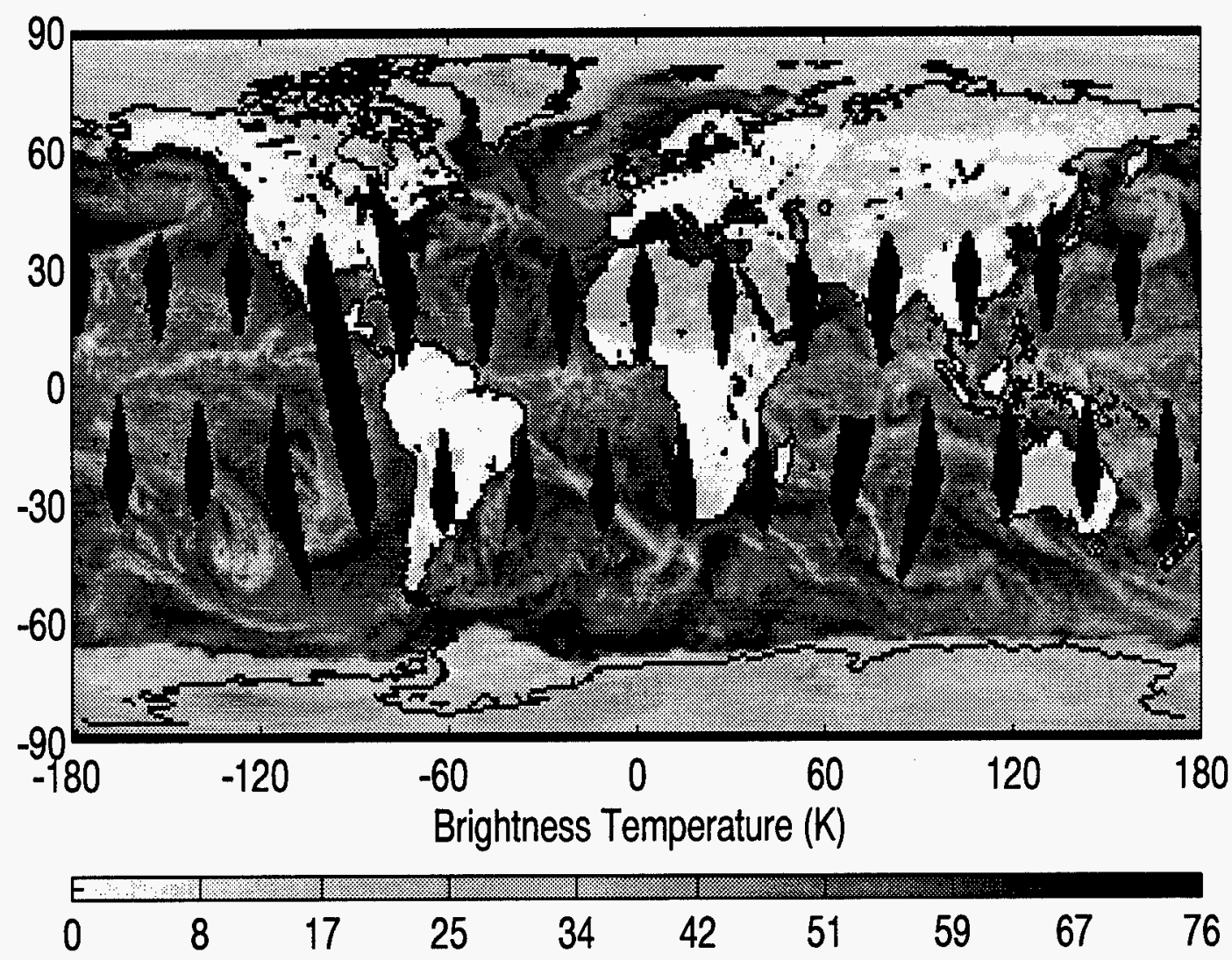

Figure 2.9. SSM/I $37 \mathrm{GHz}$ brightness temperature polarization difference for May 1,1988 gridded to one degree resolution. 


\section{CHAPTER 3}

\section{RAINFALL ESTIMATION USING SSM/I}

\subsection{Algorithm formulation}

The theoretical brightness temperatures $T_{b}$ calculated as a function of rain rate are used to develop an algorithm for estimating rainfall from SSM/I brightness temperatures (Ferriday and Avery 1994). Separate formulations are constructed for ocean and land backgrounds to account for dissimilar background $T_{b}$ signatures. In order to utilize information available from the polarization and emission features at low rain rates, the ocean algorithm is based on polarization differencing and mixed emission-scattering response. Over land, the algorithm relies primarily on scattering information because the bright land background obscures hydrometeor emission. Channel combinations sensitive to low rain rates are chosen to aid in rain thresholding. Creating a normalized brightness temperature by adding and subtracting equal numbers of channels reduces the influence of background surface and atmospheric variability from different climatic regions (Spencer et al. 1989). Finally, channels are corrected for beam filling errors so that they vary nearly linearly with rain rate. The algorithm comprises two basic steps: the data are first screened to detect rain and to remove non-raining cases which exhibit $T_{b}$ signatures similar to rain, and then a rain rate is calculated using a linear combination of $T_{b}$. The algorithm is constructed to perform consistently with both low and high rain rates for a variety of rain cloud systems over the highly variable Earth background. 


\subsection{Rain screening}

The effects of raining hydrometeors on radiances measurable by SSM/I are similar to the signatures of many surface and non-raining atmospheric conditions (Grody 1991). Therefore, an algorithm constructed simply to quantify rain rate can often misclassify these non-raining conditions by assigning a rain rate. Surfaces such as ice, snow, sand, cold ground, and moist soil exhibit signatures similar to rainfall. Variations in atmospheric water vapor, cloud liquid water, non-precipitating ice and temperature profiles produce attenuation and scattering which also may resemble the effects of rainfall (Wilheit 1986). There are, however, subtle differences in the brightness temperature response measurable by SSM/I that are useful in distinguishing among these conditions. Prior to a rain rate calculation, the algorithm tests the SSM/I data to distinguish between possible raining events and underlying surface and atmospheric conditions exhibiting a potentially erroneous rainfall signature.

Each of the non-raining conditions may be distinguished from rain using a testing logic based on separate scattering, attenuation and polarization criteria. Over land, the data are flagged as non-raining cold or ice/snow covered ground if the $19 \mathrm{GHz} T_{b}$ is less than $265 \mathrm{~K}$. Also over land, if the polarization difference at 37 $\mathrm{GHz}$ or $19 \mathrm{GHz}$ is greater than $10 \mathrm{~K}$, the pixel is flagged as desert or moist or flooded soil. These tests are derived from the theoretical brightness temperature response curves in section 2.4 and the polarization curves in Figure 3.1, by noting the $T_{b}$ and polarization for low rain rate thresholds. Over ocean the polarization difference at $19 \mathrm{GHz}$ must be below $60 \mathrm{~K}$ to signal the possible presence of rain. The rain rate calculation, outlined in the next section, tests for the combined presence of emission and scattering associated with hydrometeors. Because it is possible to distinguish between raining and non-raining pixels in most cases over a multitude of different surfaces, flagged pixels in this algorithm are set to zero rain rate rather than left indeterminate. 
The impact of employing this screening technique is evident in zonal and meridional brightness temperature averages computed from one day of SSM/I data for the vertically polarized $19 \mathrm{GHz}$ channel (Figure 3.2 ) and the polarization differences at $19 \mathrm{GHz}$ (Figure 3.3) and $37 \mathrm{GHz}$ (Figure 3.4). The most noticeable feature for the vertically polarized $19 \mathrm{GHz} T_{b}$ is the latitudinal dependence of the global mean over land which ranges from about $220 \mathrm{~K}$ near the poles to about 270 $\mathrm{K}$ near the equator. The meridional trend is primarily due to the dependence of $T_{b}$ on surface temperature. The same feature is evident over ocean, with a range of 185 $\mathrm{K}$ to $220 \mathrm{~K}$. The $19 \mathrm{GHz}$ polarization is less dependent on latitude, with a range over ocean of $70 \mathrm{~K}$ to $55 \mathrm{~K}$ and over land of $50 \mathrm{~K}$ to $10 \mathrm{~K}$ from pole to equator. The polarization at $37 \mathrm{GHz}$ is similar to the $19 \mathrm{GHz}$ polarization except that the magnitude is always less by about $10 \mathrm{~K}$.

The land algorithm temperature threshold at the vertically polarized 19 $\mathrm{GHz}$ channel of $265 \mathrm{~K}$ will remove the colder regions at high latitudes where the primary precipitation is snow and where the radiances resemble raining cases because of the snow, ice and cold ground. The further addition of the polarization checks at 19 and $37 \mathrm{GHz}$ remove high latitude areas with polarization resulting from snow and ice. Over ocean, the algorithm utilizes a polarization difference to flag nonraining cases; however this screen is minimal relative to the land screening because the emission and scattering response of hydrometeors is more easily detected over the uniform backdrop of the ocean surface. 


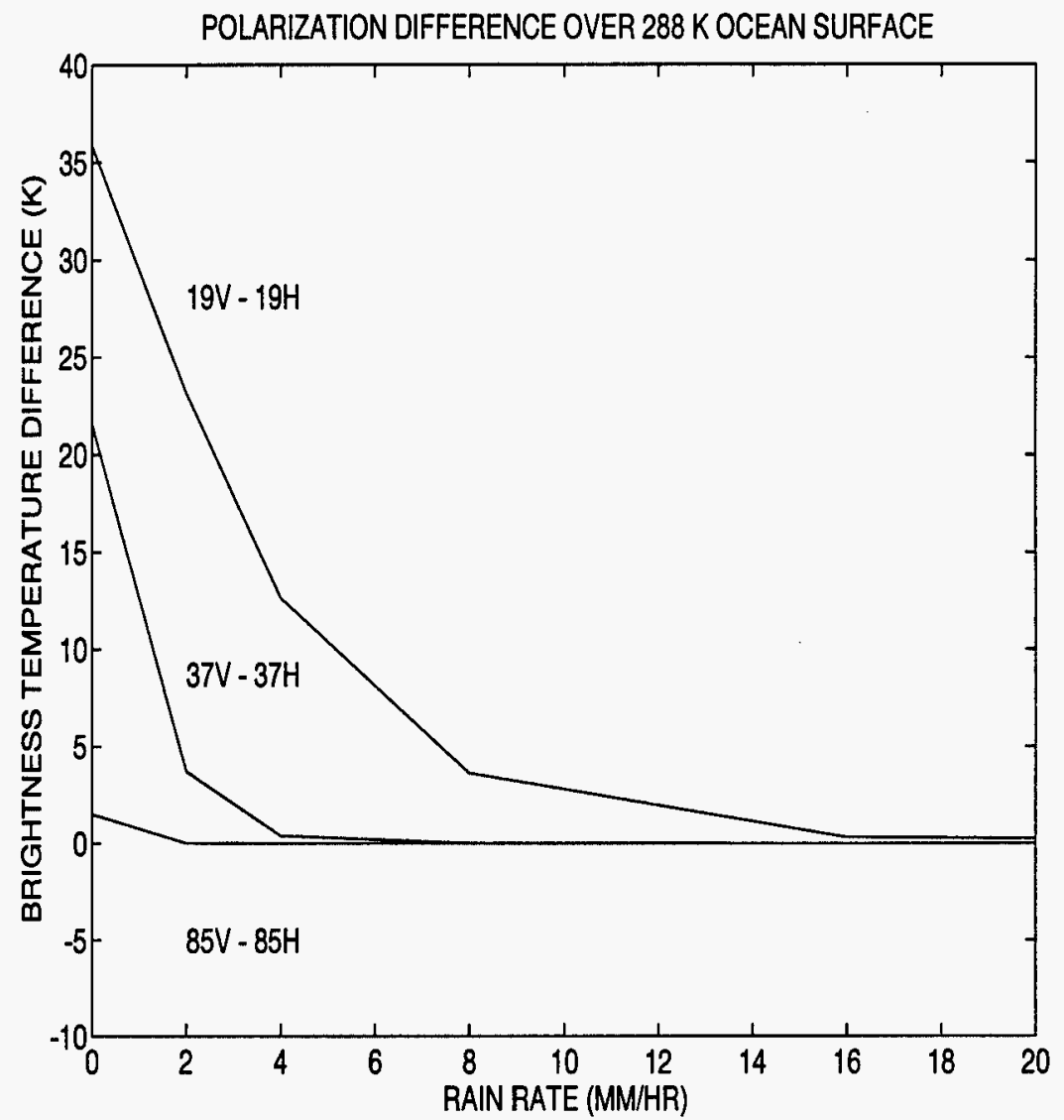

Figure 3.1. Theorectically calculated polarization difference at SSM/I frequencies over an ocean surface with increasing rain rate. 
ZONAL AND MERIDIONAL AVERAGES OF SSM/19 GHZ V POLARIZED TB
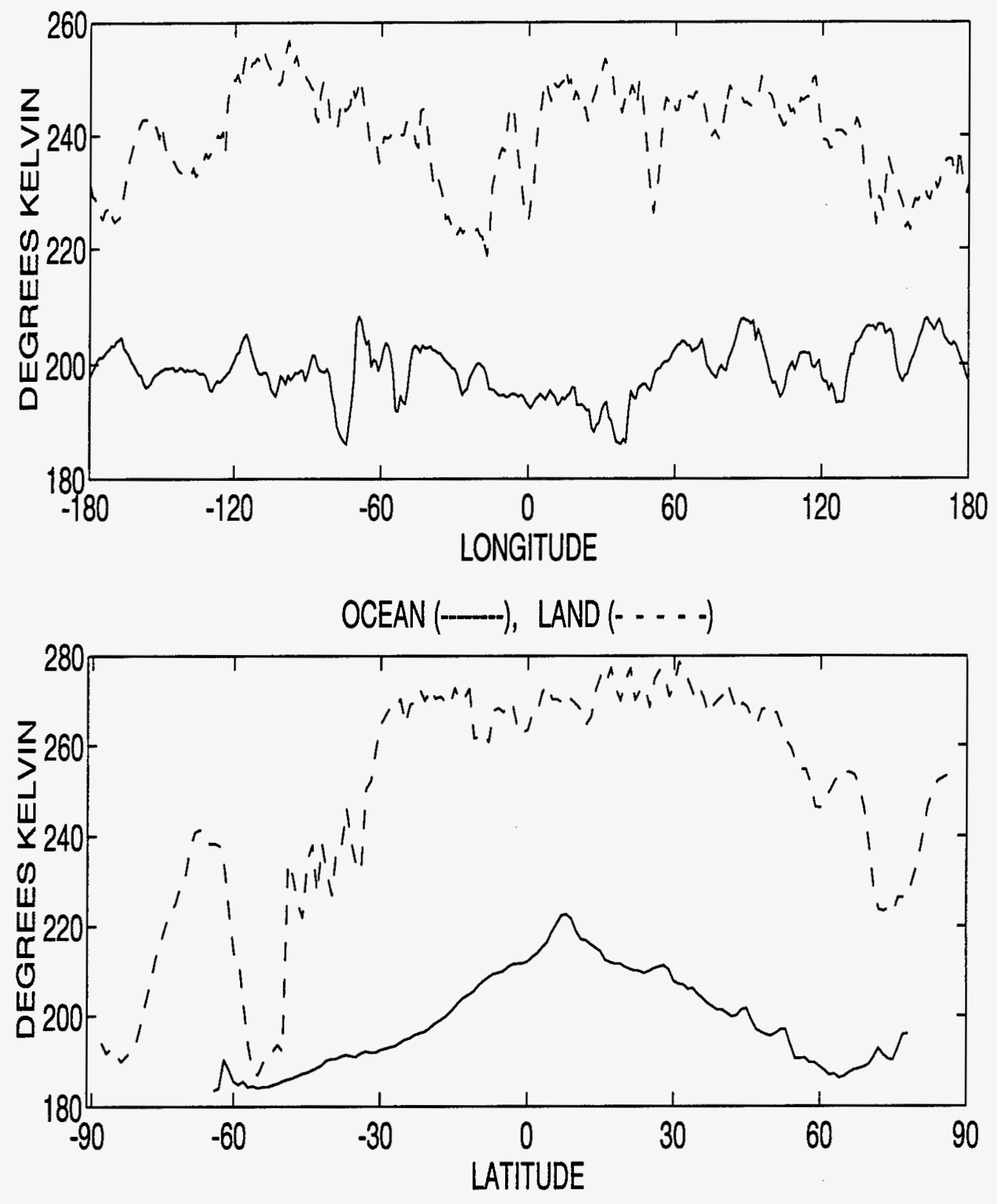

Figure 3.2. Zonal (top) and meridional (bottom) averages of vertically polarized 19 $\mathrm{GHz}$ brightness temperatures calculated separately over land and ocean from SSM/I data on August 2, 1987. 

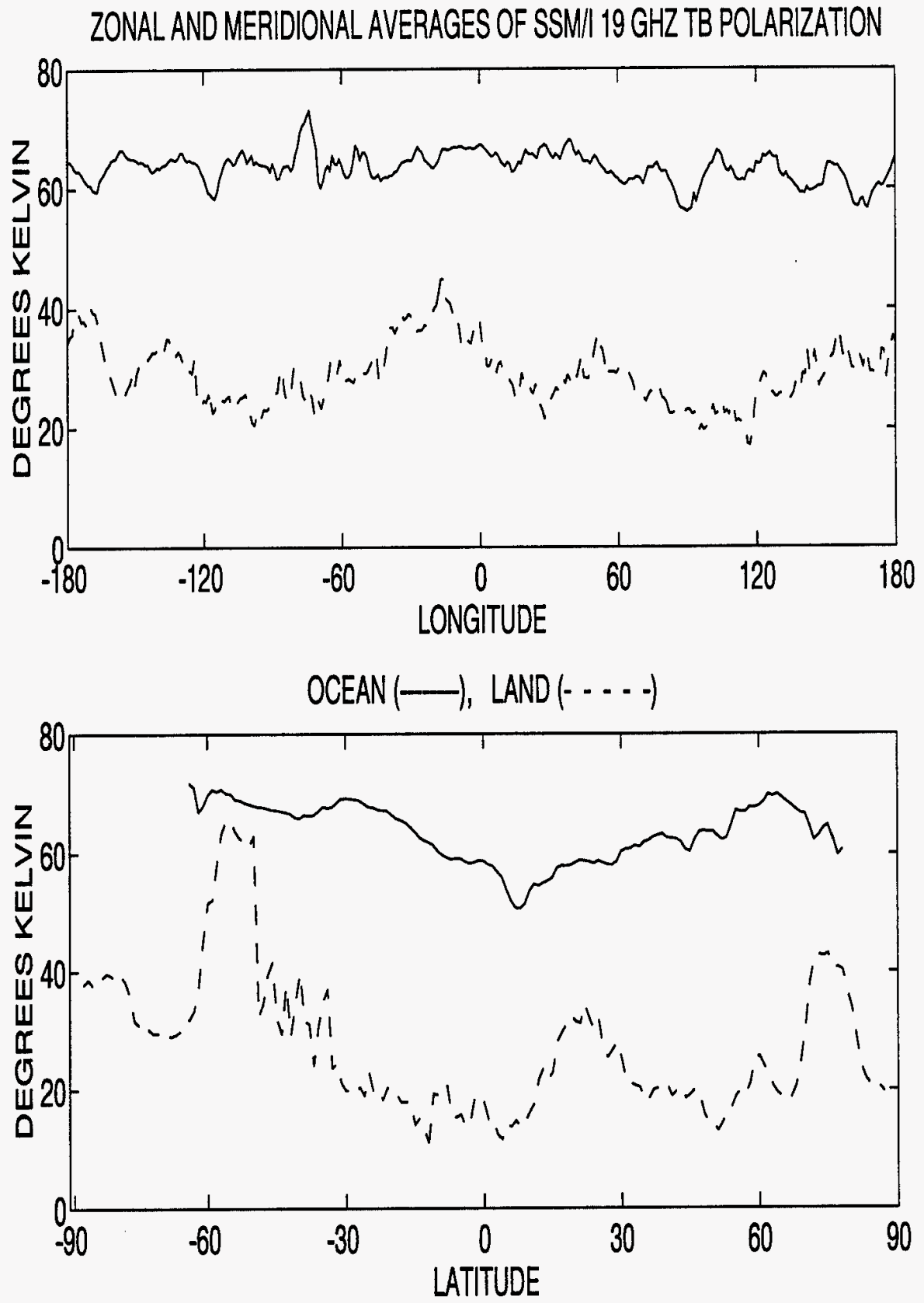

Figure 3.3. Zonal (top) and meridional (bottom) averages of $19 \mathrm{GHz}$ brightness temperature polarization difference calculated separately over land and ocean from SSM/I data on August 2, 1987. 

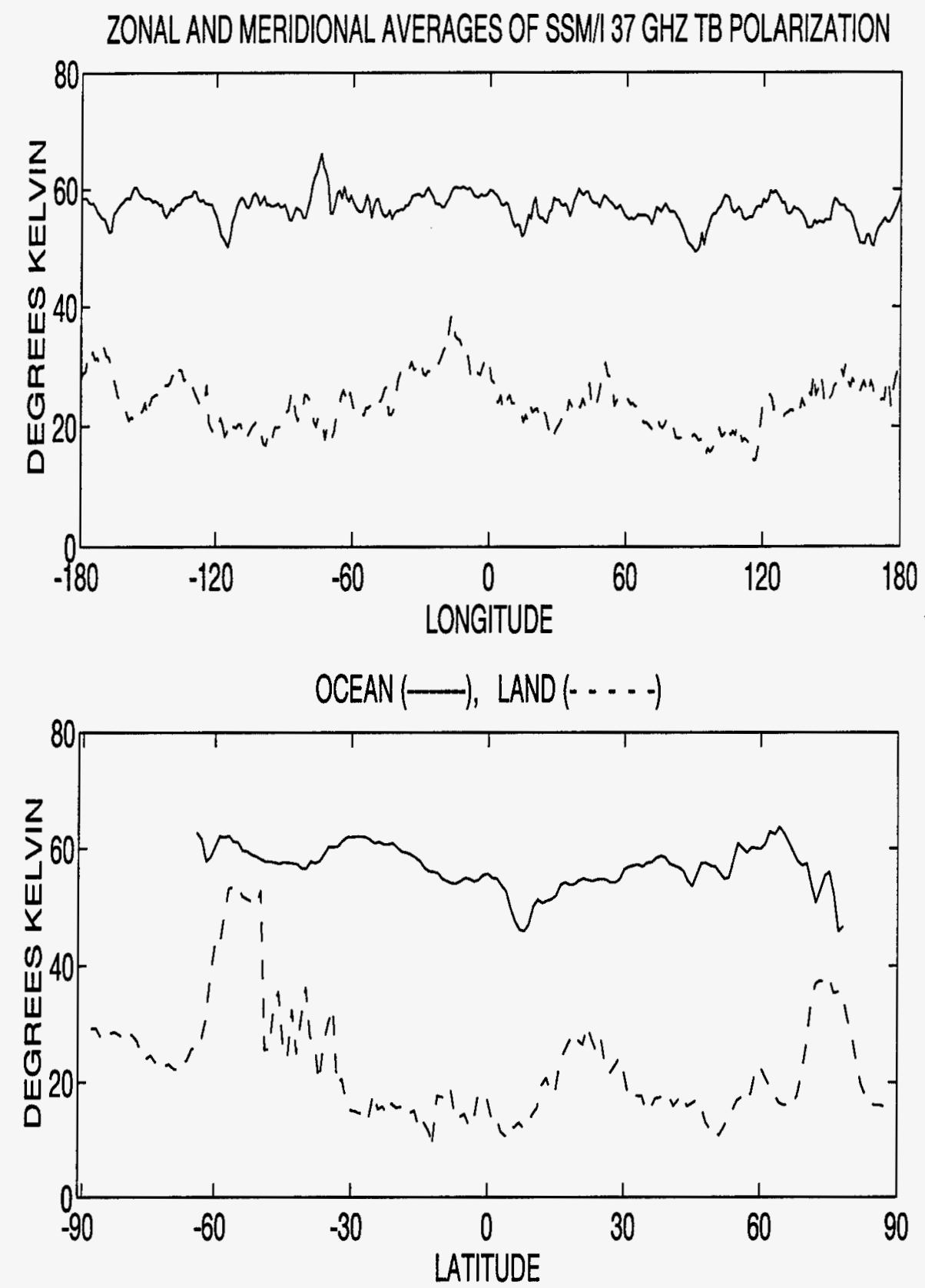

Figure 3.4. Zonal (top) and meridional (bottom) averages of $37 \mathrm{GHz}$ brightness temperature polarization difference calculated separately over land and ocean from SSM/I data on August 2, 1987. 


\subsection{Rain rate calculation}

Over ocean, the channel combination chosen to form the core of the rain rate retrieval algorithm is $(19 h+19 v+37 h-22 v-37 v-85 h)$, where the notation describes the frequency and polarization of the SSM/I channel. The basis for this selection, in addition to satisfying the algorithm requirements outlined in section 3.1 , lies in the sensitive response of the low frequency horizontally polarized channels to low rain rates and the depolarization accompanying attenuation by liquid and scattering by ice observed in section 2.4. A further attribute is that while the lower frequency response increases primarily for low rain rates, at high rain rates the higher frequency response continues to decrease when the low frequencies have saturated, so that the algorithm is extended in dynamic range. The channel combination used for the calculation of land surface rain rates is $(19 h+37 h-2 * 85 h)$. The use of only one polarization over land minimizes the effect of surface moisture variations. Since the no-rain signal is already depolarized in most cases and polarizing effects from non-spherical hydrometeors are not modeled, polarization information over land is limited to screening non-raining surfaces such as ice and moist soil. Subtracting the higher frequency channels from the low frequency channels gives a nearly linear channel combination dependence on rain rate.

Using the brightness temperatures calculated from the combination of channels selected for the algorithms, a threshold is chosen to signal the presence of rain. There is a tradeoff between lowering the threshold to allow sensitivity at lower rain rates, and raising the threshold to adequately screen out non-raining cases. In the ocean algorithm, thresholding between non-precipitating clouds containing significant amounts of cloud liquid water, and cases where rain drops are actually reaching the ground, is especially difficult. A bias is added to the brightness temperatures such that the threshold is at a rain rate of $0.5 \mathrm{~mm} / \mathrm{hr}$. The bias for the ocean algorithm is $170.2 \mathrm{~K}$, and the bias for the land algorithm is $-15.6 \mathrm{~K}$. 
Inhomogeneous distributions of rain rates within a satellite instantaneous field-of-view (IFOV) can cause an underestimation in uncorrected retrieval algorithms developed from idealized rain distributions (Chiu et al. 1990). The underestimation, known as "beam filling errors", results from an inhomogeneously filled IFOV because there is a non-linear relationship between brightness temperature and rain rate especially at lower frequencies. When an ensemble of $T_{b}$ contributions from a distribution of rain rates are averaged together in one satellite measurement, the apparent $T_{b}$ as calculated from a model of homogeneous rates indicates a lower rain rate than the true value (Ferriday and Kummerow 1992).

The $T_{b}$ combinations are adjusted to compensate for beam filling errors. The errors occur in the emission regime with rain rates of $0-20 \mathrm{~mm} / \mathrm{hr}$. The beam filling error is negligible in the scattering regime with rain rates greater than 20 $\mathrm{mm} / \mathrm{hr}$ because the $T_{b}$ are nearly linearly related to rain rate. From studies of rainfall in the Global Atlantic Tropical Experiment (GATE) the beam filling error was measured to result in an underestimation in rainfall retrievals of about $50 \%$ (Short and North 1990; Chiu et al. 1990). To correct for this underestimation, the $T_{b}$ combinations are adjusted in the emission regime. The theoretical $T_{b}$ combination is shifted so that it will retrieve twice the rain rate in the range $0-20 \mathrm{~mm} / \mathrm{hr}$. The correction linearizes the $T_{b}$-rain rate curve in a manner which is consistent with other beam filling correction methods (Liu and Curry 1992; Chiu et al. 1990).

A regression line is fit to the bias and beam filling corrected brightness temperatures to create an inversion formula for converting $T_{b}$ to rain rates. In Figure 3.5 and Figure 3.6 the beam filling corrected $T_{b}$ combinations are plotted along with the regression line. Over ocean the slope is $18.3 \mathrm{~K} / \mathrm{mm}$ and over land the slope is $9.1 \mathrm{~K} / \mathrm{mm}$. The straight line fit to the $T_{b}$ preserves simplicity in algorithm implementation and in future modifications. Slope and bias corrections obtained from comparisons with alternative rain rate retrievals can be incorporated as a calibration 
in future versions of the algorithm. Although the regression line does not match the modeled $T_{b}$ directly, it is more effective than a non-linear fit because actual satellite footprint averaged $T_{b}$ exhibit a nearly linear response to averaged rain rates (Spencer 1986). In both Figure 3.5 and Figure 3.6 the $T_{b}$ corresponding to a cloud model rain rate of $32 \mathrm{~mm} / \mathrm{hr}$ is an outlier relative to the regression line. It is not expected that this will cause significant error in actual retrievals because the area-average rain rate in a satellite footprint that is $25 \mathrm{~km}$ across seldom reaches higher than 20 $\mathrm{mm} / \mathrm{hr}$. The algorithm validation and error budget in Chapter 4 further support this assumption. 


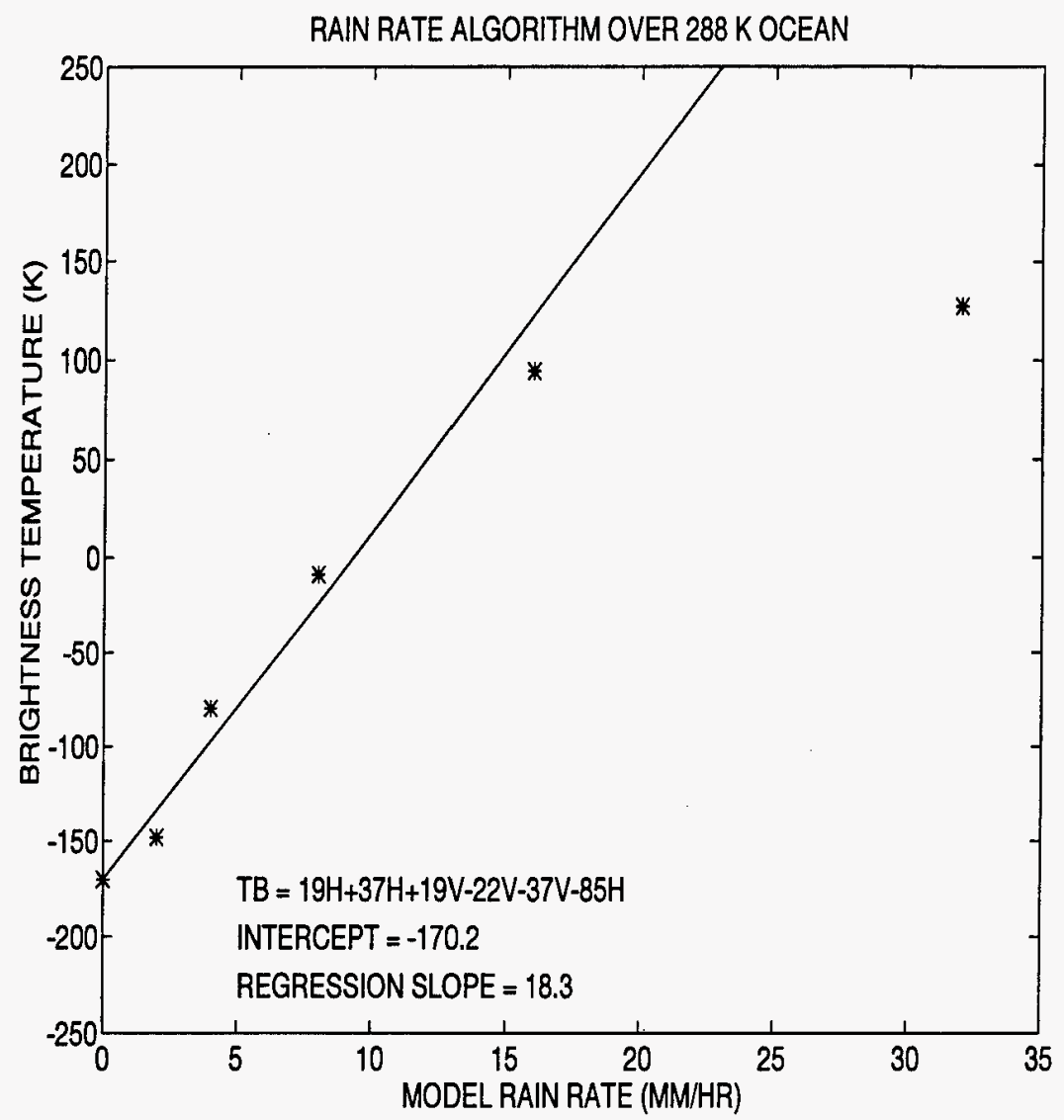

Figure 3.5. Formulation of the SSM/I land rain rate algorithm: the $T_{b}$ are linearly combined, corrected for beam filling, and plotted as a function of cloud model rain rate. A regression line is fit through the $T_{b}$ points providing the slope and bias used to invert actual measured $T_{b}$ to rain rates. 


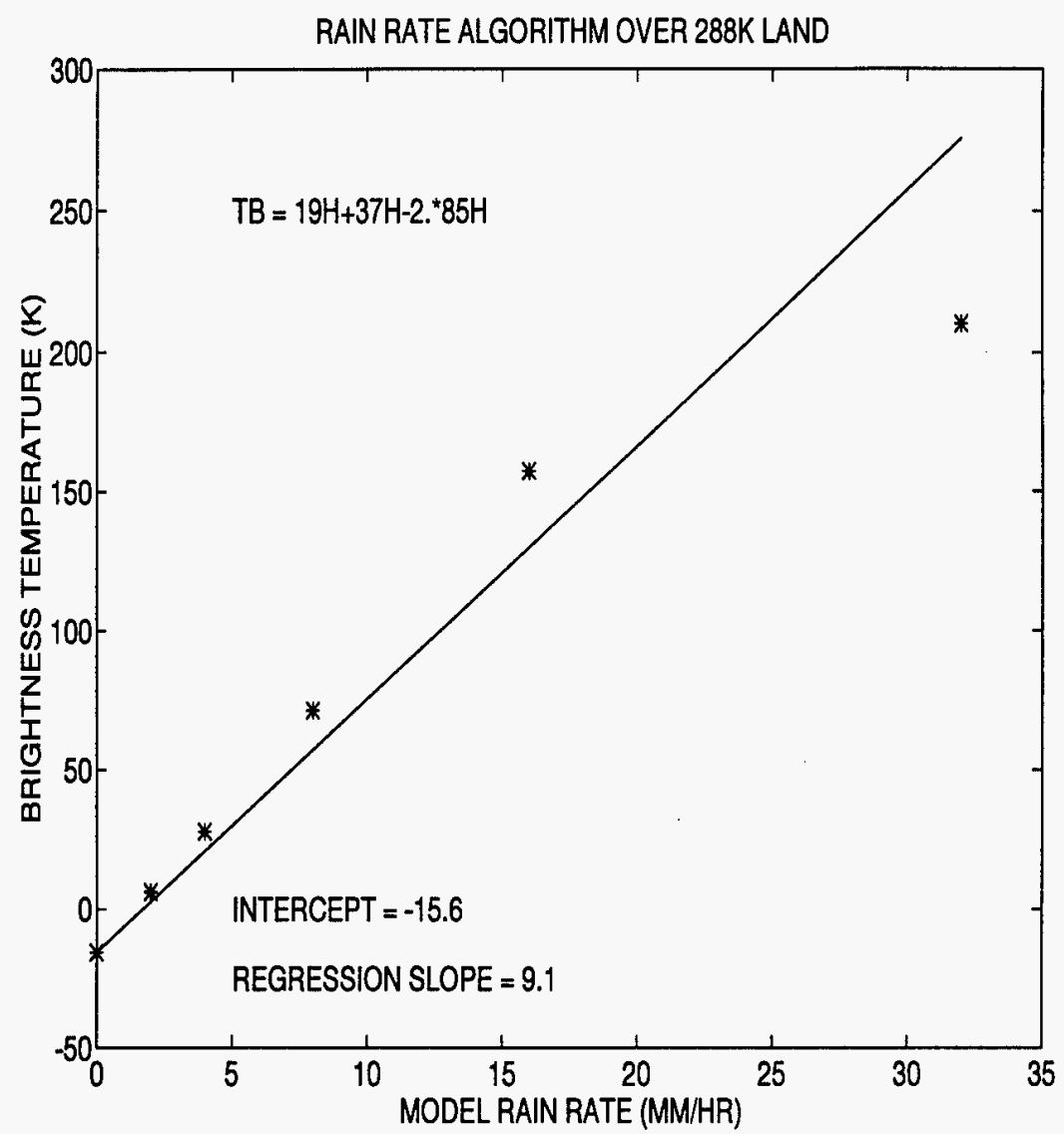

Figure 3.6. Formulation of the SSM/I land rain rate algorithm: the $T_{b}$ are linearly combined, corrected for beam filling, and plotted as a function of cloud model rain rate. A regression line is fit through the $T_{b}$ points providing the slope and bias used to invert actual measured $T_{b}$ to rain rates. 


\subsection{Algorithm sensitivity analysis}

The rainfall algorithm is tested for theoretical sensitivity to variations in background atmospheric and surface parameters. The sensitivity analysis is achieved by creating cloud models that differ from the original model by the variation of a single parameter at a time. Theoretical radiances are calculated through the altered model, the algorithm is applied and the difference between the modeled and retrieved rain rate is noted over the range of rain rates. Models are constructed with varying surface temperature, cloud liquid water, ice content, precipitable water, and freezing level. Separate analyses are conducted for the ocean and land algorithms. The results of the sensitivity test detail the expected errors when the actual atmospheric composition and surface characteristics are different from those specified by the model system used for the algorithm derivation.

The influence of removing the entire layer of cloud liquid water from the cloud model, and of reducing the water vapor content by $50 \%$, on expected retrieval accuracies for the ocean algorithm is very slight (Figure 3.7). Ice in the mixed and upper layers of the cloud model, on the other hand, dramatically affects the algorithm. With ice removed from the cloud model the algorithm saturates at rain rates of approximately $7 \mathrm{~mm} / \mathrm{hr}$ because the high frequency channels are not depressed by scattering; the algorithm is responding to increases in the lower frequency channels due to the emission by raindrops. A low rain rate saturation is characteristic of algorithms that respond exclusively to emission. This sensitivity should not compromise retrievals because cloud types that do not generally contain an ice layer, such as stratiform clouds or low level convection, also do not generally exhibit high rain rates. Usually intense rain rates are associated with strong convective upwelling which is most often above the freezing level and contains ice.

Over land the sensitivity of the rain rate algorithm to atmospheric constituents is shown in Figure 3.8. Similar to the ocean algorithm, the effects of 
variations in cloud liquid water and water vapor on the land algorithm are negligible compared with the absence of ice. Although it is argued that the absence of ice would not adversely affect the retrievals over ocean, the land algorithm is more reliant on an ice layer. The physical explanation is that since the emission response is masked by the warm land background, rain rates over land are identified to a great extent by the ice associated with raining clouds. The sensitivity analysis indicates that retrievals over land using passive microwaves require a scattering signal.

The sensitivity of both algorithms to surface temperature is shown in Figures 3.9 and 3.10. The land algorithm is more sensitive to surface temperature variations than the ocean algorithm. At a rain rate of $5.0 \mathrm{~mm} / \mathrm{hr}$ there is a variation of approximately $2.0 \mathrm{~mm} / \mathrm{hr}$ over ocean and approximately $3.0 \mathrm{~mm} / \mathrm{hr}$ over land associated with variations in surface temperature. Using results over a 288 ${ }^{\circ} K$ surface to construct the algorithm, the errors introduced from surface temperature variations do not pose a significant problem since they are a small fraction of the total rain rate. The channel differencing technique is primarily responsible for significantly reducing surface temperature effects.

To investigate the sensitivity of the algorithm to the vertical temperature profile a model is constructed with a surface freezing level. The climatological freezing level is dependent on latitude and at latitudes near 60 degrees the freezing level frequently reaches the Earth's surface. The attenuation of upwelling microwaves by raindrops is dependent on the column ensemble of droplets such that when the freezing level drops there are fewer droplets through which the radiances must pass. In extreme cases, such as when the surface precipitation is frozen, there would be only a scattering signal measurable by the radiometer.

When the model is altered so that the freezing level is at the surface, the ocean algorithm underestimates the rain rates with a maximum underestimate at 4-8 $\mathrm{mm} / \mathrm{hr}$ of about $2.5 \mathrm{~mm} / \mathrm{hr}$ (Figure 3.11 ). This is the expected result since there 
would be reduced emission from the reduced column of raindrops. Over land the underestimate is more severe (Figure 3.11), with an underestimate for all rain rates below $10 \mathrm{~mm} / \mathrm{hr}$. Because of the magnitude of this error a climatological freezing level correction is introduced to the algorithm. A bias is added to the land channel combination which is a function of season and latitude and is is derived from global trends in seasonal and meridional freezing levels. The land surface threshold bias becomes $-15.6+(X / 5)$ where $\mathrm{X}$ is the absolute value of latitude + seasonoff set. The seasonof fset is 20 during December, January and February; -20 during June, July and August; and 0 for the remaining months. The ocean algorithm underestimates are relatively slight and are not uniform over the model rain rate so no further correction is added. 


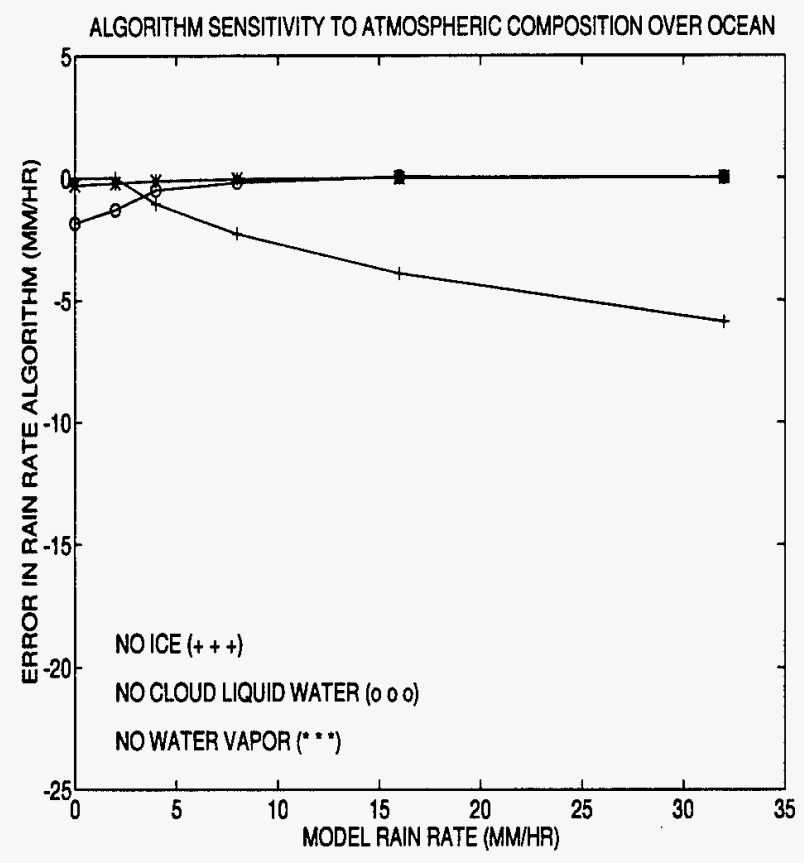

Figure 3.7. Theoretical sensitivity of the ocean rainfall algorithm to cloud liquid water, water vapor and ice.

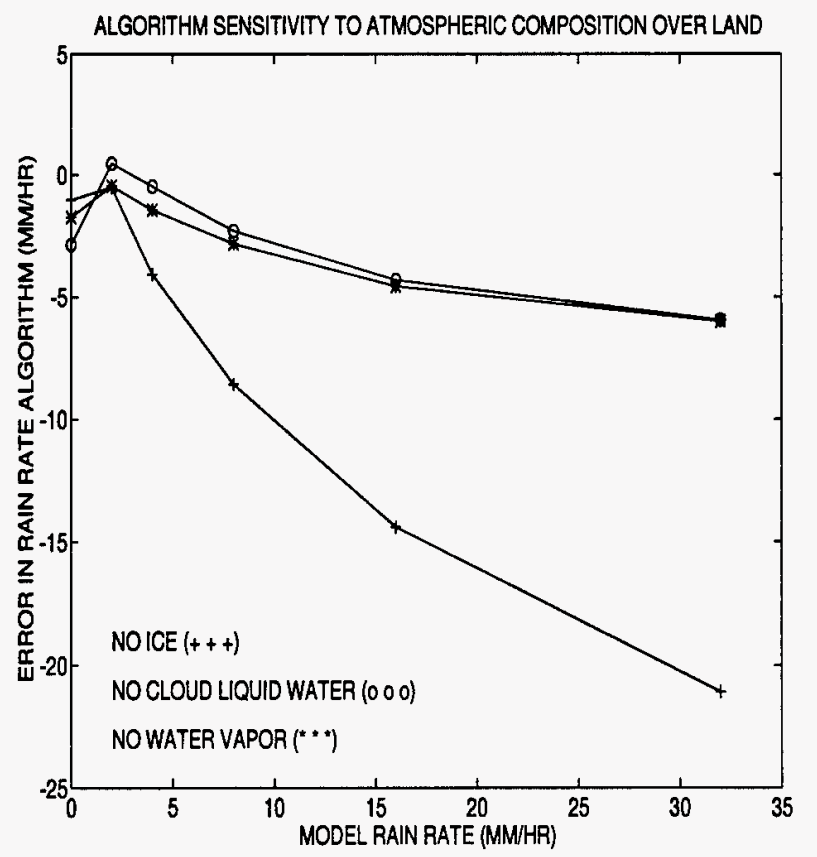

Figure 3.8. Theoretical sensitivity of the land rainfall algorithm to cloud liquid water, water vapor and ice. 


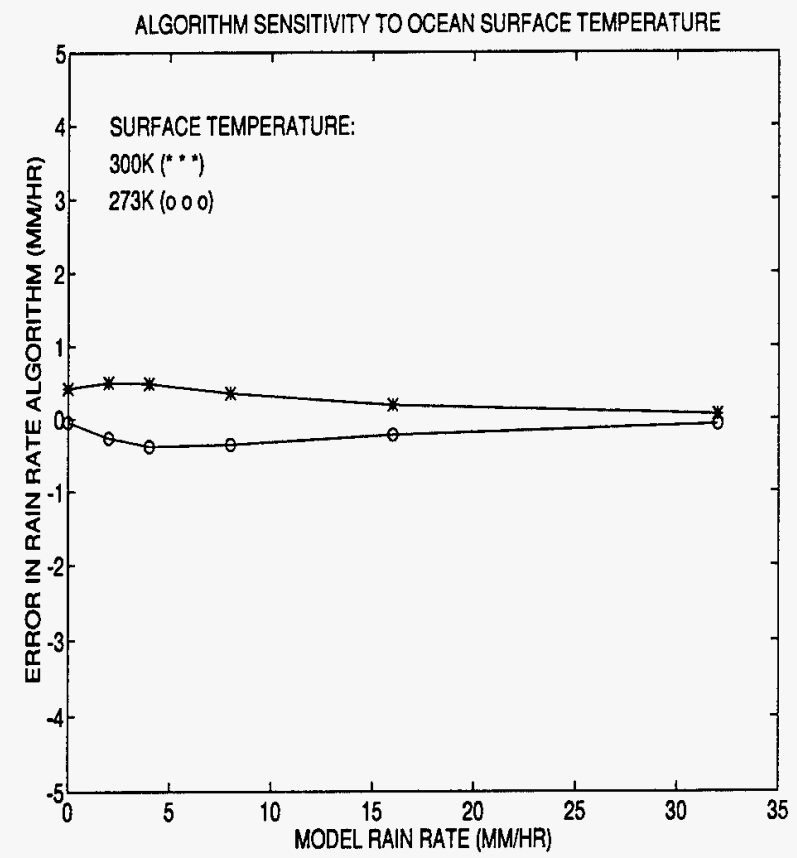

Figure 3.9. Theoretical sensitivity of the ocean rainfall algorithm to surface temperature.

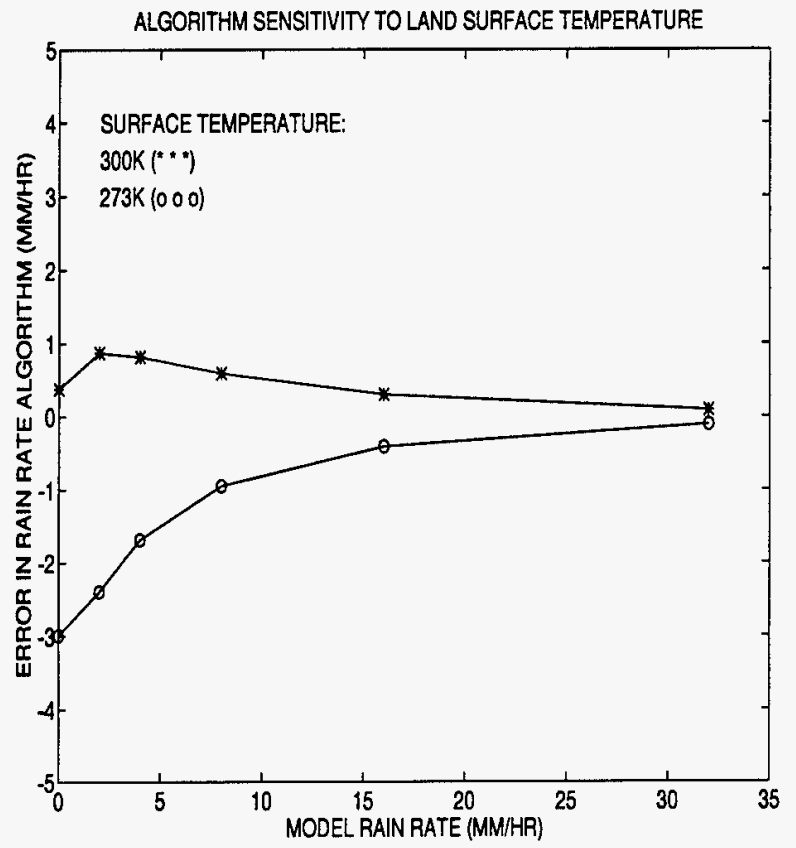

Figure 3.10. Theoretical sensitivity of the land rainfall algorithm to surface temperature. 


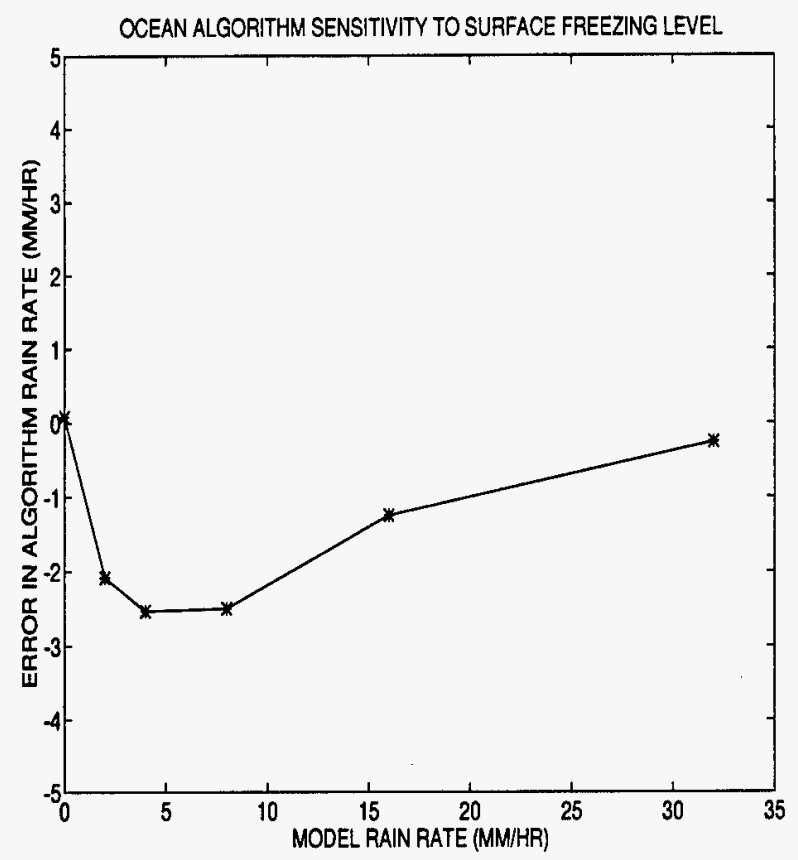

Figure 3.11. Theoretical sensitivity of the ocean rainfall algorithm to surface freezing level.

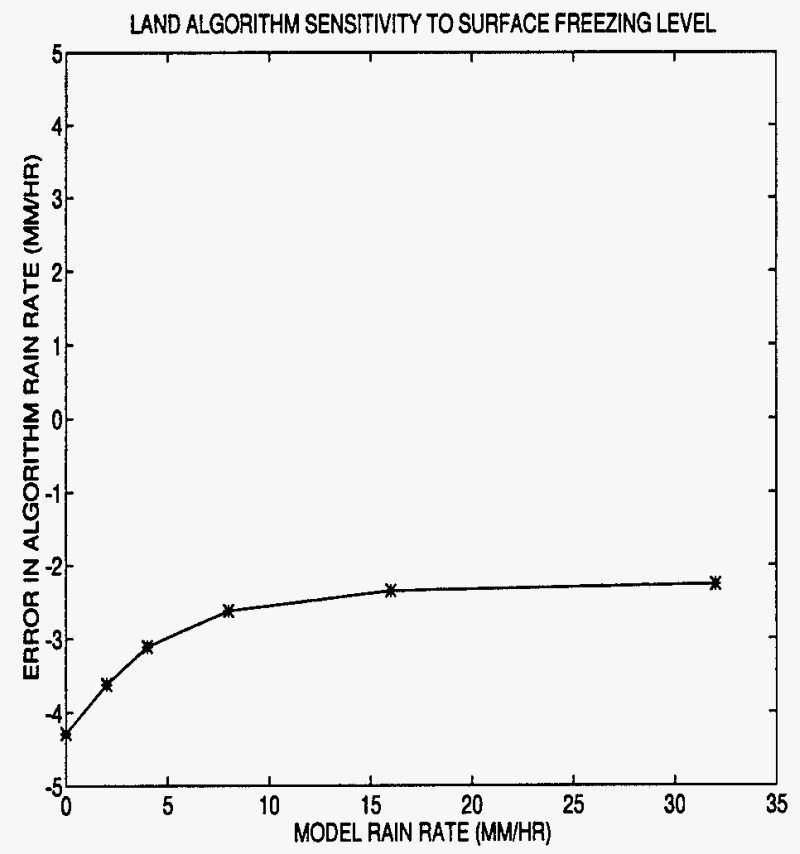

Figure 3.12. Theoretical sensitivity of the land rainfall algorithm to surface freezing level. 


\subsection{Algorithm implementation}

Rain rates and composite rainfall data maps are computed from the ocean and land algorithms using SSM/I data formatted and packaged according to Wentz (1991). Rain rate estimates are computed on a scan-by-scan basis for each pixel at the $25 \mathrm{~km}$ all-channel SSM/I resolution. The antenna temperatures are converted to brightness temperatures, mislocated data are removed and a geolocation correction is applied according to Wentz (1991). Scans which deviate significantly from neighboring scans are also filtered out according to Berg (1993), and the original footprint resolution of different frequencies is retained. The surface type flags contained in the data records are used to identify underlying surfaces: land, ocean and coastline. Pixels flagged by the algorithm using the screening procedures are set to zero rain rate. The land algorithm is applied to pixels identified as coastline in the data records. The rainfall algorithm is applied only to data located between $60^{\circ}$ north and south latitude. A summary of the rain rate algorithm structured for straightforward conversion into computer code is outlined in Figure 3.13. 
Global Rain Rate Algorithm for SSM/I

Applicable Between $+-60^{\circ}$ Lattitude

Land Surface:

If $(37 v-37 h<10.0)$ and $(19 v-19 h<10.0)$ and $(19 v>265.0)$

Then $($ RainRate $=(19 h+37 h-2 . * 85 h+X) / 9.1 \mathrm{~mm} / \mathrm{hr}$

Where $X=(-15.6+\mid($ latitude + seasonoffset $) / 5 \mid)$

and seasonoffset $=$

20 during December, January and February

-20 during June, July and August and

0 during remaining months

Otherwise Rain Rate is set to $0 \mathrm{~mm} / \mathrm{hr}$

Ocean Surface:

If $((19 v-19 h)<60.0)$

Then RainRate $=((19 h+19 v+37 h-22 v-37 v-85 h+170.2) / 18.3) m m / h r$ Otherwise Rain Rate is set to $0 \mathrm{~mm} / \mathrm{hr}$.

Figure 3.13. Algorithm for estimating rain rate from SSM/I brightness temperatures. 
Rainfall totals are computed by integrating an average of all rain rate estimates over the time period of interest. Spatial averaging is achieved by a simple average of all estimates within a given grid cell. The algorithm is applied to selected SSM/I overpasses containing a variety of surface and rainfall types. In Figure 3.14 a mid-latitude depression over the United Kingdom contains an East-West band and a rainfall cell. In Figure 3.15 an SSM/I overpass of Hurricane Andrew over the U.S. shows the continental scale rainfall produced as the hurricane was dissipating. In Figure 3.16 in the Tropical Pacific during the Toga Coare period an intense rainstorm in the Coral Sea outlines the fine scale features of a tropical cyclone.

Global rainfall is typically reported as totals from a month or more so that enough samples are available to represent the average global distribution. An example of a monthly composite rainfall map is presented in Figure 3.17. Approximately a gigabyte of satellite data is processed to derive one monthly rainfall map. In this particular monthly composite simple averaging is used to compute monthly totals at one degree resolution. The data values range from $0.0-0.5$ meters of rainfall. When a monthly total is computed at one degree grid cell sizes, the sampling errors are reduced. One or two samples a day undersamples rainfall in time, but the large areas used in the integration compensate with large spatial averaging.

The general pattern of global rainfall is well represented in a monthly map. Of particular interest is the strong band of intense convective rainfall along the ITCZ where most of the global rainfall is measured. The ITCZ stretches along the Earth's tropics over both land and ocean. The mercator map projection distorts the relative magnitudes of the Earth's surface area by stretching the zonal dimension at high latitudes to equal that of the equatorial regions. In reality, tropical rainfall, falling primarily along the intertropical convergence zone, represents about $80 \%$ of the Earth's total rainfall. 


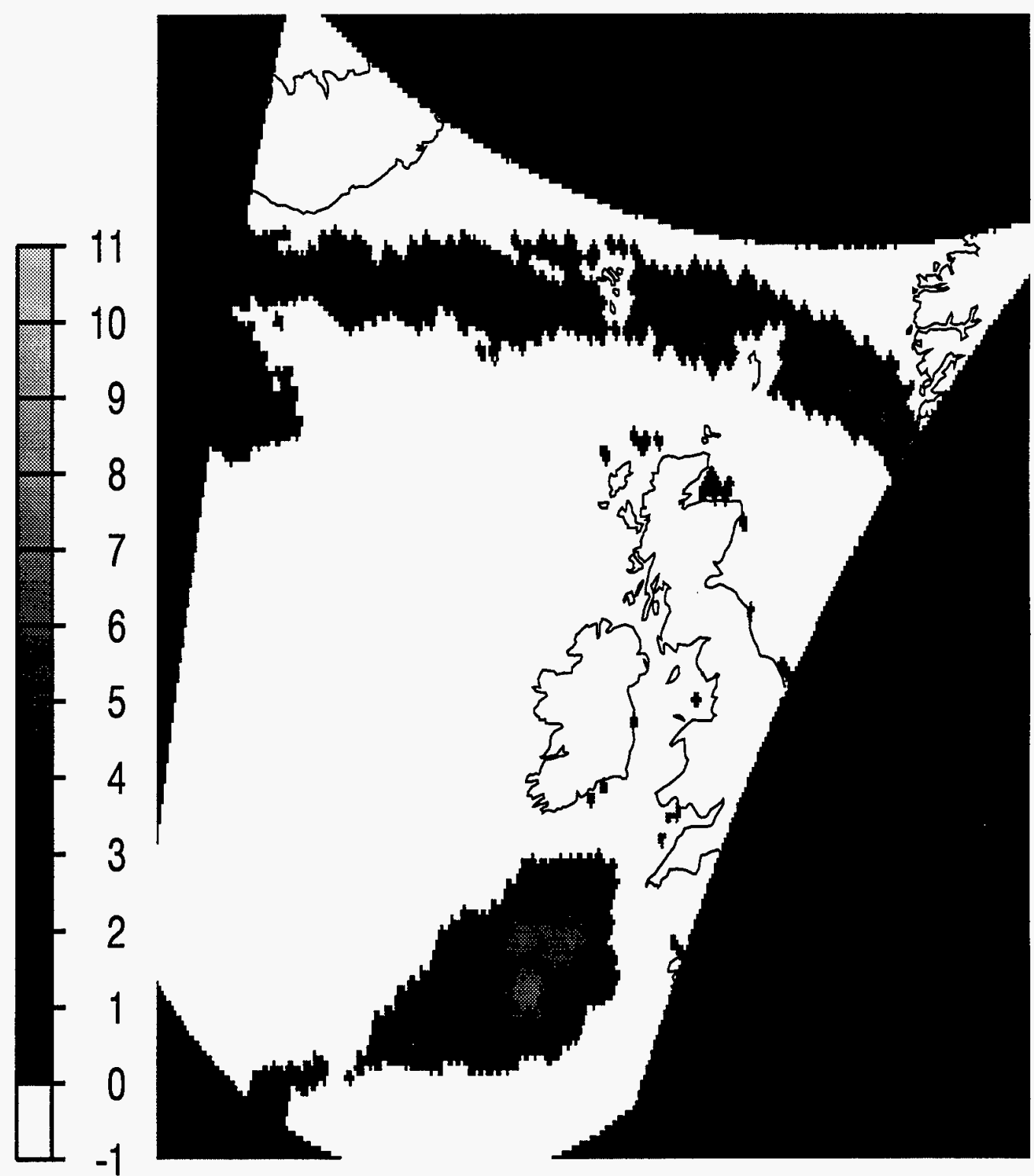

Figure 3.14. Rain rates $(\mathrm{mm} / \mathrm{hr}$ ) during a United Kingdom mid-latitude depression derived from F11 SSM/I data on 08/23/92 at 06:53 UTC. 


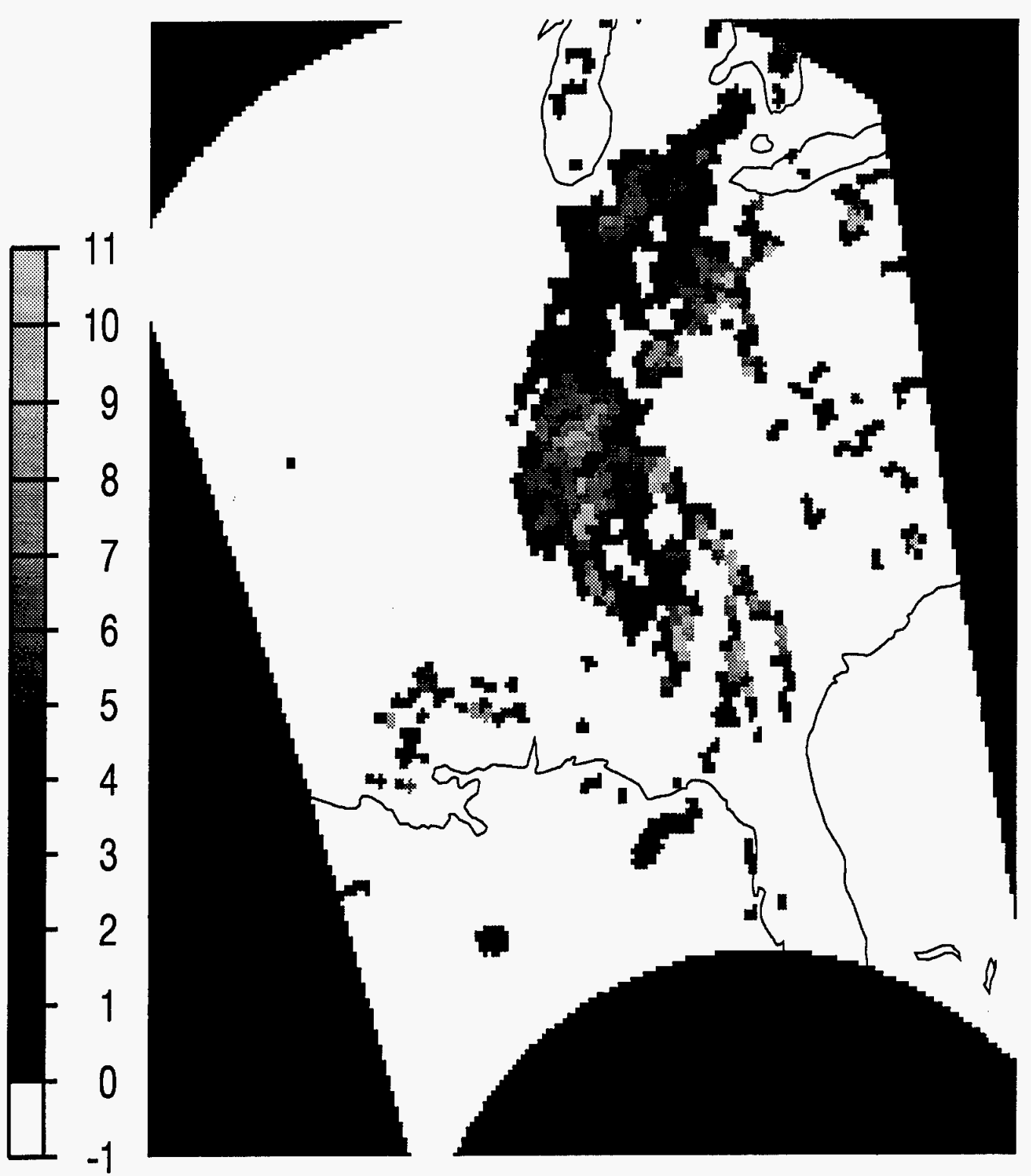

Figure 3.15. Hurricane Andrew rain rates $(\mathrm{mm} / \mathrm{hr}$ ) derived from SSM/I F11 data on $08 / 27 / 92$ at $22: 35$ UTC. 


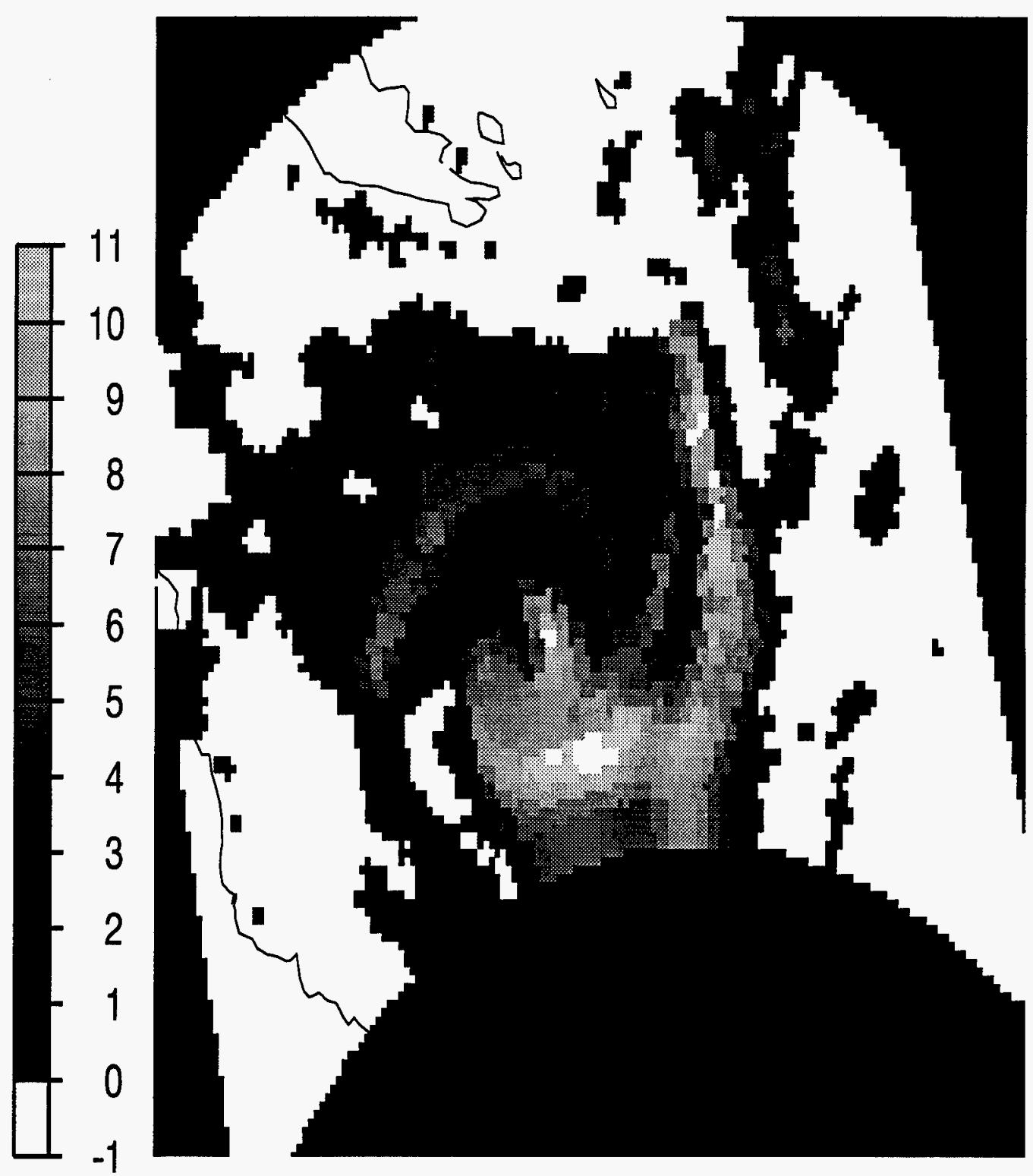

Figure 3.16. Rain rates $(\mathrm{mm} / \mathrm{hr})$ during TOGA-COARE derived from F11 SSM/I data on $02 / 06 / 93$ at $07: 24$ UTC. 
Rainfall (mm) from SSMI/ for August, 1987
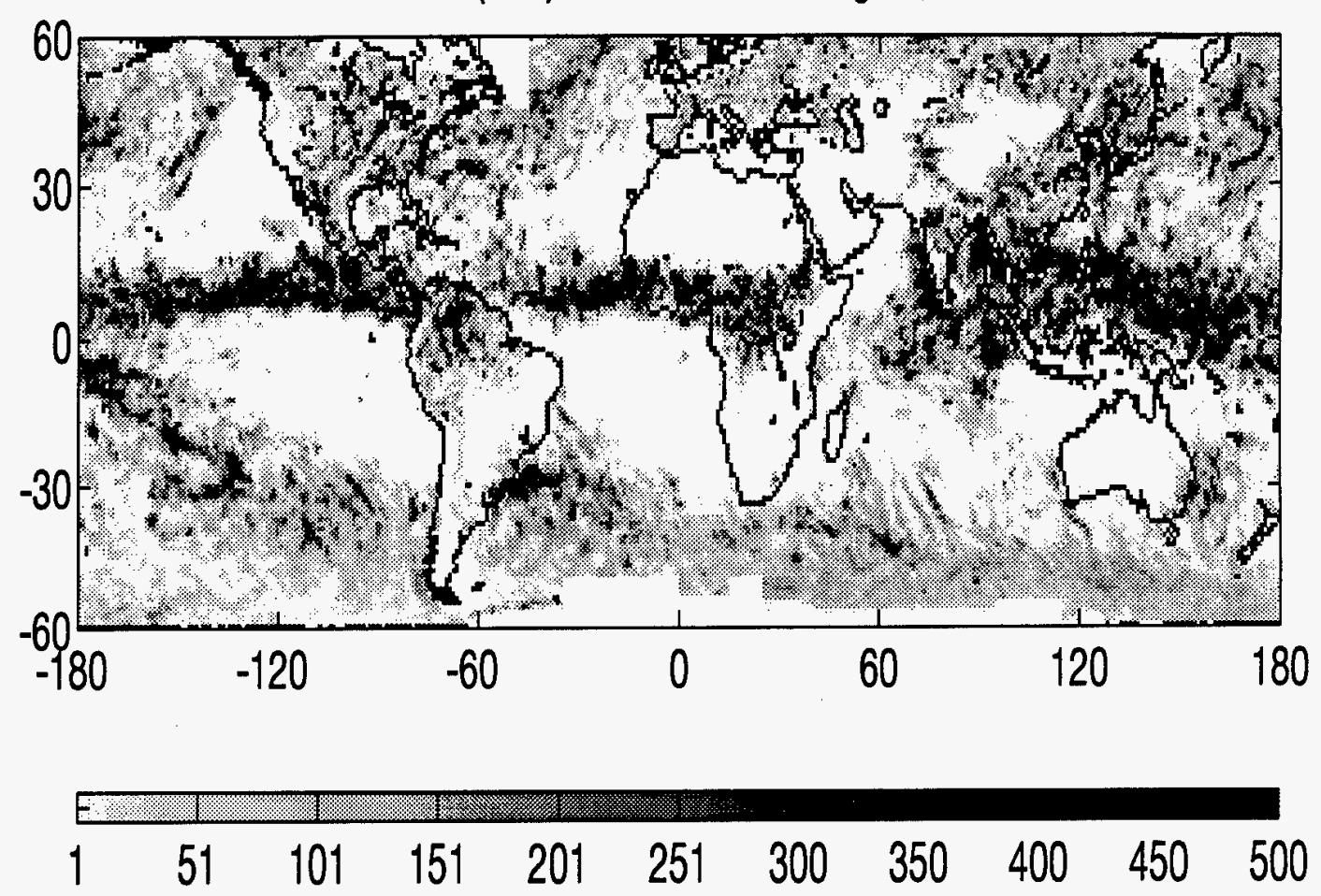

Figure 3.17. Rainfall total for the month of August, 1987, derived from SSM/I data. An average of all rain rate observations within each one degree grid point is used to compute the monthly total. 


\section{CHAPTER 4}

\section{ALGORITHM VALIDATION AND ERROR BUDGET}

\subsection{Characterization of errors}

The accuracy of the rainfall estimates is determined using theoretical error calculations and comparisons with alternative rainfall data. The calculation of an algorithm error budget relies on comparisons with alternative data from rain gauges and surface precipitation radars coincident in time and space with satellite overpasses. Error estimates are hampered by the scarcity of such validation data, by the challenges of comparing dissimilar data types, and because validation data sets cannot readily be treated as "ground truth". Rain rates derived from surface radars rely on the same remote sensing methods that contribute to errors in current satellite estimates: empirical assumptions of hyrometeor drop-size distributions in the formulation of a reflectivity-rain rate inversion can introduce significant errors. Rain gauges are known to underestimate rainfall due to collection inaccuracies (Legates and Willmott 1990) and it is non-trivial to compare point source gauges with areaaveraged rain rates from satellite (Morrissey and Greene 1993). The calculation of an error budget must also account for the temporal and spatial scales over which the estimates are reported. Instantaneous estimates are often averaged in space and time to produce monthly totals at $1-5$ degrees resolution. Although random errors in instantaneous estimates tend to cancel out when averaged together over longer time and space scales, the extreme variability of rainfall results in spatial and temporal sampling errors (Atlas et al. 1990; North and Nakamoto 1989).

The sources of error in satellite rainfall estimates can be logically divided 
between instantaneous algorithm estimate errors and monthly time and space integration errors. The algorithm errors include contributions from the satellite data, the surface screening techniques, rainfall thresholding and rain rate quantification. The SSM/I data set contains erroneous data due to mislocation, scans with systematically high values, and random $T_{b}$ noise. In most cases the removal of the erroneous SSM/I data is successful and the effect of the $T_{b}$ accuracy is negligible. Surface screening techniques introduce significant errors, especially over land, which can be geographically and seasonly dependent. The thresholding technique used to distinguish the onset of rainfall introduces another source of error in the algorithm which is equally important over ocean and land. Over ocean the main difficulty is in distinguishing significant non-precipitating cloud liquid water from low-lying stratiform "warm rain" events. The detection of rainfall over land is more difficult due to the inhomogeneous surface background. The land screening techniques use combined $T_{b}$ and polarization thresholding which introduce errors if there is no scattering by frozen hydrometeors associated with the underlying liquid hydrometeors. The quantification of rain rates introduces another error that results from differences between the structure of the rain cloud under investigation and the reference cloud modeled in the radiative transfer calculations. When the radiometer field-of-view is filled with an inhomogeneous distribution of rain rates an underestimation often results from an algorithm developed from plane parallel cloud models.

When the algorithm results are integrated in space and time to produce rainfall totals, additional errors result from inadequate temporal sampling by the sunsynchronous near-polar orbit and inadequate spatial sampling due to the diffraction limits of the satellite antenna pattern (Bell et al. 1990). The spatial autocorrelation of instantaneous rainfall fields is about $10 \mathrm{~km}$, less than the $12 \mathrm{~km}$ resolution of the highest frequency SSM/I $85 \mathrm{GHz}$ footprint. The temporal autocorrelation for SSM/I resolution is typically found to be less than 12 hours so that the 24 hour temporal 
sampling frequency of SSM/I undersamples severely in time. The significance of the temporal and spatial sampling errors depend on the scales at which the rainfall is reported. Instantaneous rain rate errors are usually reported to be about a factor of two, whereas sampling errors are usually reported to be between $25 \% 50 \%$ for global monthly oceanic totals (Chang et al. 1993; North and Nakamoto 1989). The diurnal cycle of rainfall, more pronounced over land due to the convection initiated by the daytime warming of the surface, is not adequately sampled by a sun-synchronous orbit. Over ocean the mean diurnal cycle is estimated to be about $10 \%$, but over land the diurnal cycle is dependent on surface type, season, and atmospheric conditions, and in general is closer to $10 \%-25 \%$ of the mean rainfall.

The calculation of an error budget in sections 4.2-4.7.2 is based on the statistics generated from comparisons with alternative rain estimates and from theoretical considerations of the various error sources. Errors associated with the instantaneous rain rates are analyzed separately from the errors associated with temporal and spatial averages. Instantaneous validation are conducted through comparisons to different land surface screening methods, a dynamical cloud model and precipitation radar data. Comparisons with rain gauge composite data and an alternative SSM/I algorithm serve to validate the algorithm on global seasonal scales. Since there is no "ground truth" the comparisons determine the agreement between the microwave technique and conventional methods. Theoretical sampling error calculations will establish the relative importance of the different categories of errors. The results from participation in independently proctored algorithm intercomparison programs are presented, as well as error budgets reported in the literature. As a final formulation of the error budget, the statistics generated by the validation comparisons are compared with the statistics calculated by theoretical means, and a comprehensive error budget is derived. 


\subsection{Intercomparison of rainfall detection procedures over land}

An investigation of the instantaneous error budget begins with the rainfall screening process. Due to the relatively high microwave emissivity of land surfaces and the variability of the spectral properties of different land surfaces, false rain signatures often result from ice, snow, sand, and moist or cold ground (Grody 1991). Further rain detection problems result from atmospheric cloud liquid water and from significant frozen hydrometeor content without associated low-level precipitation. Over ocean the uniform background means that the most significant detection problem is in distinguishing rain from other atmospheric conditions. Over land the contribution from the surface creates screening problems of greater severity.

The validity of rainfall algorithms over land depends on a robust method for screening out surfaces which mimic rainfall signatures. Screening and detection of land surfaces rely on the scattering of the higher frequency channels and attenuation and depolarization of the lower frequency channels. It is understood that snow and ice tend to exhibit cold scattered signals. The fact that the frozen hydrometeors in the upper layers of clouds have scattering and lowered radiances similar to snow and ice on the ground creates the false rain signatures. Fortunately, there is a difference between frozen hydrometeors on the ground and in the cloud; surface snow tends to have a higher polarization and is discarded in the screening process. Another important land surface feature, moist and flooded soil, exhibits a highly polarized signal like that of the ocean, so polarization screens are adequate for distinguishing rainfall. Finally, sand is screened out based on its highly polarized emissivity at the lower SSM/I frequencies. Each of the screening procedures employs a slightly different combination of these principles.

There are currently several screening techniques available which utilize different channels and polarization tests. Prior to the launch of F8, an operational algorithm for screening rainfall over land was described for SSM/I by Hollinger et al. 
(1987). A low frequency threshold flags ice and glacial snow, a low frequency polarization difference screens flooded land and a high frequency polarization difference detects scattering associated with rainfall. As part of the calibration and validation of the F8 SSM/I instrument (Hollinger 1991), the technique is improved to correct the misclassification of non-raining pixels over land (McFarland 1991). Grody (1991) developed a screening technique to distinguish precipitation from from all other atmospheric and surface variables. Discriminant analysis is used to obtain channel relationships in a decision tree algorithm. The water content of moist soil, vegetation, cloud liquid water, and melting snow and the associated increase of absorptance with frequency leads to an "absorptive" classification. Snow, precipitation clouds, and ice exhibit radiative properties leading to a "scattering" classification. Non-scattering lower frequencies are combined to estimate the scattering $85 \mathrm{GHz}$ channel so that scattering associated with precipitation can be detected. Spencer et al. (1989) utilizes a polarization corrected temperature in which the two $85 \mathrm{GHz}$ channels are normalized so that scattering associated with convection is detected.

Precipitation screening methods from Grody (1991), Spencer (1989) and McFarland-Neal (Hollinger 1991) are applied globally to one day of SSM/I data and intercompared with the screening method developed here. The results of applying the different screening procedures to one day of SSM/I data are displayed in Figures 4.14.4. The images represent the normalized fraction of pixels within each one degree grid cell that pass through the screening process and are considered to be possibly raining. The McFarland-Neale algorithm, part of the Calibration Validation Project for SSM/I, successfully identifies likely raining areas while screening out the majority of the pixels. Spencer's polarization corrected brightness temperature at $85 \mathrm{GHz}$ does not screen out high latitude areas where the temperatures are scattered by cold ice and snow covered ground. The Grody algorithm screens out the areas that the other methods have missed and retains pixels located in the Amazon, south central Africa 
and Malaysia where rainfall is expected. The Ferriday rainfall screening procedure identifies likely raining areas while screening out the majority of the data. There are no clearly misdiagnosed surfaces; areas identified as possibly raining are in accord with the other techniques. 
Cal/Nal Land Rainfall Screening Algorithm, 11/02/87

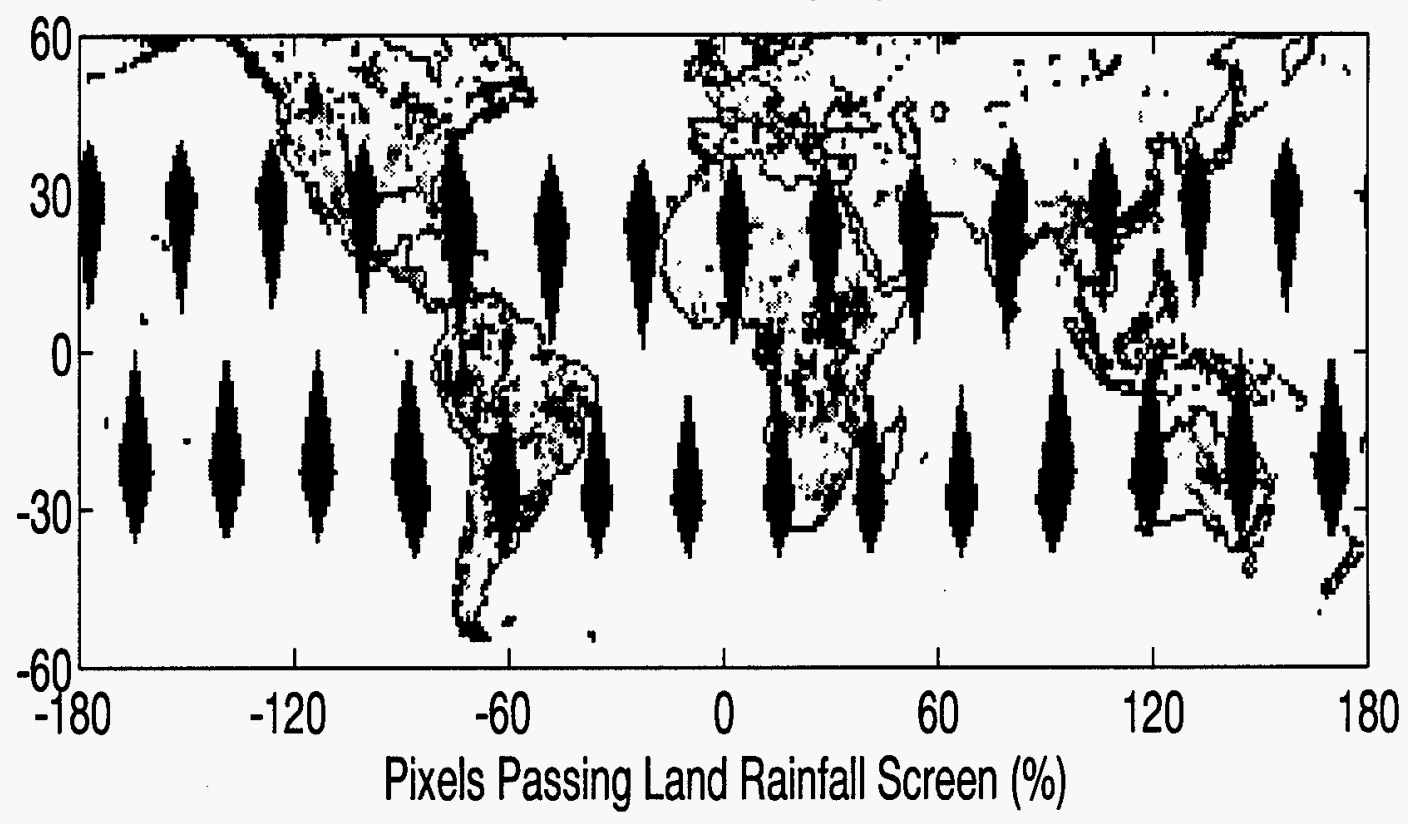

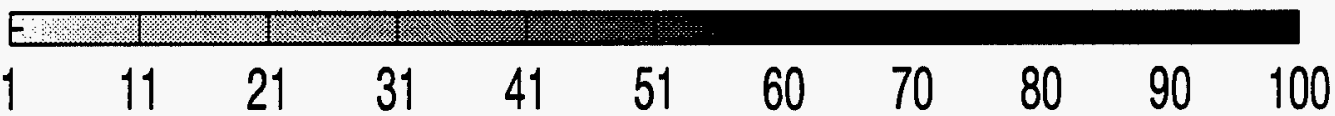

Figure 4.1. Normalized fraction of SSM/I pixels within each one degree grid box which are flagged as possibly raining by the McFarland Neale Calibration-Validation screening algorithm. 

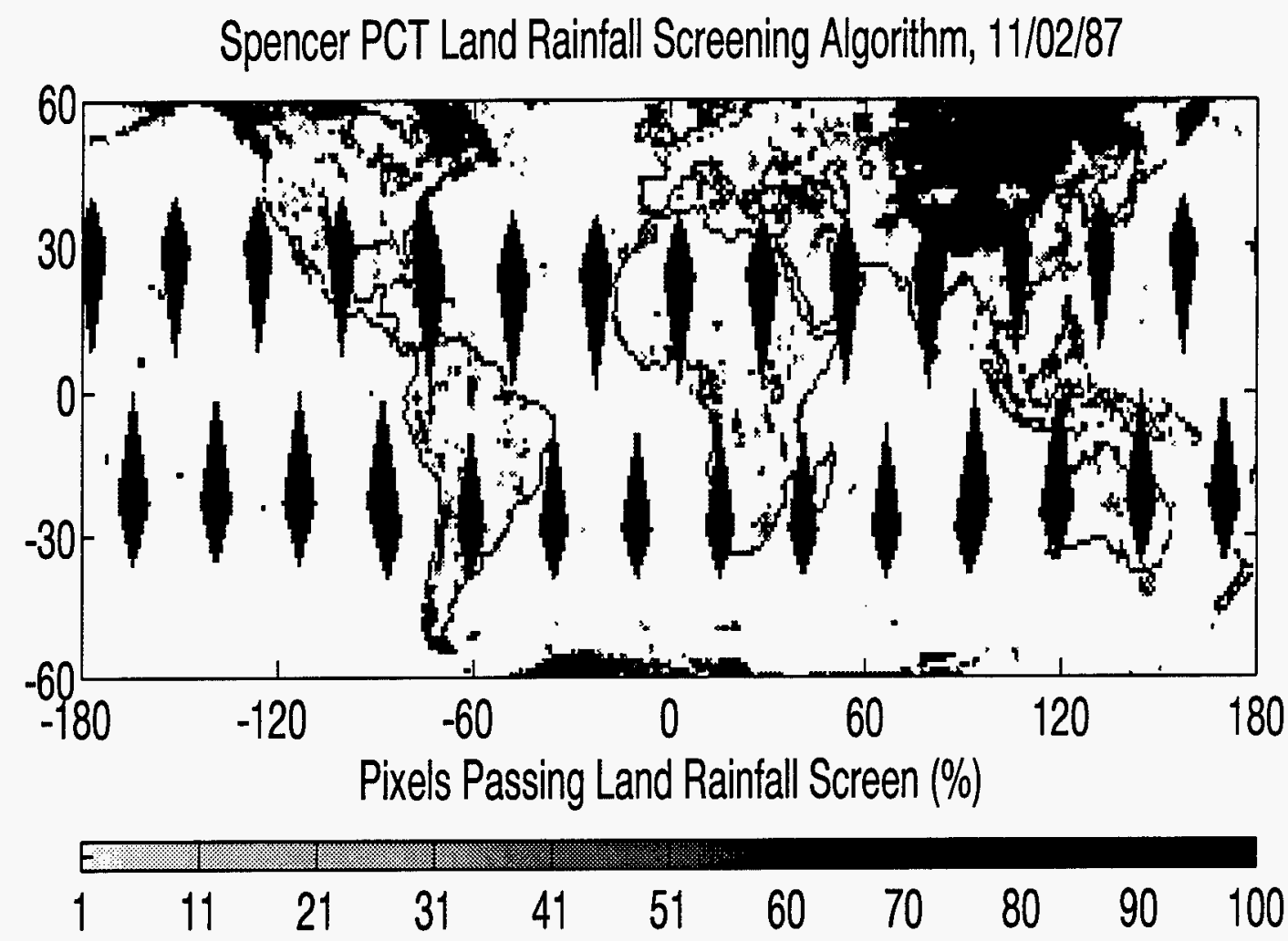

Figure 4.2. Normalized fraction of SSM/I pixels within each one degree grid box which are flagged as possibly raining by the Spencer polarization corrected temperature scattering based screening algorithm. 
Grody Land Rainfall Screening Algorithm, 11/02/87

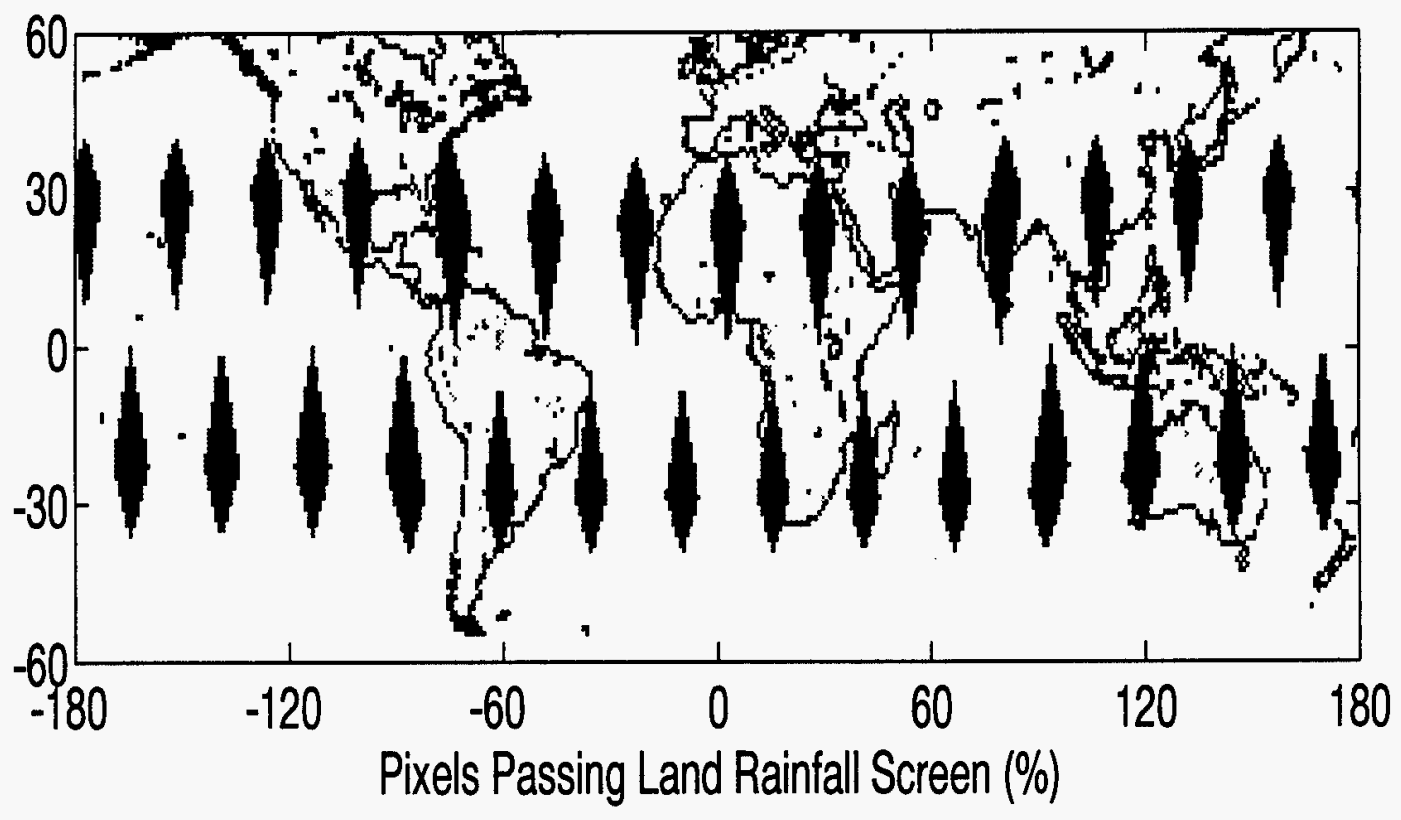

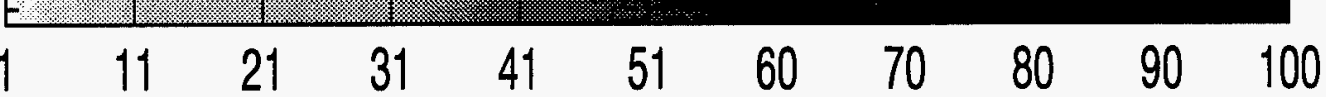

Figure 4.3. Normalized fraction of SSM/I pixels within each one degree grid box which are flagged as possibly raining by the Grody screening algorithm. 
Ferriday Land Rainfall Screening Algorithm, 11/02/87

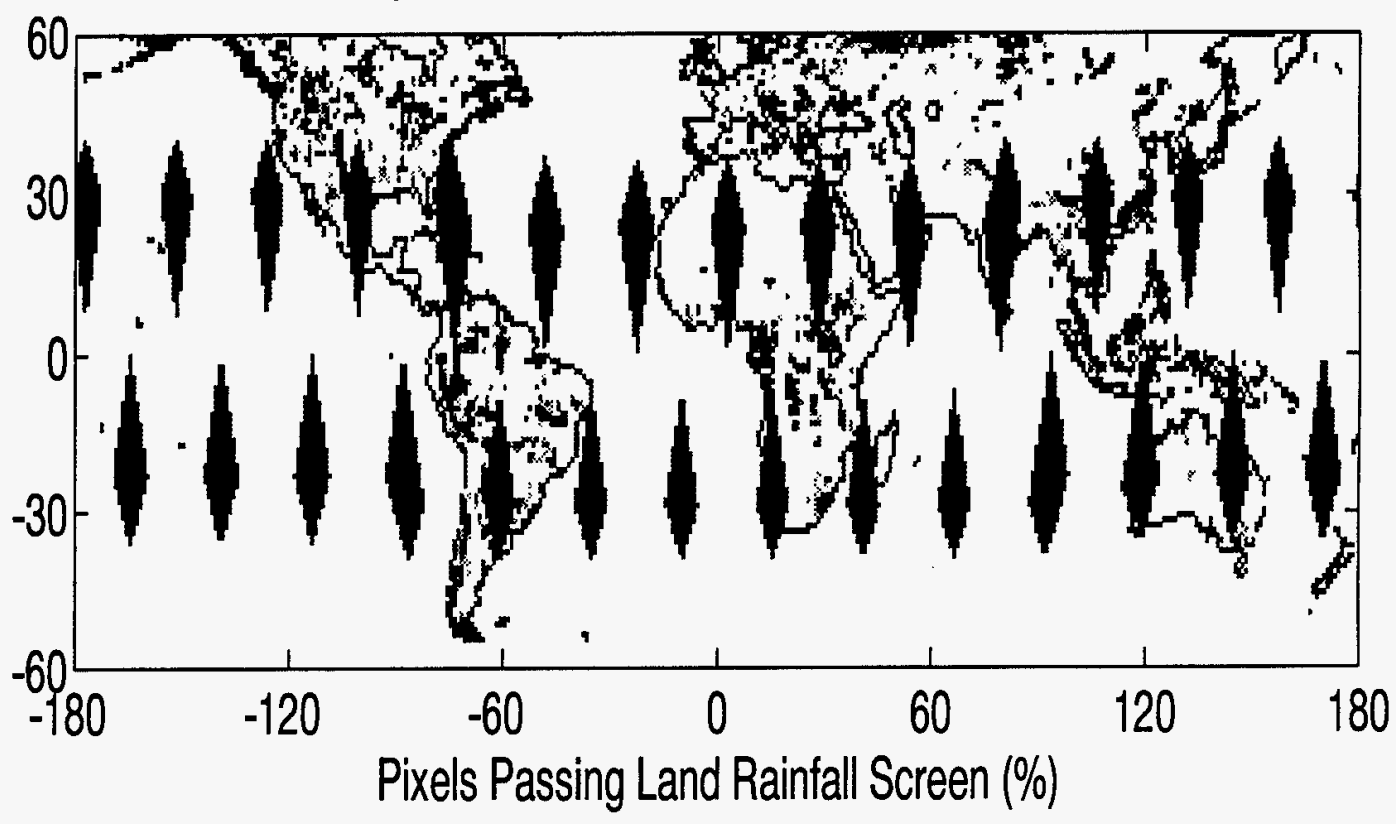

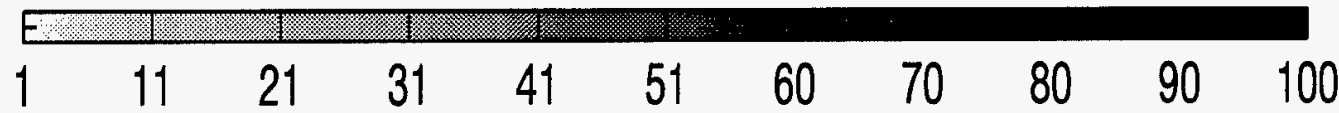

Figure 4.4. Normalized fraction of SSM/I pixels within each one degree grid box which are flagged as possibly raining by the Ferriday SSM/I screening algorithm. 


\subsection{Comparison to a dynamical cloud model}

To validate the rainfall estimates on an instantaneous basis over ocean the rainfall algorithm is applied to simulated SSM/I $T_{b}$ upwelling from a dynamic cloud model. A three-dimensional ensemble cloud system with parameterized microphysics is used to simulate a fast-moving ocean squall line (Tao et al. 1987). A three dimensional ray trace image, in Figure 4.5, outlines the shape of the storm defined by the cloud surface where the rain rate is $5 \mathrm{~mm} / \mathrm{hr}$. The individual convective towers and the larger stratiform cloud mass characterizing the "ensemble" model are visible in the image, which has a spatial resolution of approximately $1 \mathrm{~km}$. In Figure 4.6 , the rain rate at the lowest level of the cloud model, corresponding to the rain rate reaching the ocean surface, is averaged to the SSM/I all-channel resolution. The region for the average rain rates is a subsection of the original data because a point is included only if there are enough points surrounding it to complete a spatial average. The clustering and high rain rate variability visible in the full resolution image are smoothed considerably in the SSM/I footprint average.

Rain rates retrieved by the SSM/I ocean algorithm from brightness temperatures simulated through the cloud model are shown in Figure 4.7. The brightness temperatures are first simulated through the vertical cloud distribution at the original model resolution and then averaged to the SSM/I footprint. The algorithm is applied to the averaged brightness temperatures so that the effects of beam filling are accurately modeled. In Figure 4.8, the SSM/I estimates derived from the algorithm are plotted against the model surface rain rates. The retrieved rain rates are virtually identical to the model surface rain rates with a slope and correlation near unity and a bias near zero. The algorithm senses both the light rainfall near $1 \mathrm{~mm} / \mathrm{hr}$ and the relatively high rain rates of $20 \mathrm{~mm} / \mathrm{hr}$. In Figure 4.9, all rain rates from the model and the algorithm are used to compute a histogram. The distribution of rain rates are consistent for all rain rates in the model. The model is 
representative of a realistic storm; however, because the $T_{b}$ utilized in the retrieval are calculated theoretically by a radiative transfer model, the model and algorithm estimated rain rates cannot be considered uncoupled. The results support the use of the beam filling adjusted $T_{b}$ and the linear fit to the $T_{b}$ combinations forming the temperature inversion technique. 


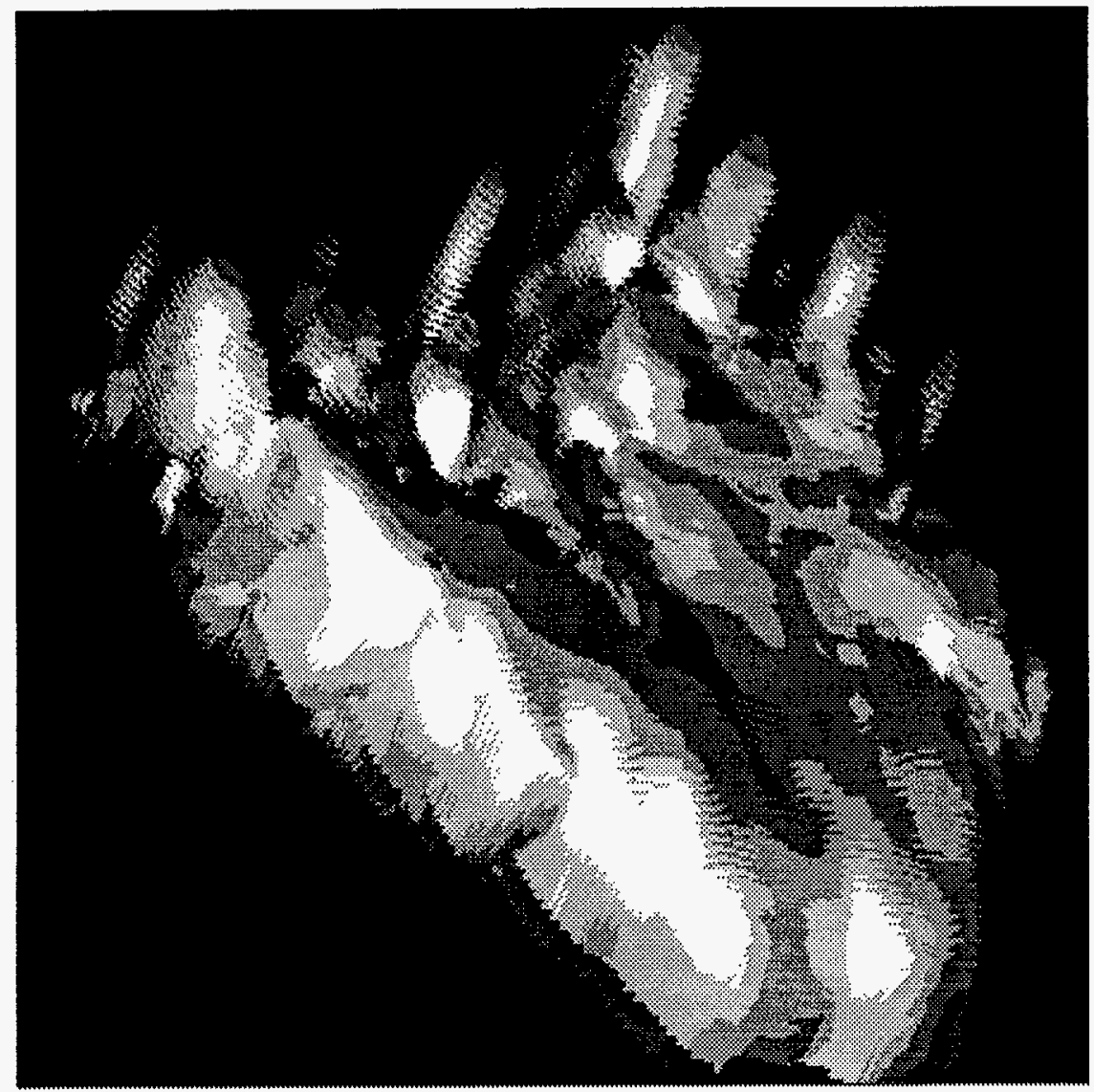

Figure 4.5. Goddard Cummulus Ensemble Model shaded with a ray tracing technique showing the outline of the cloud where the rain rate is $5 \mathrm{~mm} / \mathrm{hr}$. (Image courtesy of Kelly Luetkemeyer) 


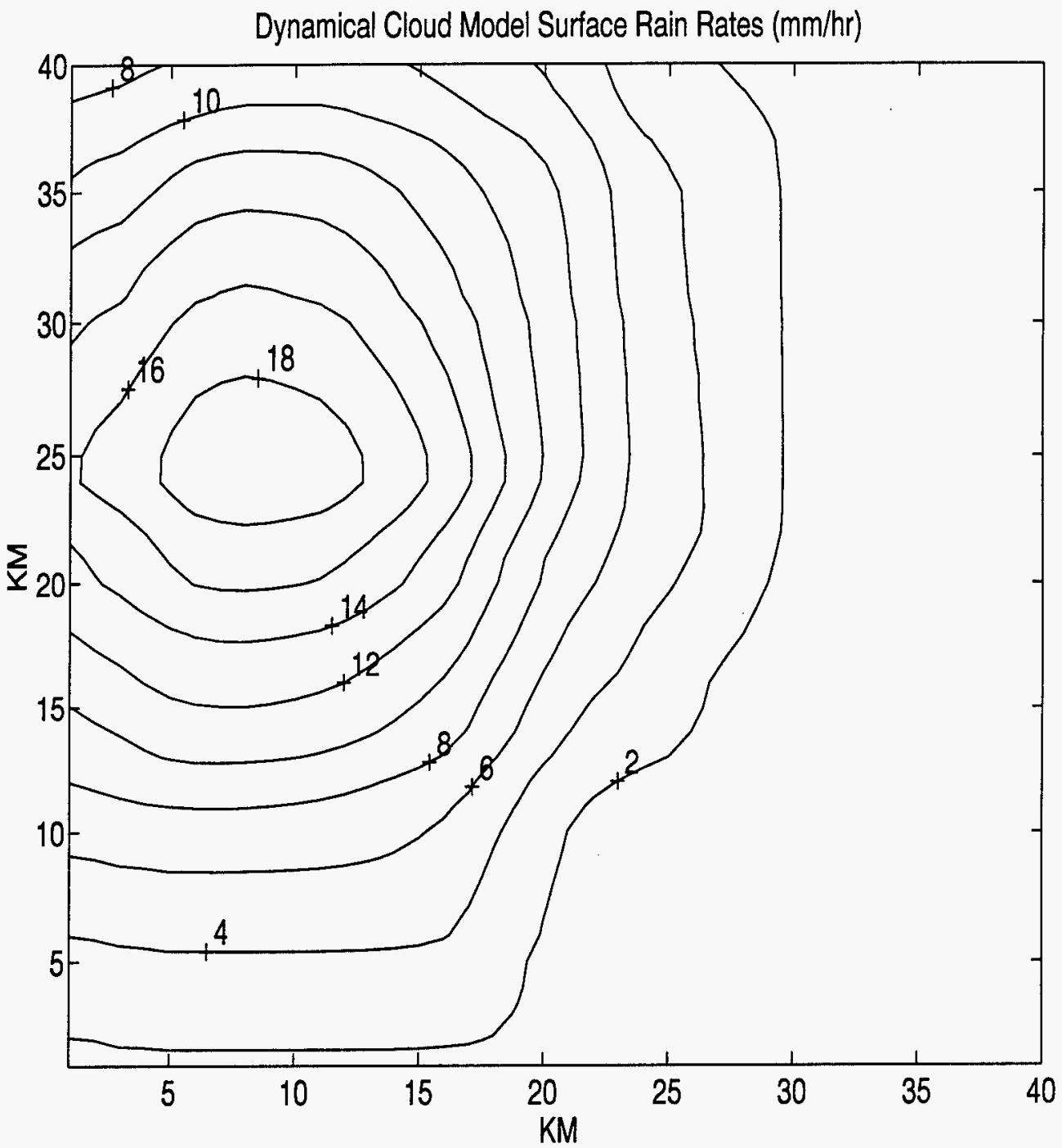

Figure 4.6. Surface rain rates from an area average of the Goddard Cumulus Ensemble Model. 


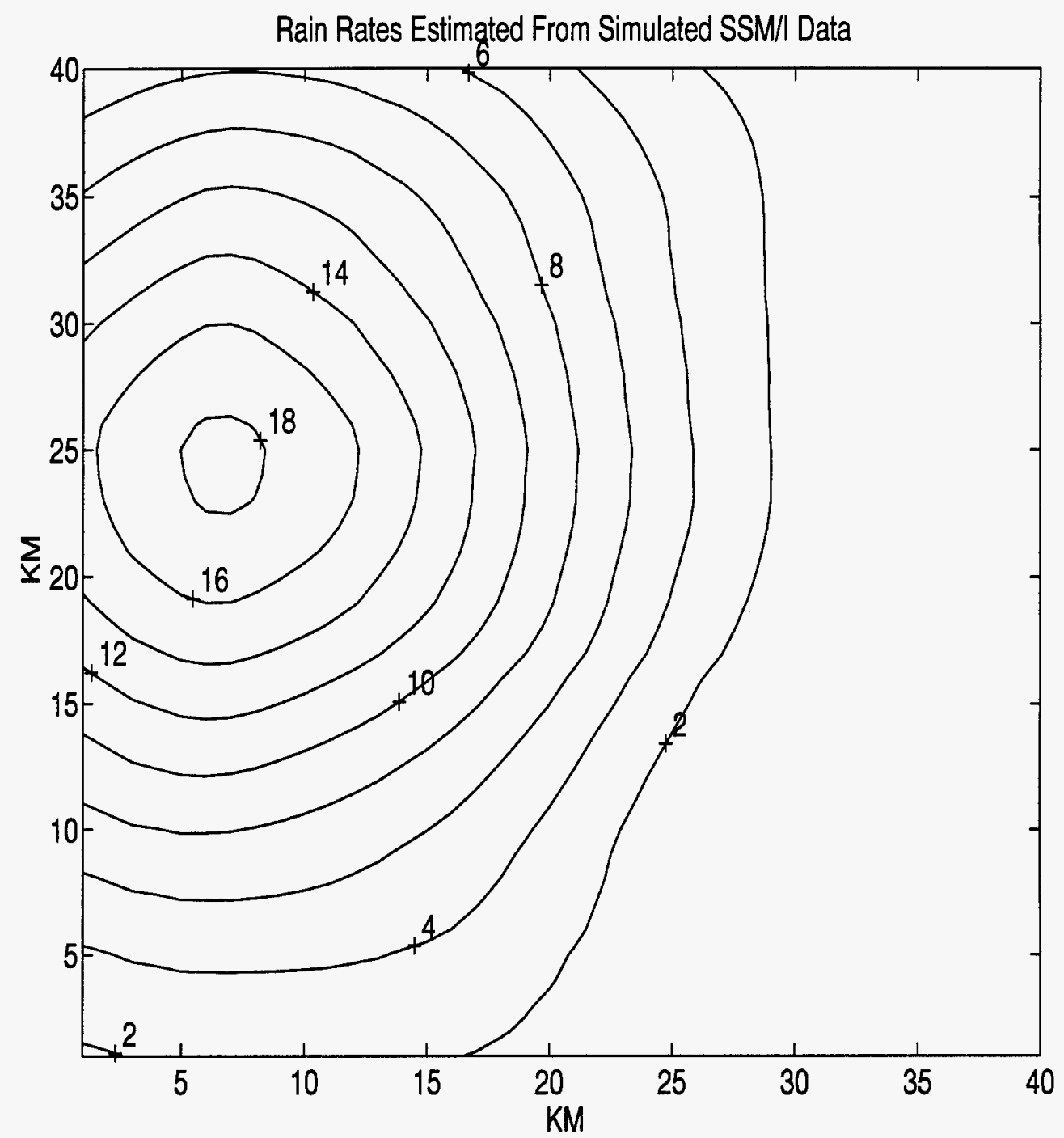

Figure 4.7. Rain rates estimated by the ocean rainfall algorithm from simulated SSM/I brightness temperatures upwelling through the GCEM. 


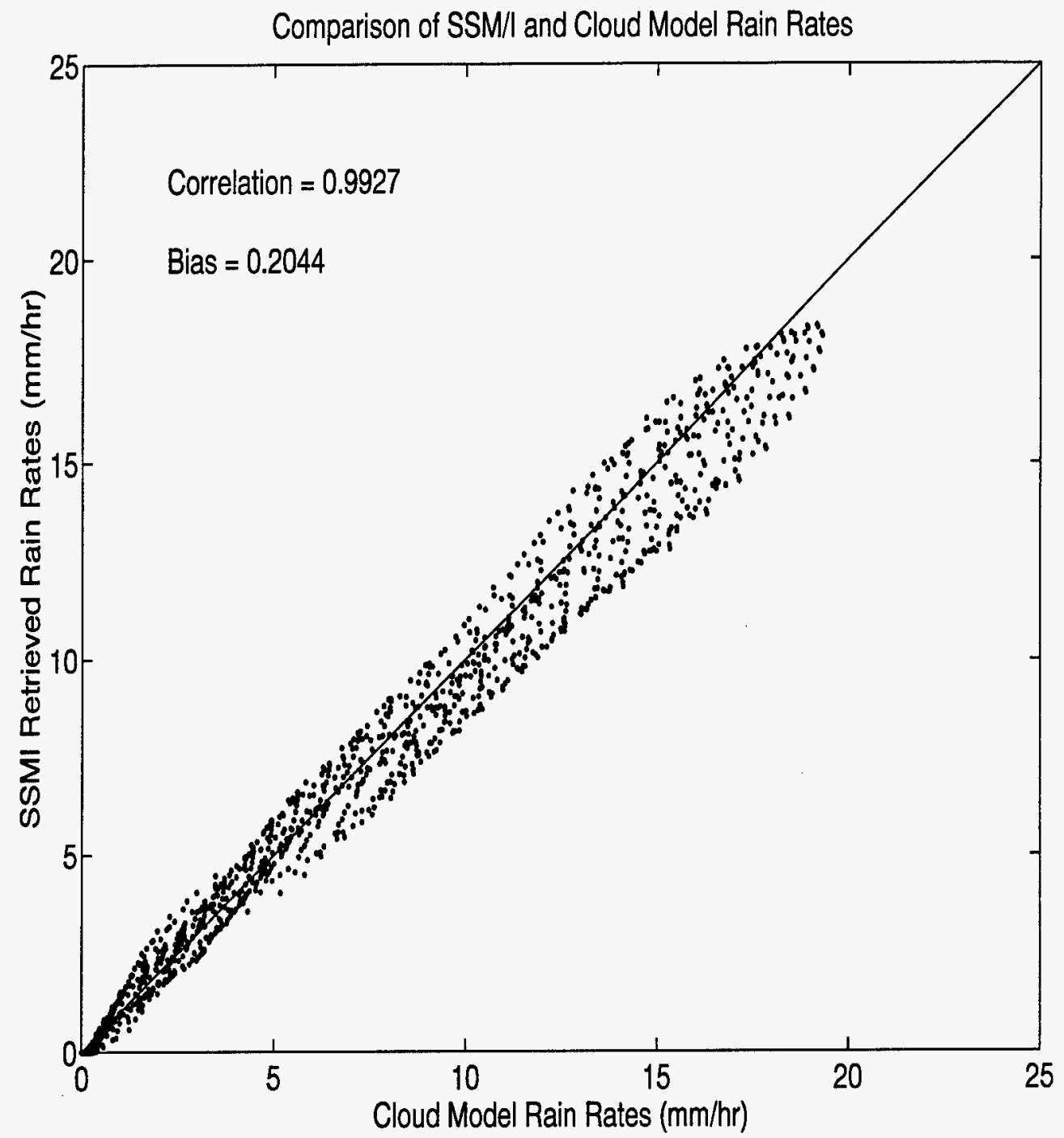

Figure 4.8. A comparison of surface rain rates from the Goddard Cumulus Ensemble Model (GCEM) with rain rates estimated by the application of the SSM/I ocean algorithm to brightness temperatures simulated through the model. 

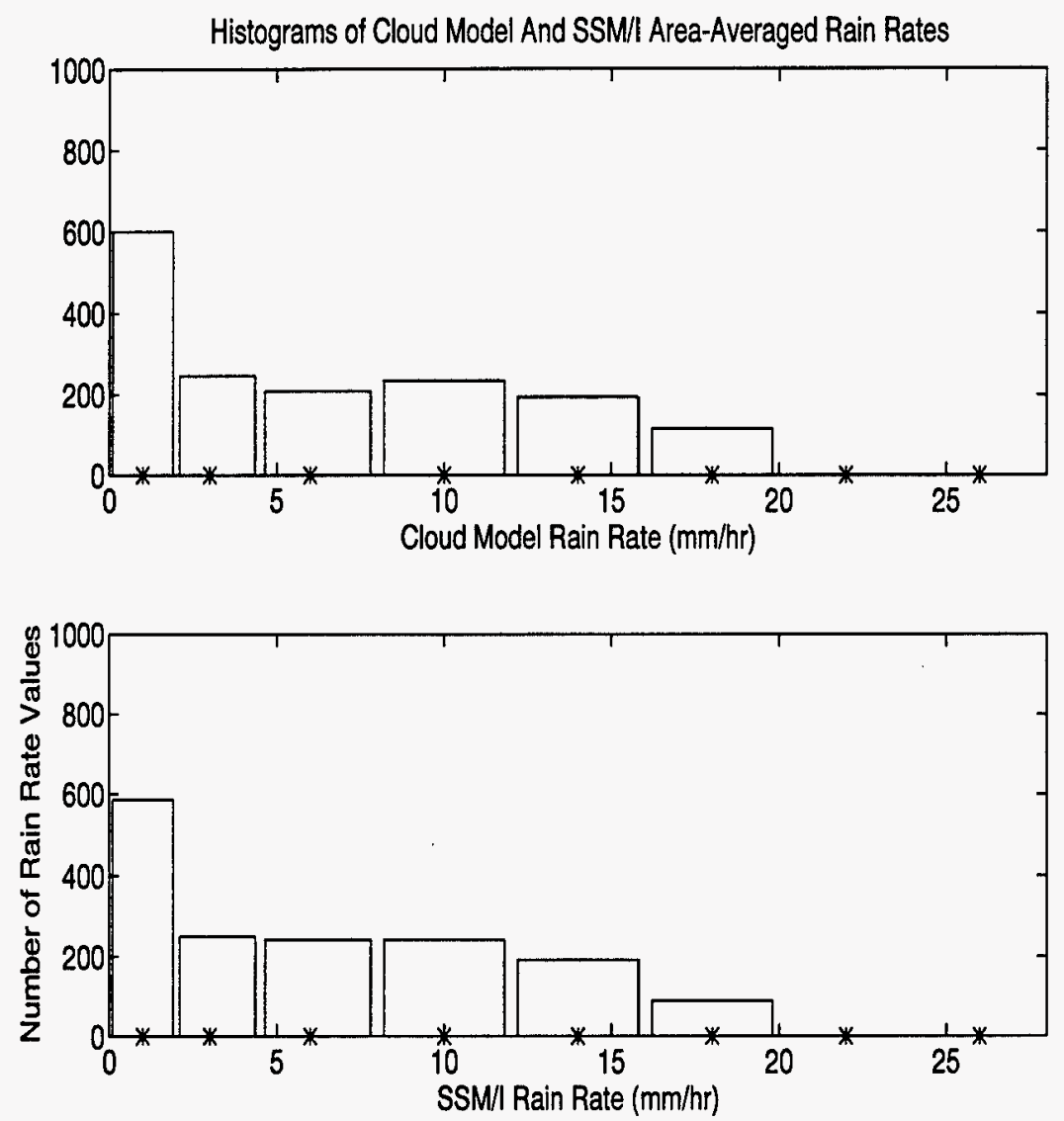

Figure 4.9. Histograms of the rain rates from the surface level of the Goddard $\mathrm{Cu}-$ mulus Ensemble Model and from ocean rainfall algorithm estimates using simulated upwelling brightness temperatures through the model. 


\subsection{Comparison with surface radar}

The SSM/I rain rate algorithm is compared with surface radar rain measurements. The radar data are primarily located over land and serve to validate the instantaneous land rainfall algorithm estimates. Radar scans and SSM/I overpasses coincident in space and time are directly compared for three climatologically distinct stations: Darwin, Australia; Cape Canaveral, Florida; and Oklahoma City, Oklahoma. The radar data, part of the Atmospheric and Oceanographic Information Processing System (AOIPS) at NASA/Goddard Space Flight Center, are C and S band Doppler radars with 5 and $10 \mathrm{~cm}$ wavelengths. Table 4.1 provides the location coordinates for each of the radars and Table 4.2 provides the time of each of the nine radar scans.

Coincident SSM/I and radar data for three selected cases are displayed in Figures 4.10-4.12 The radar resolution, initially reported at $1 \mathrm{~km}$, is co-located in time and space with SSM/I pixels and averaged to match the SSM/I all-channel footprint. The range is bounded by $20 \mathrm{~km}$ and $180 \mathrm{~km}$ to reduce ground clutter and range errors. The radar data are received with rain rate in $\mathrm{mm} / \mathrm{hr}$ after calibration by separate Z-R relationships tuned for each of the radar locations. The radar scan time coincides to within 5 minutes with the coincident SSM/I overpass data.

In all cases the absolute difference between the totals for the SSM/I and radar estimates is less than the radar mean rain rate. The differences between the radar and SSM/I are probably due to a combination of algorithm error, coastline effects, satellite mis-navigation, instrument viewing geometry and inaccuracies in the empirically derived Z-R relationships. The Darwin radar scan encompasses a great deal of coastline which is not excluded because the resulting data points would be too few. The SSM/I navigation errors are known to typically reach $10 \mathrm{~km}$ and are possibly the cause of the displacement of the squall line in Figure 4.12. The radar estimates of rain rate on the far side of clouds may be adversely influenced by the 
Table 4.1. Coordinate locations of surface precipitation radar sites used in comparisons with coincident SSM/I overpasses.

\begin{tabular}{|l|l|l|}
\hline Location & Latitude & Longitude \\
\hline \hline Darwin, Australia & -12.457 & 130.925 \\
\hline Cape Canaveral, Florida & 28.255 & -80.606 \\
\hline Oklahoma City, Oklahoma & 35.40 & -97.60 \\
\hline
\end{tabular}

Table 4.2. Times (UTC) for nine precipitation radar scans used in comparisons with coincident SSM/I overpasses.

\begin{tabular}{|l|l|l|l|}
\hline Location & case & YY/MM/DD & HR:MM \\
\hline \hline Darwin & 1 & $02 / 11 / 88$ & $21: 18$ UTC \\
\hline & 2 & $02 / 14 / 88$ & $09: 44$ \\
\hline & 3 & $02 / 26 / 88$ & $08: 30$ \\
\hline Florida & 1 & $01 / 25 / 88$ & $00: 04$ \\
\hline & 2 & $12 / 11 / 88$ & $23: 44$ \\
\hline & 3 & $10 / 06 / 88$ & $11: 19$ \\
\hline Oklahoma & 1 & $07 / 13 / 87$ & $01: 20$ \\
\hline & 2 & $09 / 12 / 87$ & $12: 00$ \\
\hline & 3 & $09 / 18 / 87$ & $12: 30$ \\
\hline
\end{tabular}


intermediate cloud attenuation through the storm. Likewise, the SSM/I brightness temperatures from the lowest layers of heavy storms are, in some cases, completely obscured by the higher layers (Smith and Mugnai 1988). Histograms for each radar site and for combined data, in Figure 4.13, shows that in each case the majority of the rain rates for both radar and satellite are between $0 \mathrm{~mm} / \mathrm{hr}$ and $2.5 \mathrm{~mm} / \mathrm{hr}$ with decreasing frequency to a limit near $20 \mathrm{~mm} / \mathrm{hr}$. The distribution of the Oklahoma rain rates has a lognormal shape while the others are logarithmically decreasing with rain rate. In all cases the algorithm detects an appropriate rain area and then estimates a reasonable rain rate. Statistics from the comparison are presented as part of the error budget in section 4.7 . 


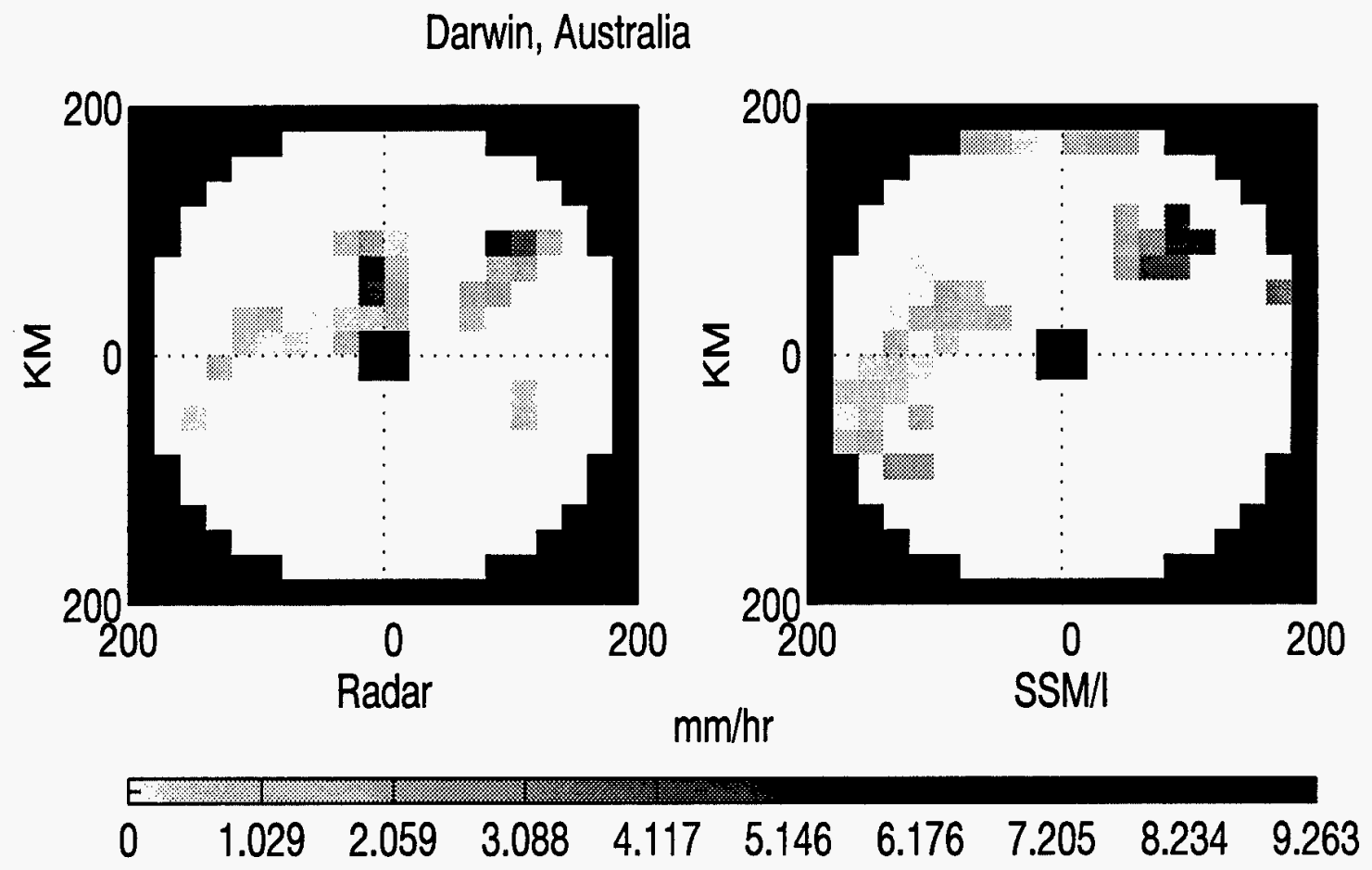

Figure 4.10. Coincident rain rates estimated from SSM/I and the Darwin, Australia precipitation radar for February 11, 1988 at 21:18 UTC. 
Cape Canaveral, Florida

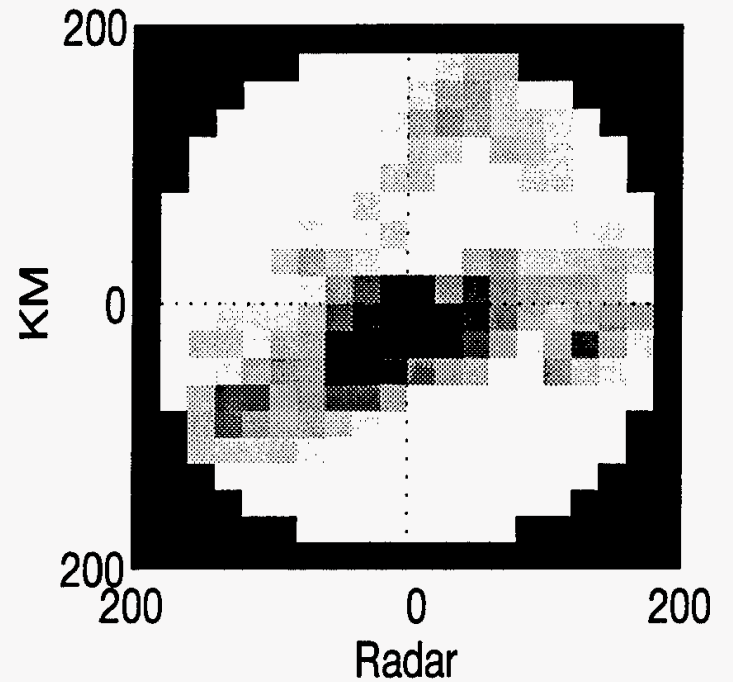

$\mathrm{mm} / \mathrm{hr}$
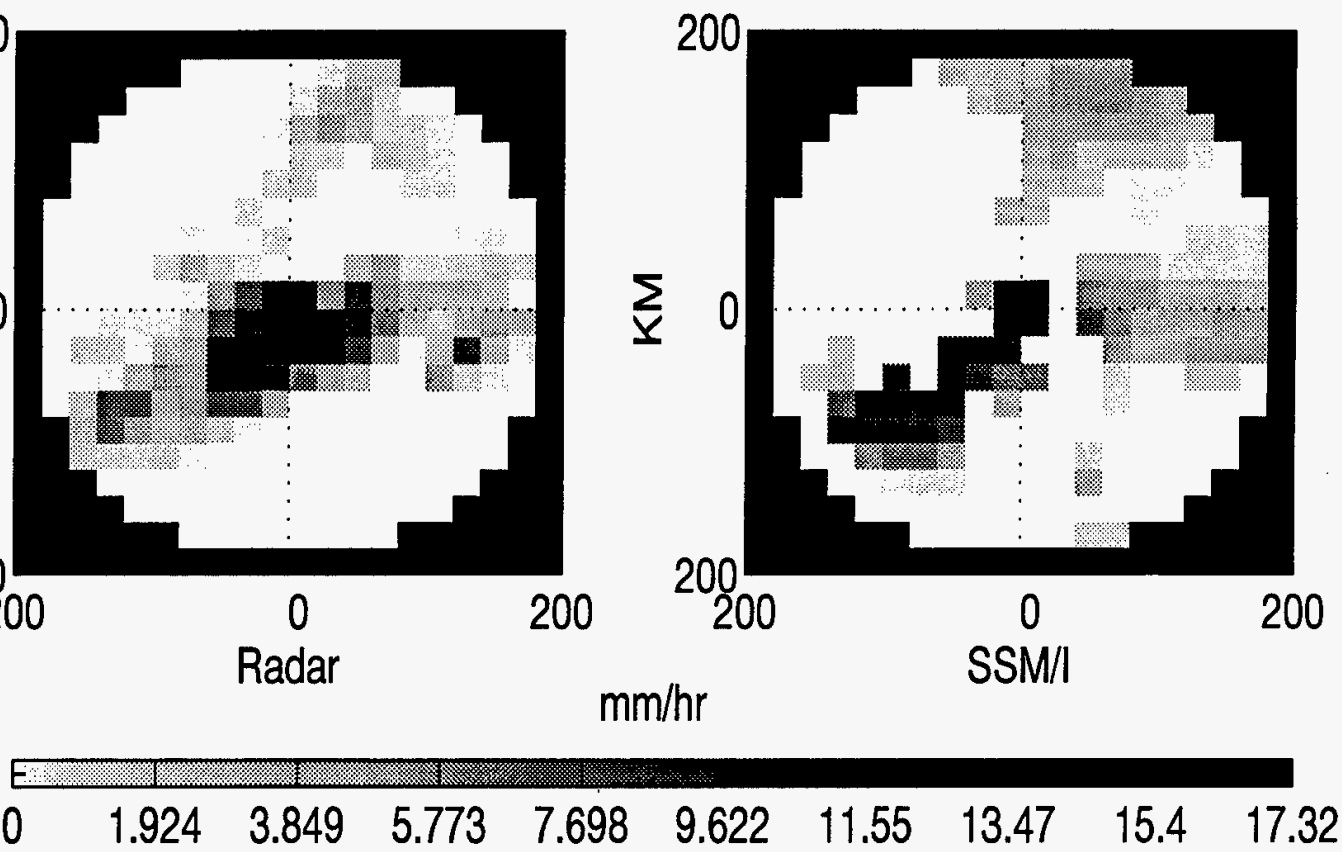

Figure 4.11. Coincident rain rates estimated from SSM/I and the Cape Canaveral, Florida precipitation radar for December 11, 1988 at 23:44 UTC. 


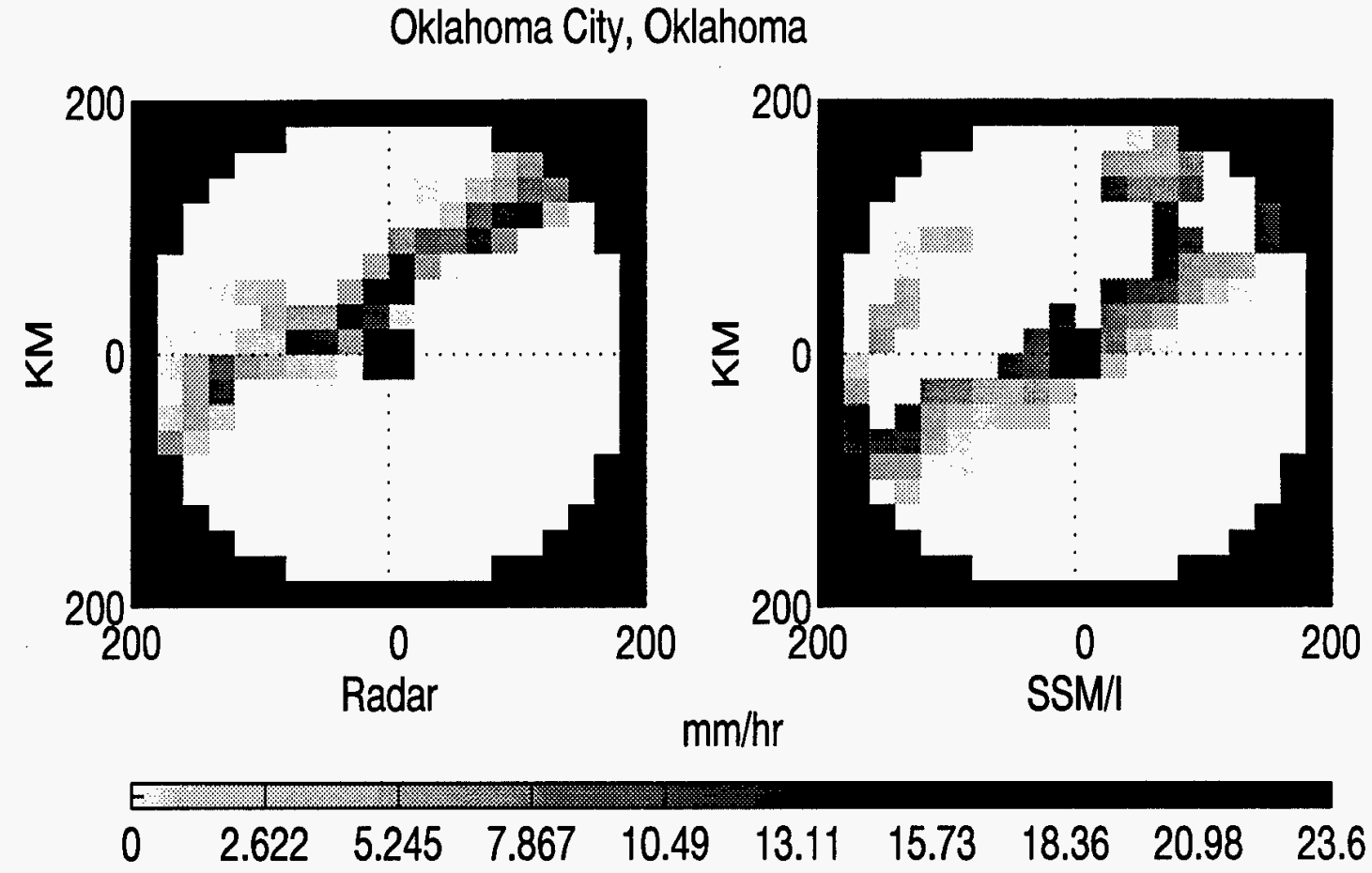

Figure 4.12. Coincident rain rates estimated from SSM/I and the Oklahoma City, Oklahoma precipitation radar for July 13, 1987 at 01:20 UTC. 

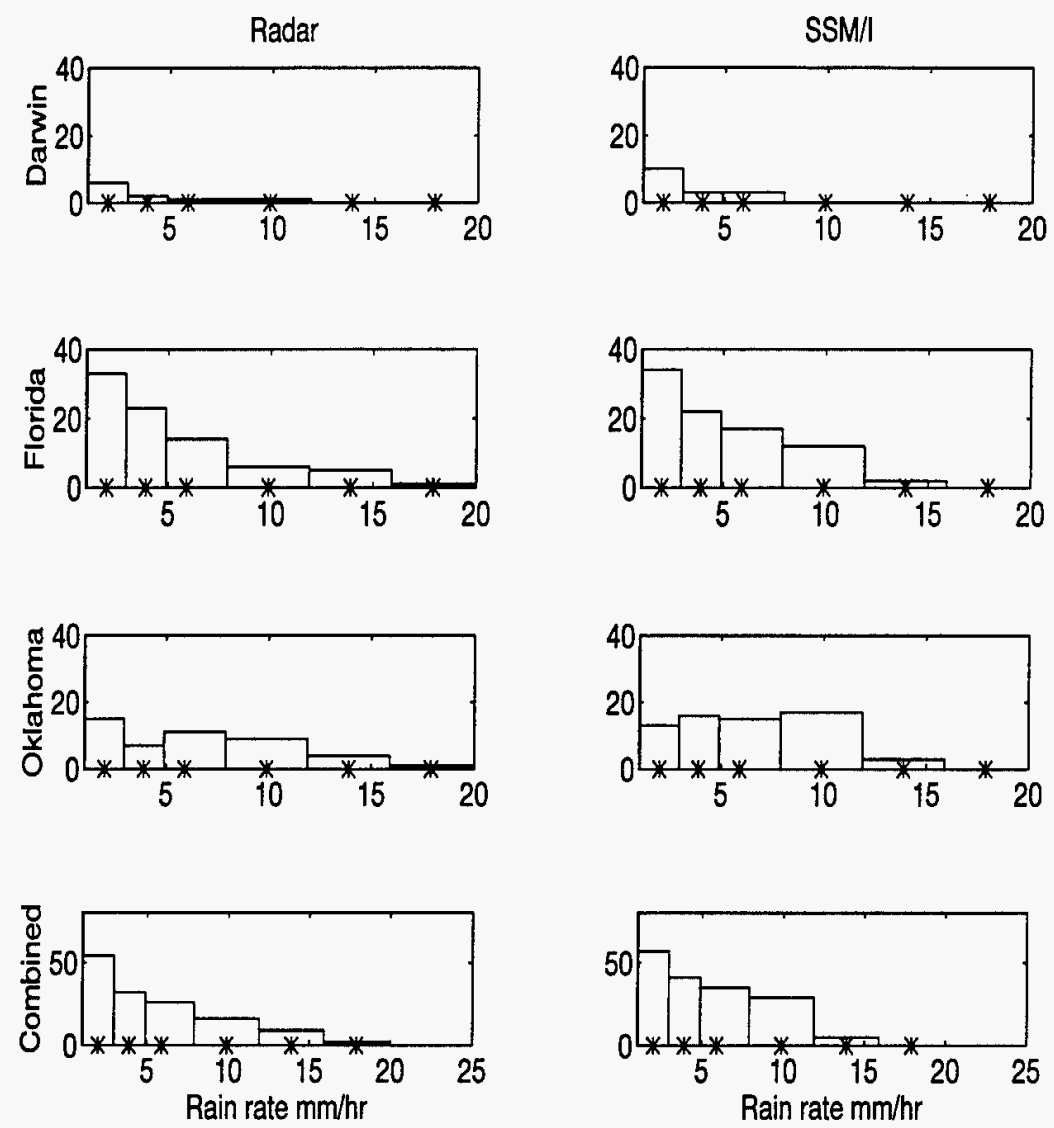

Figure 4.13. Satellite and radar rain rate histograms showing the number of retrievals corresponding to rain rate intervals. The precipitation radars are located at Darwin, Australia, Cape Canaveral, Florida and Oklahoma City, Oklahoma. The satellite overpasses coincide in time and space with the radar scans. The radar rain rates are spatially averaged to match the SSM/I all-channel resolution and the land SSM/I rain rate algorithm is applied to coastline pixels. 


\subsection{Algorithm intercomparison programs}

The development of the rainfall algorithm and an understanding of the error budget has benefited from participation in a number of independently proctored algorithm intercomparison programs conducted to quantify the accuracies in stateof-the-art algorithms. The World Meteorological Organization (WMO) completed the first and second Algorithm Intercomparison Programs (AIP / 1,2) as part of the Global Precipitation Climatology Project (GPCP). In AIP/2, a number of SSM/I precipitation algorithms were intercompared along with surface precipitation radars over the area surrounding and including Western Europe. Another project, the NASA WetNet First Precipitation Intercomparison Project (PIP/1), intercompared global monthly SSM/I precipitation maps submitted by rainfall algorithm developers with atoll and continental raingauge data sets (Barrett et al. 1994; Wilheit et al. 1994). Selected results from the PIP/1 program are listed in Tables 4.3 and 4.4 .

A developmental version of the algorithm was submitted to the AIP / 2 and the PIP/1. The results from these intercomparisons were used to modify the theory, development and implementation of the algorithm. The results of the intercomparisons are therefore useful in assessing the usefulness of the algorithm as long as the subsequent changes are also considered. In both intercomparisons the algorithm performed satisfactorily relative to others and the surface data. In the AIP/2, the microwave algorithms performed poorly overall when compared with the surface radars over both land and ocean. The errors resulted from the cold land surfaces, low-lying frontal systems and light rain rates comprising the bulk of the selected $\mathrm{SSM} / \mathrm{I}$ cases. The most important changes to the algorithm based on the results of AIP / 2 are in the screening of coastlines, the substitution of a polarization screen for oceanic precipitation instead of a thermometric screen and more careful screening of land surfaces to delineate snow, ice, and cold ground. 
In PIP/1 the algorithm global monthly maps were compared to atoll raingauge data in the tropical Pacific and global continental raingauge data over land. The atoll data were combined into 2.5 degree resolution boxes according to Morrissey and Greene (1991). A grid box was used only when it contained at least 2 gauges. The four month SSM/I rainfall totals corresponding to each atoll raingauge box were statisticly compared with all data pairs. The mean SSM/I estimate was $157.6 \mathrm{~mm}$ and the mean gauge estimate was $213.8 \mathrm{~mm}$ yielding a relative bias of 0.74 , a mean error of $-56.2 \mathrm{~mm}$, a mean absolute error of $80.4 \mathrm{~mm}$, and a correlation coefficient of $0.84 \mathrm{~mm}$. This suggests that the algorithm is underestimating over tropical oceans and, since the mean error is almost as large as the rms error, the bias comprises the bulk of the algorithm error.

The land surface comparison in PIP/1 utilized a continental raingauge data set from the Global Precipitation Climatology Center (GPCC). The raingauge data from the four-month period were used at a resolution of 2.5 degrees for the region between $60 \mathrm{~N}$ and $60 \mathrm{~S}$. SSM/I and GPCC data were paired for non-coastline areas whenever there was at least one raingauge in the grid cell. Using 1032 data pairs the $\mathrm{SSM} / \mathrm{I}$ mean estimate was $310.3 \mathrm{~mm}$ and the GPCC mean was $231.6 \mathrm{~mm}$ yielding a relative bias of 1.34 , a mean error of $78.36 \mathrm{~mm}$ and a correlation coefficient of 0.57 . In this case the SSM/I algorithm overestimated rainfall over land due mainly to very large positive errors over high latitude cold, ice-covered surfaces.

The results from PIP/1 were more useful both in improving the algorithm and in characterizing its accuracy. The PIP/1 also served to gage the algorithm relative to other current algorithms. The results showed that there was no one algorithm which was the best over the whole Earth for all months, but instead, different algorithms operate more or less successfully depending on underlying surface, type of rain, season etc. This algorithm compared quite satisfactorily with the other algorithms and with the raingauge data sets. PIP1 results were used to improve the 
algorithm through an improved cold land surface screening technique and a polarization screen over oceans. The improved algorithm and two global raingauge data sets are compared for August through November, 1987, in the next section. The results from the intercomparison projects establish this algorithm as a legitimate method of retrieving global scale precipitation both in comparison to surface data and to alternative SSM/I algorithms. 
Table 4.3. Statistics calculated from a comparison of the SSM/I algorithm and the Global Precipitation Climatology Center continental raingauge database using monthly total rainfall between $60^{\circ} \mathrm{N}$ and $60^{\circ} \mathrm{S}$ latitude for the period of August through November, 1987 at a resolution of $2.5^{\circ}$. Data pairs are selected whenever the GPCC contained at least one raingauge for values greater than or equal to zero, for all non-coastline land locations. The statistical parameters are SSM/I estimated mean, GPCC observed mean, relative bias, mean error, mean absolute error, correlation coefficient, and number of data pairs.

\begin{tabular}{|l|l|}
\hline mean estimate & $310.3(\mathrm{~mm})$ \\
\hline mean observation & $231.6(\mathrm{~mm})$ \\
\hline relative bias & 1.34 \\
\hline mean error & $78.63(\mathrm{~mm})$ \\
\hline mean absolute error & $171.3(\mathrm{~mm})$ \\
\hline correlation coefficent & 0.57 \\
\hline number of data pairs & 1032 \\
\hline
\end{tabular}

Table 4.4. Statistics calculated from a comparison of the SSM/I ocean algorithm and the Morrissey and Greene Pacific Atoll Raingage Data Set using $2.5^{\circ}$ resolution monthly totals for the period August through November, 1987. Data pairs are selected for all points greater than or equal to zero when there are at least two rain gauges in the pixel. The statistical parameters are SSM/I estimated mean, atoll observed mean, relative bias, mean error, mean absolute error, correlation coefficient, and number of data pairs.

\begin{tabular}{|l|l|}
\hline mean estimate & $157.6(\mathrm{~mm})$ \\
\hline mean observation & $213.8(\mathrm{~mm})$ \\
\hline relative bias & 0.74 \\
\hline mean error & $-56.16(\mathrm{~mm})$ \\
\hline mean absolute error & $80.4(\mathrm{~mm})$ \\
\hline correlation coefficent & 0.84 \\
\hline number of data pairs & 44 \\
\hline
\end{tabular}




\subsection{Validation of monthly global rainfall totals}

Intercomparisons conducted on a climate scale are important for testing the algorithm during different seasons and locations, and for assessing the severity of sampling errors. Validation of climate-scale rainfall estimates accounts for sampling errors introduced by temporal and spatial averaging. To establish the validity of the algorithm for estimating rainfall globally, rainfall maps derived from SSM/I are compared to the Legates and Willmott precipitation climatology (Legates and Willmott 1990), the Global Precipitation Climatology Program (GPCC) raingauge composite (GPCC 1992), and the Berg SSM/I oceanic rainfall maps (Berg and Chase 1992).

Monthly rainfall totals from each data set for August through November, 1987, corresponding to the WetNet First Precipitation Intercomparison Project, are used in the comparison. The global distribution of rainfall from each of the three sources are shown in Figures 4.14- 4.17. Total precipitation is calculated at $1^{\circ}$ resolution for $+-180^{\circ}$ longitude and $+-60^{\circ}$ latitude, excluding coastlines. The Legates and Willmott and Ferriday maps cover both land and ocean, while the Berg map is for oceans only and the GPCC is for land only. Over land the SSM/I rainfall maps are compared to raingauge composites. The Legates and Willmott (L/W) data are a climatological monthly mean of terrestrial rainfall totals. The GPCC is derived from raingauge measurements taken each month during 1987 . Over ocean the SSM/I algorithm is compared with an alternative SSM/I algorithm from Berg, and to shipboard raingauge measurements composited in the $\mathrm{L} / \mathrm{W}$ ocean data.

The $\mathrm{L} / \mathrm{W}$ data base is derived from raingauges over land and shipboard measurements over ocean. The precipitation values reported are "corrected" using techniques for removing raingauge and shipboard biases and for computing monthly values. The data represent a climatological mean rather than estimates for any particular month. Therefore, the comparison to SSM/I is limited by the incongruencies 
in the time period. The data are reported at one-half-degree resolution and are derived from a 60 year time series of measurements. The GPCC was initiated by the World Meteorological Organization as part of the Global Precipitation Climatology Project established by the World Climate Research Programe. Monthly precipitation totals are reported at 2.5 degree resolution for the global continents. A total of 6600 reporting stations are utilized in an interpolation averaging scheme. The Berg monthly data are produced by fitting instantaneous SSM/I estimates derived from a modified version of the Hughes algorithm to a lognormal distribution. The monthly values are reported at one-half-degree resolution and have been rigorously verified relative to atoll raingauges and alternative satellite precipitation retrievals.

A number of statistics are used to compare the alternative data sets with the SSM/I algorithm. The method of comparison is to compute zonal and meridional means, correlation coefficients, and mean and absolute mean differences. The zonal and meridional means are computed from all data within the appropriate land or ocean category and include values of zero precipitation. The correlation coefficients are calculated from the scatter plot of all coincident one-degree resolution point estimates and include zeroes. The GPCC and SSM/I continental comparison results are listed in Table 4.5. The mean SSM/I value is $240.8 \mathrm{~mm}$ and the mean GPCC value is $222.0 \mathrm{~mm}$, yielding a mean difference of $18.7 \mathrm{~mm}$. The mean of the absolute difference between pairs of spatially coincident rainfall is $155.1 \mathrm{~mm}$ and the correlation of the totals is 0.70 . Because of the differences in temporal and spatial sampling characteristics between the SSM/I and raingauges, the absolute differences will be much higher than the difference of the mean. The satellite will typically provide one or two overpasses each day which undersamples in time while the GPCC typically contains cells with one or two gauges which undersamples in space.

Histograms of the distribution of rainfall totals for GPCC and SSM/I are shown in Figure 4.18. The GPCC contains more grid cells with totals from $0-200$ 
$\mathrm{mm}$ and the SSM/I contains slightly more cells with totals between $300-1000 \mathrm{~mm}$. The distribution of the precipitation totals suggest that the SSM/I algorithm is providing accurate totals over relatively dry continental areas as well as areas with persistent convective activity. The spatial distribution of rainfall is further analyzed in Figure 4.19, where the zonal and meridional averages of the continental four month totals are compared. The GPCC shows less high-frequency variability along both latitude and longitude, which may be the result of the raingauge interpolation technique. The two data sets are closely correlated over both latitude and longitude; the only distinguishable difference occurs between $-20^{\circ}$ and $0^{\circ}$ latitude where the SSM/I algorithm is approximately $50-100 \mathrm{~mm}$ higher than GPCC.

The L/W ocean climatology comparison results are listed in Table 4.6. The $\mathrm{SSM} / \mathrm{I}$ mean for the four month totals is $371.7 \mathrm{~mm}$ and the $\mathrm{L} / \mathrm{W}$ mean is $440.0 \mathrm{~mm}$ yielding a difference of $(\mathrm{SSM} / \mathrm{I}-\mathrm{L} / \mathrm{W})=-68.3 \mathrm{~mm}$. The mean absolute difference is $217.8 \mathrm{~mm}$ and the correlation coefficient is 0.71 . It is expected that the SSM/I should estimate precipitation more accurately over oceans than over land because of the cold polarized background provided by the ocean surface. The reason that the correlation is not higher than over land is probably because the $\mathrm{L} / \mathrm{W}$ represents a climatological mean while the SSM/I data were collected during the particular period in 1987, which also corresponds to an El Niño/Southern Oscillation event.

Histograms for the L/W SSM/I comparison shown in Figure 4.20 provide an explanation for the higher estimates from $\mathrm{L} / \mathrm{W}$. The $\mathrm{L} / \mathrm{W}$ precipitation totals are lognormally distributed whereas the SSM/I totals are logarithmically distributed. The lognormal L/W distribution is unlike the logarithmic distributions exhibited by SSM/I over land and ocean or the distribution of GPCC over land. An examination of the zonal and meridional averages in Figure 4.21 determines that the higher $\mathrm{L} / \mathrm{W}$ estimates are located south of $-10^{\circ}$ latitude and west of $-70^{\circ}$ longitude in the South Pacific Ocean. The four month comparisons for both land and oceans verify that 
the SSM/I algorithm closely agrees with surface-based precipitation retrievals when global estimates at spatial scales of $1^{\circ}$ are desired. 
Rainfall from GPCP for August-November, 1987

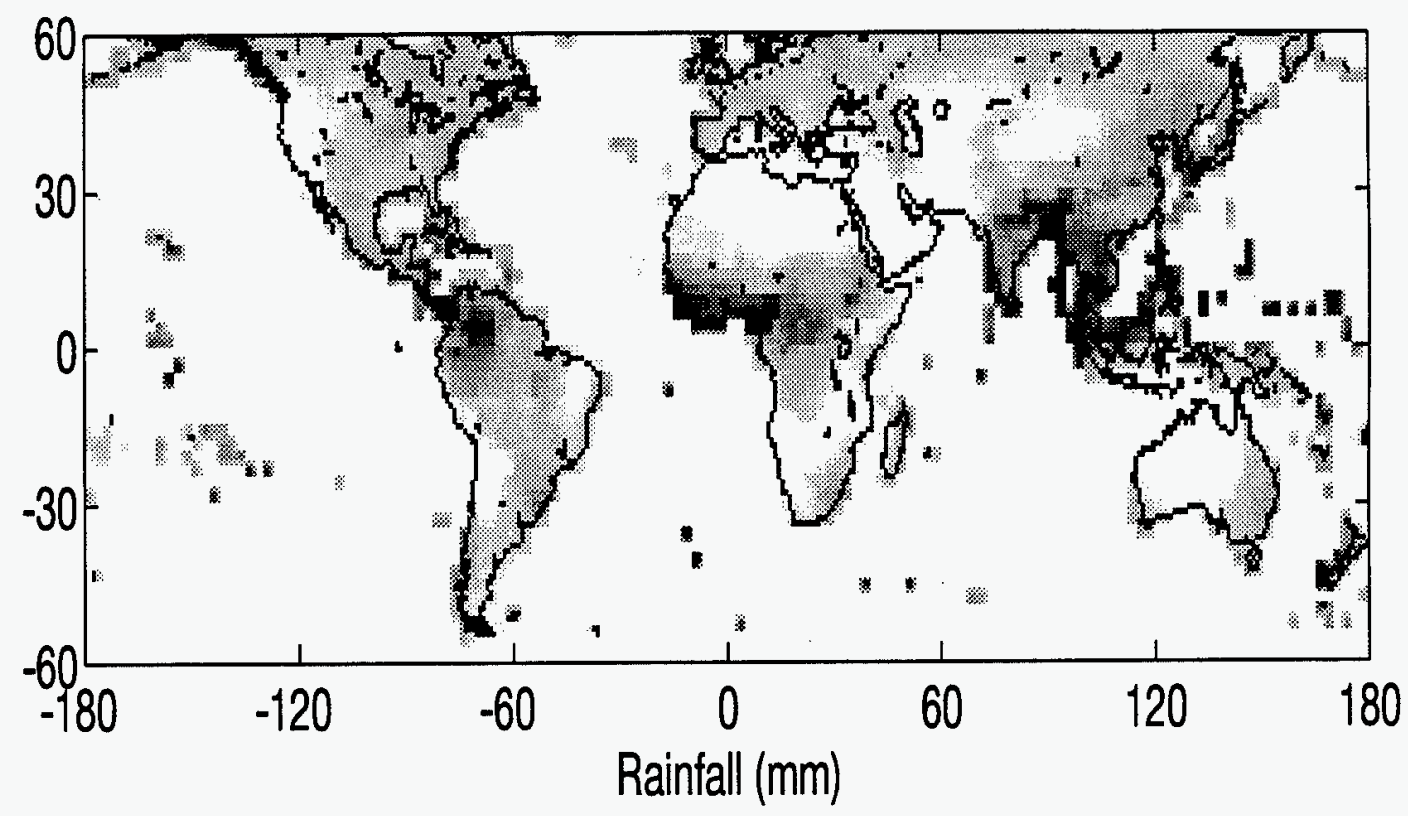

\begin{tabular}{llllllllll}
\hline 201 & 401 & 601 & 801 & 1001 & 1200 & 1400 & 1600 & 1800 & 2000
\end{tabular}

Figure 4.14. Rainfall total for August through November, 1987, from the Global Precipitation Climatology Center. Continental raingauge measurements are interpolated to a global grid. 


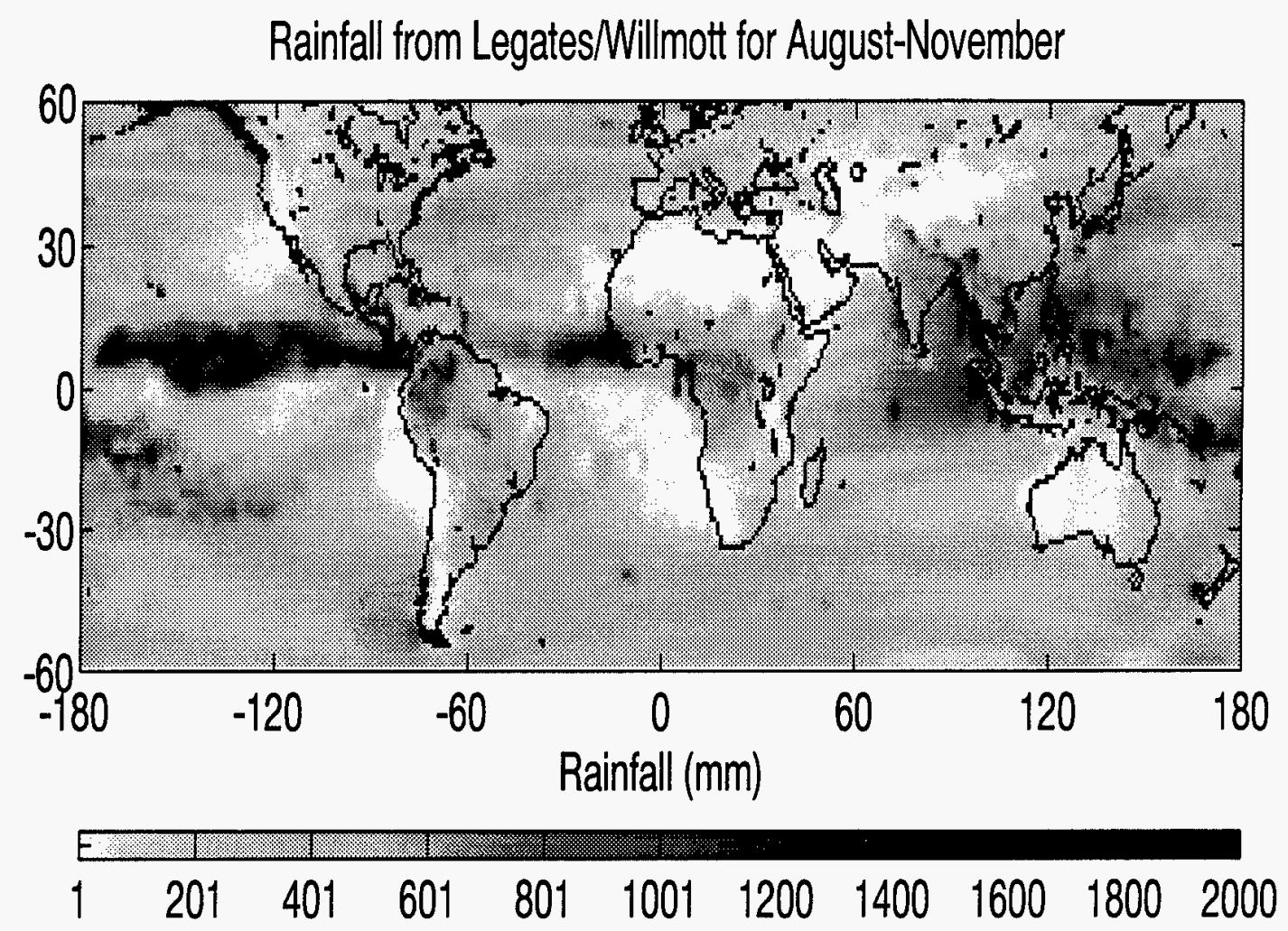

Figure 4.15. Rainfall total for August through November from the Legates \& Willmott shipboard and terrestrial raingauge climatology. 

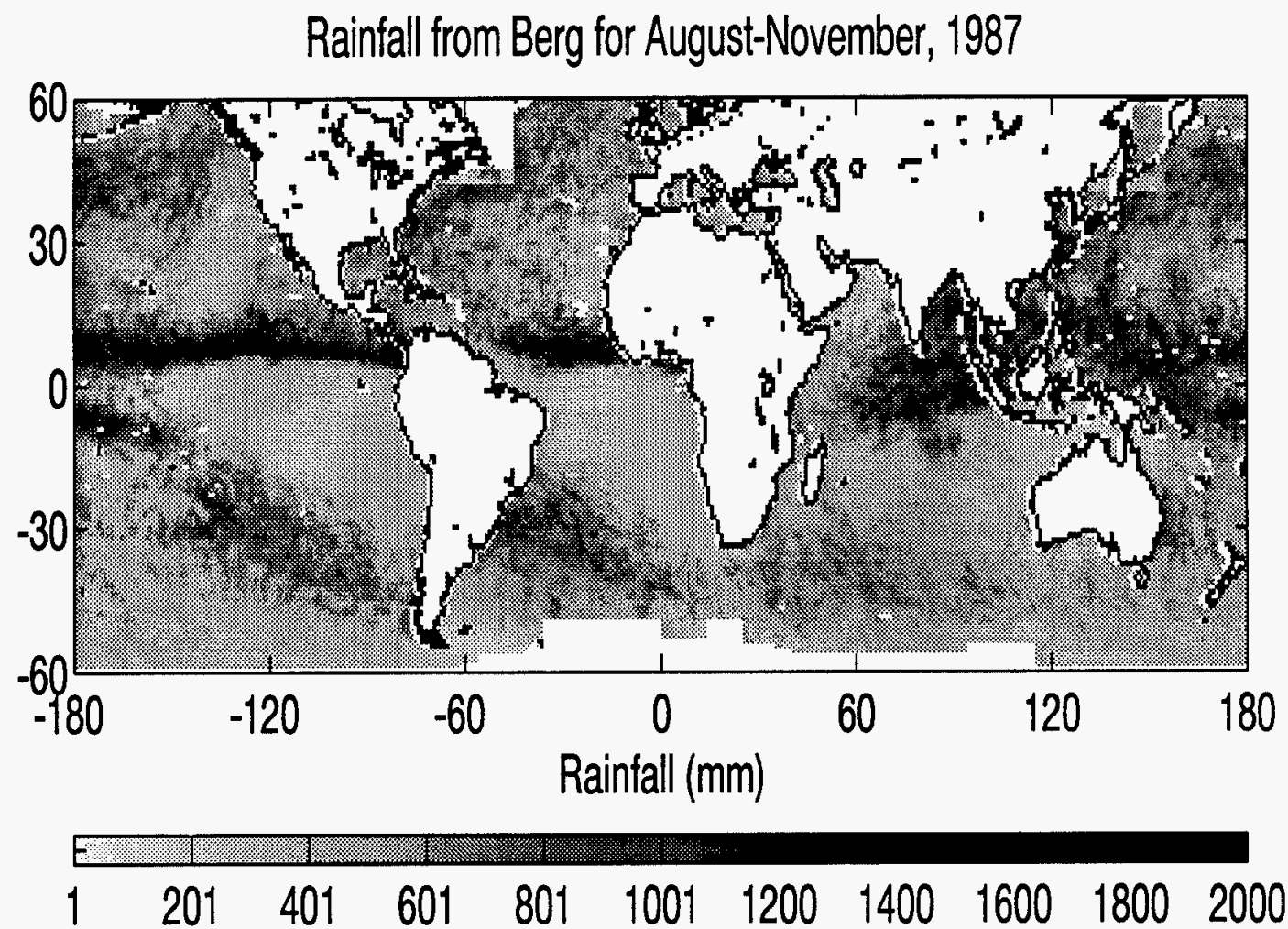

Figure 4.16. Rainfall total for August through November, 1987, reported by Berg (1994). A modified version of the Hughes algorithm is applied to SSM/I data over the oceans and a lognormal distribution is used to estimate monthly totals. 
Rainfall from SSMII for August-November, 1987

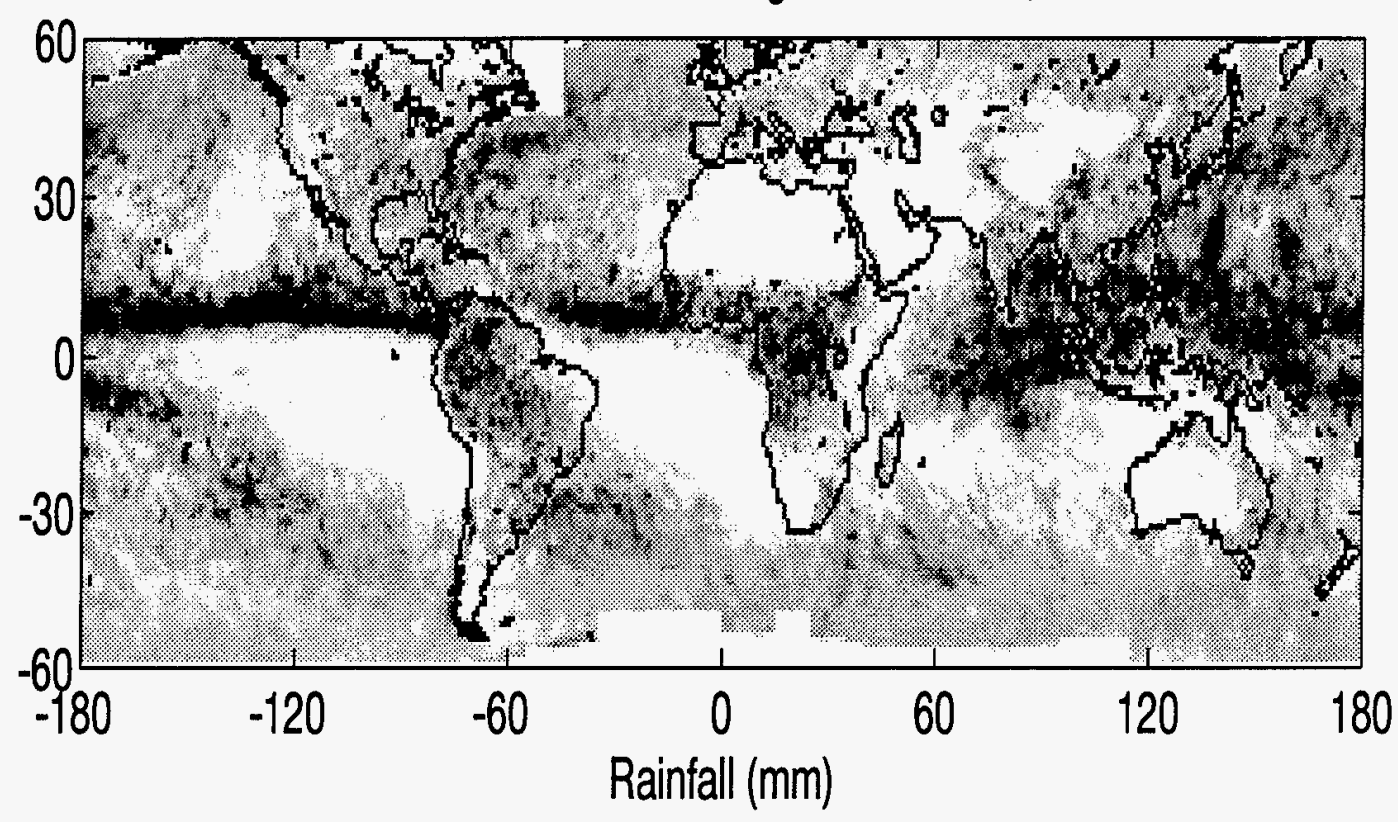

\begin{tabular}{llllllllll}
\hline & 1 & & & & & & & &
\end{tabular}

Figure 4.17. Rainfall total for August through November, 1987, from the Ferriday $\mathrm{SSM} / \mathrm{I}$ algorithm. 
Table 4.5. Statistics calculated from a comparison of the SSM/I land algorithm and the Global Precipitation Climatology Center continental raingauge data base using monthly rainfall totals at $1^{0}$ resolution for the period August through November, 1987. The mean difference, root mean square difference, and correlation coefficient are calculated by pairing corresponding gridded SSM/I and GPCC rainfall totals for all reported values over contintental surfaces below 60 degrees lattitude.

\begin{tabular}{|l|l|}
\hline SSM/I mean & $240.8(\mathrm{~mm})$ \\
\hline GPCC mean & $222.0(\mathrm{~mm})$ \\
\hline mean difference & $18.7(\mathrm{~mm})$ \\
\hline mean absolute difference & $155.1(\mathrm{~mm})$ \\
\hline correlation coefficent & 0.70 \\
\hline
\end{tabular}

Table 4.6. Statistics calculated from a comparison of the SSM/I ocean algorithm and the Legates/Willmott ( $\mathrm{L} / \mathrm{W})$ precipitation climatology using monthly oceanic precipitation totals at $1^{0}$ resolution for the period August through November, 1987. The mean difference, root mean square difference, and correlation coefficient are calculated by pairing corresponding gridded SSM/I and L/W precipitation totals for all reported values over ocean surfaces below 60 degrees latitude.

\begin{tabular}{|l|l|}
\hline SSM/I mean & $371.7(\mathrm{~mm})$ \\
\hline Legates \& Willmott mean & $440.0(\mathrm{~mm})$ \\
\hline mean difference & $-68.3(\mathrm{~mm})$ \\
\hline mean absolute difference & $217.8(\mathrm{~mm})$ \\
\hline correlation coefficent & 0.71 \\
\hline
\end{tabular}

Table 4.7. Statistics calculated from a comparison of the SSM/I ocean algorithm and rainfall totals from SSM/I by Berg using monthly precipitation totals at $1^{0}$ resolution for the period August through November, 1987. The mean difference, mean absolute difference, and correlation coefficient are calculated by pairing corresponding gridded SSM/I and Berg rainfall totals for all reported values over ocean surfaces below 60 degrees latitude.

\begin{tabular}{|l|l|}
\hline SSM/I mean & $367.4(\mathrm{~mm})$ \\
\hline Berg mean & $598.2(\mathrm{~mm})$ \\
\hline mean difference & $-230.8(\mathrm{~mm})$ \\
\hline mean absolute difference & $295.0(\mathrm{~mm})$ \\
\hline correlation coefficent & 0.88 \\
\hline
\end{tabular}



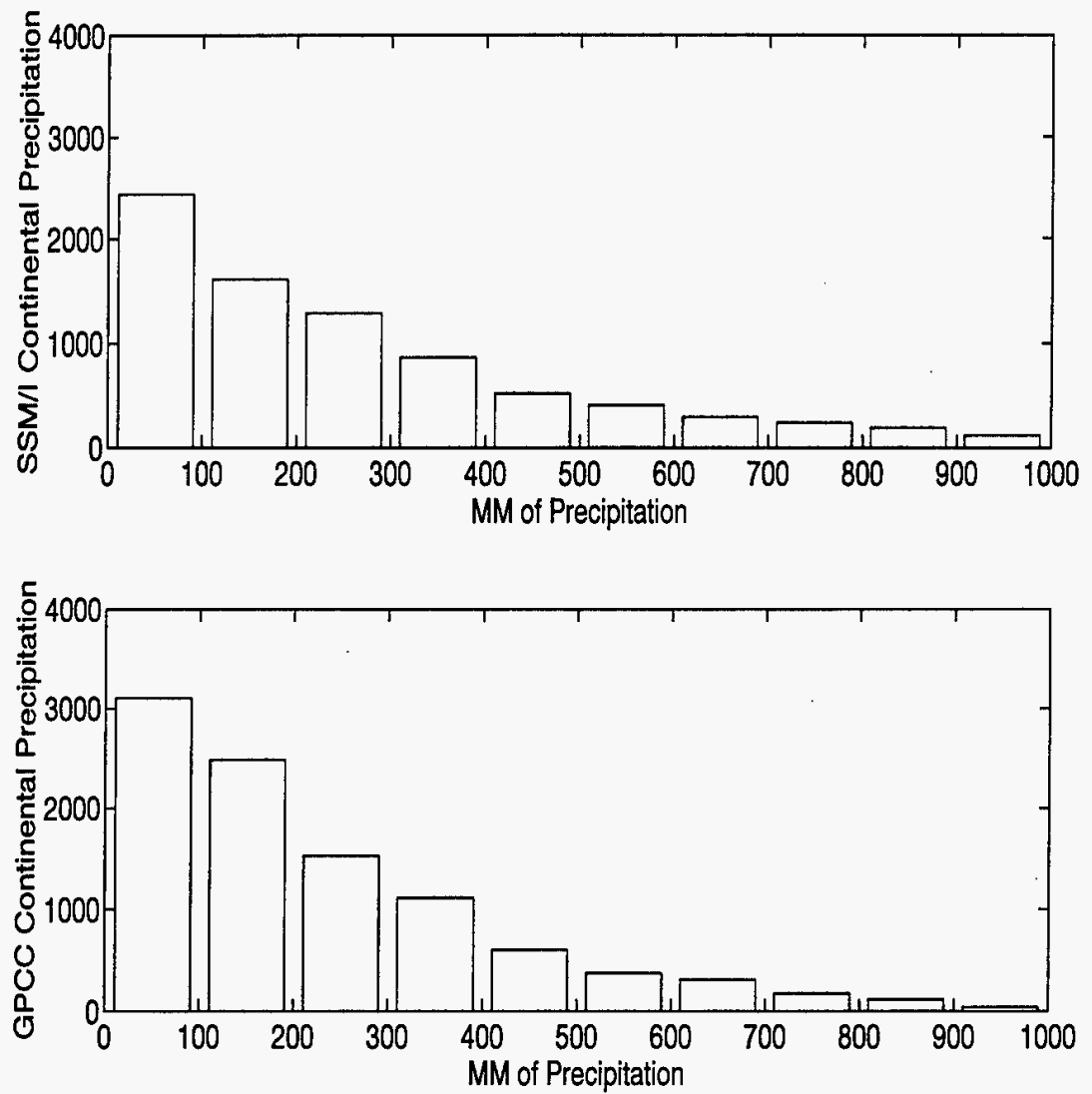

Figure 4.18. Distributions of total global continental precipitation for August through November, 1987 from estimates by the SSM/I algorithm and a raingage areal average by GPCC. 


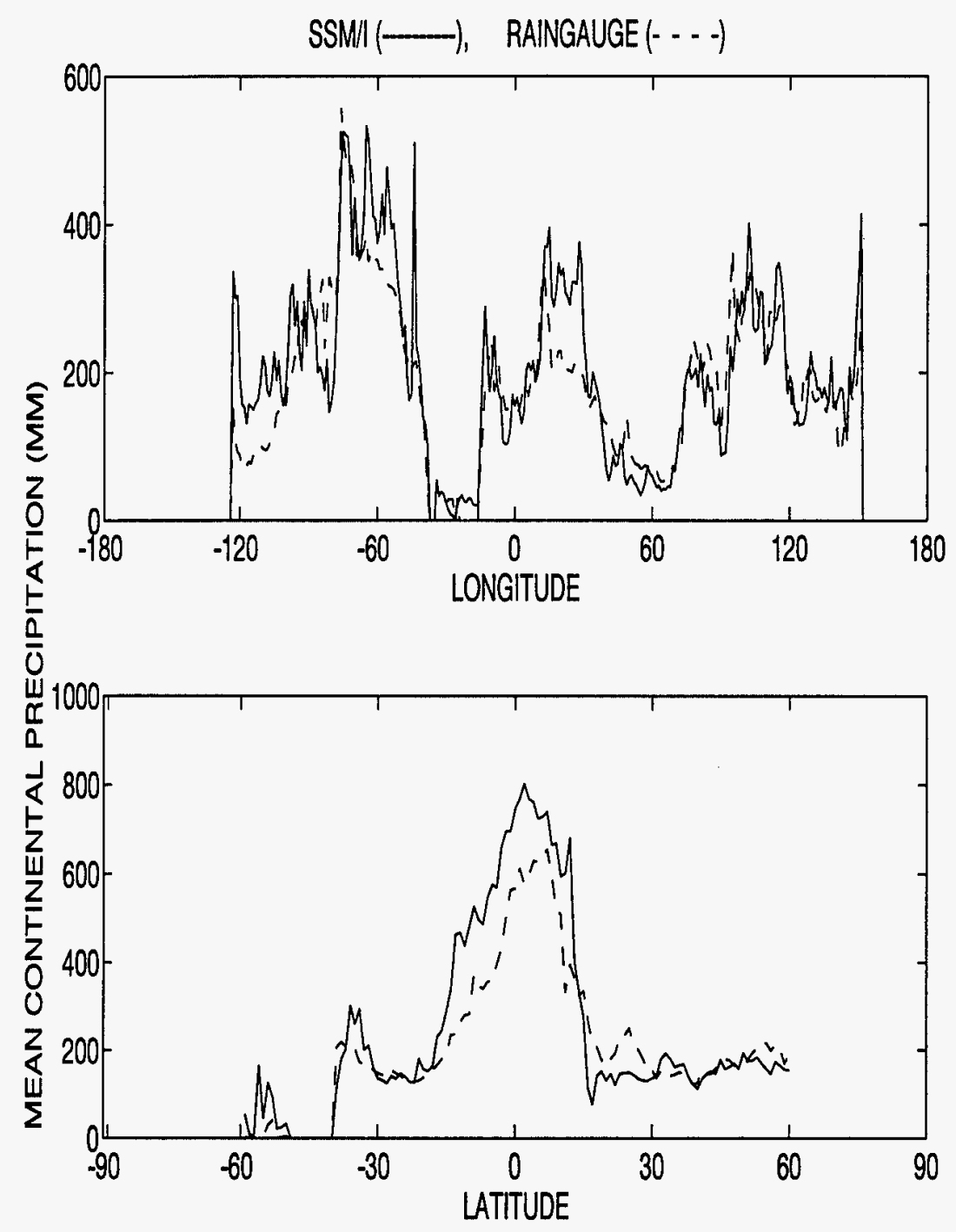

Figure 4.19. Meridionally (top) and zonally (bottom) averaged distributions of total global continental precipitation for August through November, 1987 from estimates by the SSM/I algorithm and a raingauge average by GPCC. 

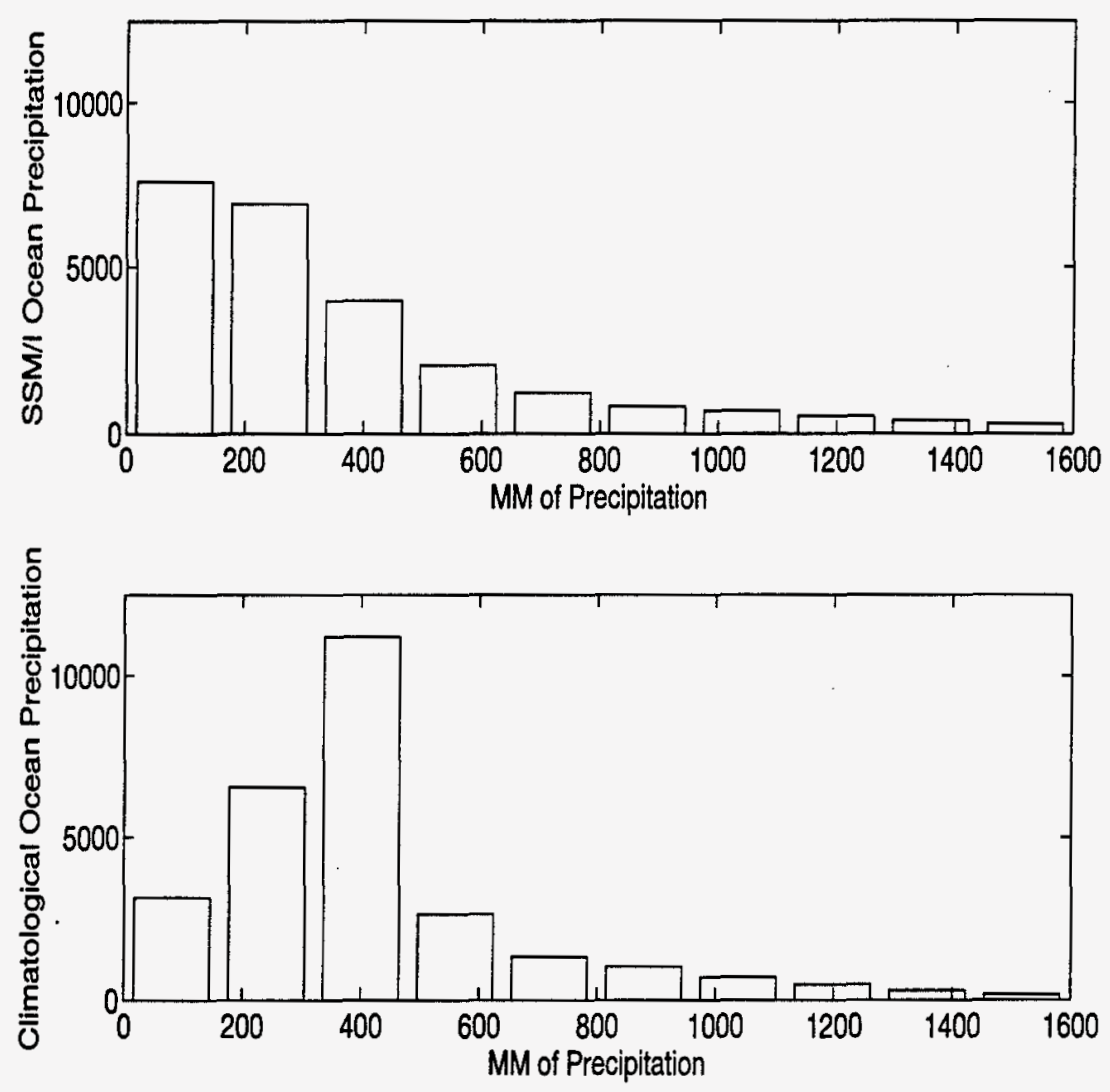

Figure 4.20. Distributions of total global oceanic precipitation for August through November, 1987 from estimates by the SSM/I algorithm and a shipboard climatology by Legates and Willmott. 


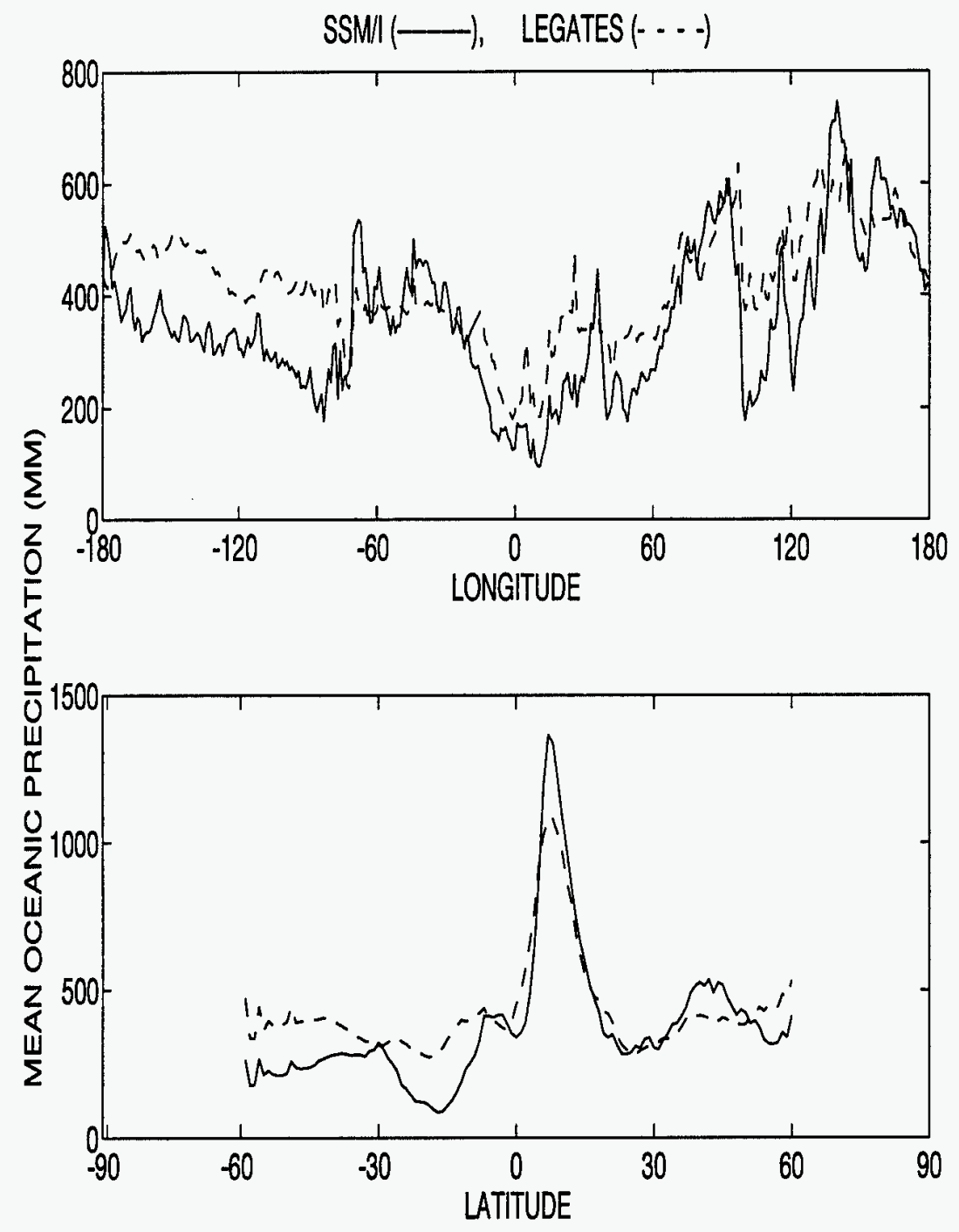

Figure 4.21. Meridionally (top) and zonally (bottom) averaged distributions of total global oceanic precipitation for August through November, 1987 from estimates by the SSM/I algorithm and a shipboard raingauge climatology by Legates and Willmott. 

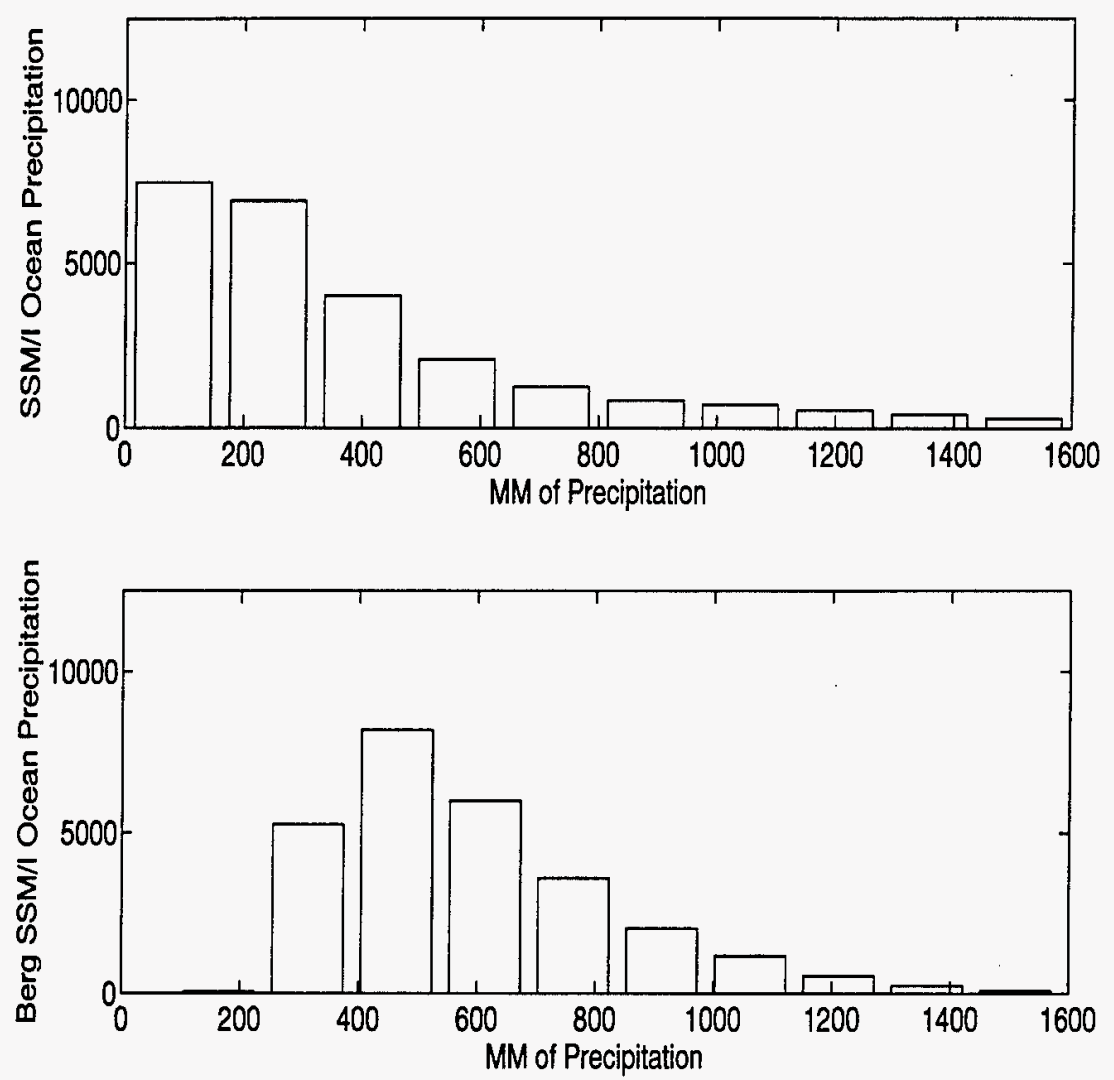

Figure 4.22. Distributions of total global oceanic precipitation for August through November, 1987 from estimates by the SSM/I algorithm and SSM/I estimates by Berg. 


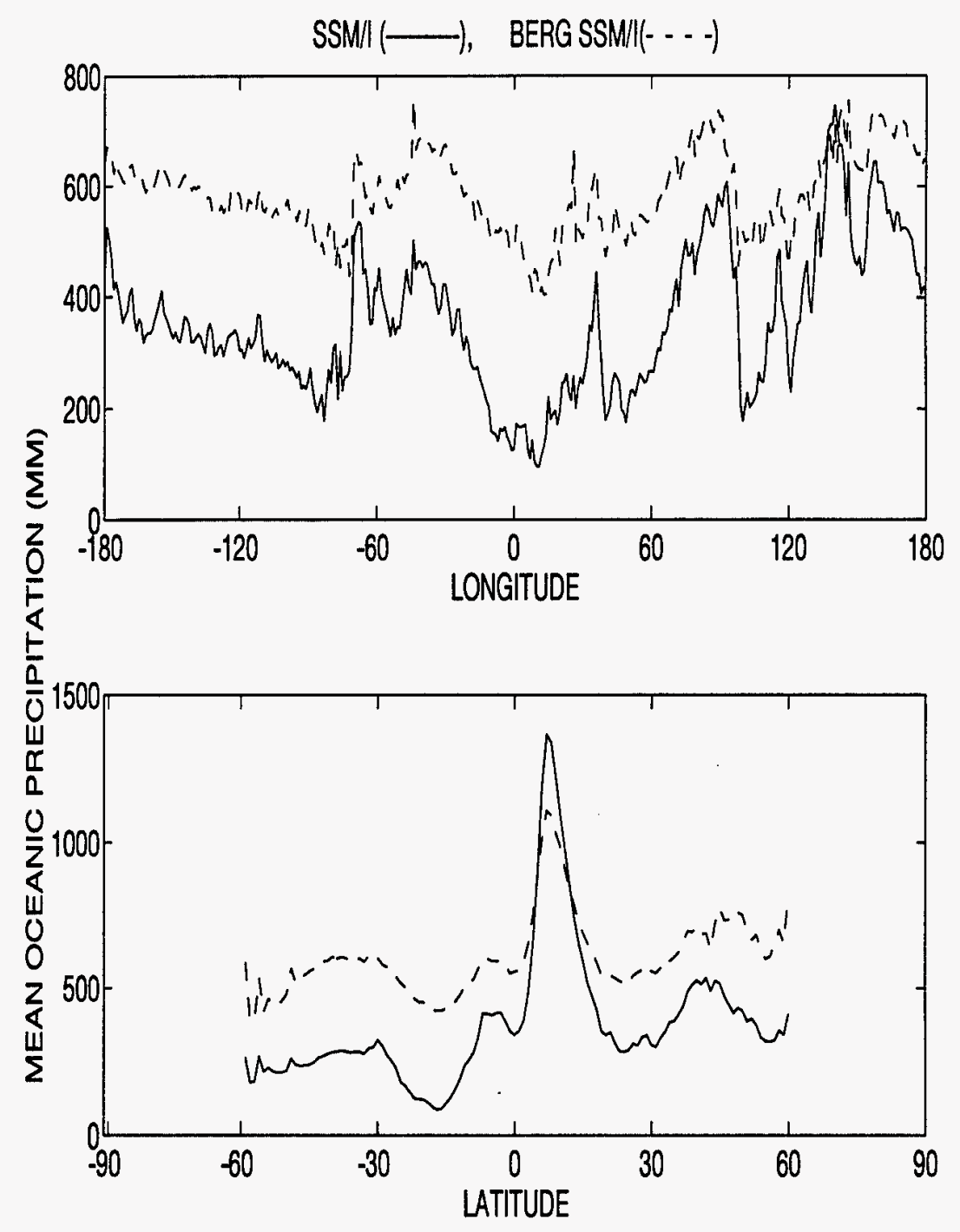

Figure 4.23. Meridionally (top) and zonally (bottom) averaged distributions of total global oceanic precipitation for August through November, 1987 from estimates by the SSM/I algorithm and SSM/I estimates by Berg. 


\subsection{Calculation of an error budget}

An algorithm error budget is constructed so that SSM/I rainfall estimates may be provided with associated uncertainties. Uncertainties are estimated both for instantaneous retrievals and seasonal means. The error budget is partly based on the validation study that compared a cloud model, surface precipitation radars, rain gauges and an alternative SSM/I algorithm to the rainfall estimates. The error budget is also based in part on theoretical calculations of sensitivity and sampling errors. The validation results and theoretical error calculations are intercompared since no "true" rainfall data is available with which to calculate an exact error budget. The final comprehensive error budget is a combination of the statistics from the validation comparisons and the theoretical calculations of sampling errors.

4.7.1 Errors in instantaneous estimates Beginning with instantaneous rainfall estimates, the major sources of error arise from radiative transfer modeling limitations, beamfilling, surface contamination and footprint mismatch. Over ocean the significant rain rate error sources include beamfilling, and misclassification of non-raining cloud liquid water. Over land the significant rain rate error sources are surface variability and non-convective raining conditions. The most severe instantaneous errors over both land and ocean are usually attributed to the beam filling error. Short and North (1990) and Chiu et al. (1990) both reported that for instantaneous rainfall estimates over ocean using an emission based algorithm uncorrected for beam filling, the underestimation error was about $50 \%$. Since the algorithm in this study has been corrected for beam filling the instantaneous error is not expected to be that high.

The error budget for instantaneous rain rates is derived from comparisons to the GCEM model and the radar data, and from the sensitivity tests using variations of the cloud model. Based on the application of the algorithm to the simulated $T_{b}$ 
Table 4.8. SSM/I rainfall algorithm errors calculated from comparisons with alternative rainfall data. The GCEM and Radar errors are for instantaneous area averaged rainfall retrievals and the GPCC and Legates Willmott errors are for global four month means.

\begin{tabular}{|c|rrrr|}
\hline & GCEM & Radar & GPCC & L/W \\
\hline bias & $3.5 \%$ & $-15.7 \%$ & $8.4 \%$ & $-15.5 \%$ \\
rms & $12.8 \%$ & $19.5 \%$ & $69.9 \%$ & $49.5 \%$ \\
\hline
\end{tabular}

through the GCEM the bias was $3.5 \%$ and the rms was $12.8 \%$. The GCEM model is over ocean so the errors are representative of expected errors in the ocean algorithm. The radar comparison yielded a bias of $-15.7 \%$ and an rms of $19.5 \%$. The bias and rms errors between the SSM/I algorithm estimates and the alternative data for instantaneous estimates are summarized in the first two columns of Table 4.8. Since most of the radar area consists of land surface, the comparison most closely represents the expected errors in instantaneous land algorithm estimates. The ocean provides a cool uniform polarized background, unlike the warm heterogeneous unpolarized land background, so the accuracy over ocean should be higher than over land.

The instantaneous error budget can be analyzed in the context of the sensitivity modeling. The dependence of the algorithm on variations in background parameters, section 3.4 , is studied through alterations in the structure of the surfacecloud model. The most significant error occurs over land if there is no ice above the rain cloud. When the freezing level is lowered or ice is removed, an underestimation results over both land and ocean. The effect of surface freezing level also causes an underestimation in both algorithms. Since the land algorithm has been adjusted to correct for surface freezing level, surface temperature variations and beam filling, and the ocean algorithm has been adjusted for beam filling, the instantaneous errors of approximately $20 \%$ over land and $13 \%$ over ocean are qualitatively consistent with the sensitivity tests. 
4.7.2 Errors in monthly estimates When rain rates from multiple satellite overpasses are averaged together, a sampling error results in the timeintegrated total. In the case of a sun synchronous polar orbiter such as SSM/I the error is quite significant when monthly or seasonal totals are computed. For a global average, the SSM/I samples about once each day, while the variability of rainfall events occurs with a much higher frequency, with a typical autocorrelation time of 6 hours for a 1.15 degree area (Laughlin 1981). This means that successive SSM/I overpasses sample uncorrelated rainfall events, and it is not uncommon for an entire rainfall event to be completely missed. Rainfall also has a strong diurnal cycle that is region dependent and most pronounced over land. The SSM/I sun synchronous orbit, with overpasses occurring at approximately the same local time each day, will introduce a bias in time integrated rainfall due to the diurnal cycle. The error contributions resulting from undersampling rainfall variability, especially the diurnal cycle, give rise to temporal sampling errors.

In addition to temporal sampling errors, the relatively low resolution of the microwave footprint causes a spatial sampling error. The spatial autocorrelation length of rainfall is about $10 \mathrm{~km}$, less than the $25-60 \mathrm{~km} \mathrm{SSM} / \mathrm{I}$ footprints. The beam filling portion of the spatial sampling error has been corrected within the algorithm formulation. Also, adjacent pixels cover the entire swath so there is almost complete spatial coverage. Therefore, the spatial sampling error is considered to be small compared with the temporal sampling error and is not included in the error budget.

The temporal sampling error has been studied both by theoretical and observational means. Chang et al. (1993) reported observations of monthly mean rainfall errors over ocean with a $5 \times 5$ degree resolution to be $57.5 \%$ of the mean. These errors were computed using an average sampling interval of 48 hours which would make the sampling error about twice what it would be for a 24 hour interval. Berg and Avery (1994) reported monthly errors over ocean of $31 \%$ using a 2.5 degree 
grid size. Weng et al. (1993) found measured sampling errors in monthly values of about $40 \%$ including land and ocean for a sampling interval of 24 hours. The sampling errors were geographically dependent with the largest values found over high latitude land, and lowest over the ITCZ, an area of persistent convection. Weng et al. (1994) also found that the difference between calculating a mean monthly rain total by fitting a lognormal curve and by simple averaging differed by less than $5 \%$. Sharma et al. (1991) found a diurnal difference in monthly oceanic rainfall between AM and PM SSM/I overpasses to be about $20 \%$. This does not represent the entire diurnal cycle only the mean difference of the diurnal cycle between two specific times of the day.

Observations can also be used to derive theoretical descriptions of sampling error. Bell (1987) found that the temporal sampling error in averaged rainfall estimates is random and follows a normal distribution about the mean. This means that a global mean monthly rainfall estimate may be very accurate even though individual grid points may have substantial sampling errors. North and Nakamoto (1989) proposed that the diurnal component of the sampling error can be separated from the random sampling error, and proposed a formulation for the random component.

As a first step in estimating the theoretical temporal sampling error for monthly and annual rainfall totals, the formulation presented by North and Nakamoto (1989) is used to calculate expected random sampling errors for SSM/I F8 monthly global rainfall totals at one degree resolution. The mean square random sampling error is derived from the characteristic temporal autocorrelation, the time between samples, the integration period, and the coefficient of variance. Assuming that the satellite completely covers an area of interest at even intervals in time, $\delta t$, over an integrating time period $T$, the mean squared error can be calculated using,

$$
\epsilon^{2} \approx \sigma_{A}^{2} \frac{1}{\pi^{2}} \frac{\delta t}{T} \frac{\delta t}{\tau_{0}}
$$

where $\sigma_{A}^{2}$ is the variance of area-averaged rain rate, and $\tau_{0}$ is the autocorrelation 
Table 4.9. Theoretical error budget for global rainfall monthly means at one degree resolution. The theoretical temporal and diurnal sampling errors are estimated for the SSM/I orbital characteristics. The algorithm error is taken from the instantaneous rms differences between SSM/I and the GCEM and radar data.

\begin{tabular}{|l|rr|}
\hline & Ocean & Land \\
\hline Temporal & $23 \%$ & $23 \%$ \\
Diurnal & $10 \%$ & $20 \%$ \\
Algorithm & $13 \%$ & $20 \%$ \\
\hline TOTAL & $46 \%$ & $63 \%$ \\
\hline
\end{tabular}

time of the rain field for a given size area. The coefficient of variation of rain rate is close to 2.5 for areas of $90 \mathrm{~km}$ on a side (North and Nakamoto 1989). The value does not drop significantly for areas larger than 1 degree. The area-averaged rain rate usually exhibits a standard deviation that is about twice the mean for area-average values below $1 \mathrm{~mm} / \mathrm{hr}$. The autocorrelation is about 3.5 hours for 1 degree areas. Using the formulation of mean square random sampling error, the estimate of the sampling error for this resolution is $23 \%$.

The random sampling error can then be added to the diurnal sampling error to give the overall error. Although Hendon and Woodberry (1992) found that the diurnal cycle is strongly geographically dependent without substantial latitudinal or longitudinal organization, estimates of the diurnal cycle made by Meisner et al. (1987) show an average value of $10 \%$ over ocean and $20 \%$ over land. Using these values for the diurnal sampling error and adding the random sampling errors yields a total sampling error of $33 \%$ and $43 \%$ over ocean and land, respectively.

A theoretical error budget, the expected absolute mean difference between the SSM/I monthly rainfall estimates at one degree resolution and the true mean rainfall, is derived by adding up theoretical sampling, diurnal, and algorithm errors. The error budget is summarized in Table 4.9 where the total expected rms error is formed by adding together the temporal sampling error, the additional diurnal sampling error due to the particular SSM/I orbit, and the algorithm retrieval error. 
The algorithm error is based on the comparisons with the cloud model simulation and the radar data. The total expected rms error budget in monthly mean rainfall is simply the addition of each of these three components. The result is an estimated $46 \% \mathrm{rms}$ error over ocean and a rms of $63 \%$ over land.

A comprehensive error budget is based on checking the theoretical total expected rms errors with the statistics generated from the four month comparison with the GPCC and Legates raingauge data. Based on the assumption that each of the data sets is unbiased, contains normally distributed sampling errors, and that the SSM/I sampling errors are greater than the comparison data set, the rms difference between them will be equal to the sampling errors of the data set with the highest sampling error. The calculated rms difference between the rain gauge data is then assumed to be equal to the SSM/I sampling error, including the instantaneous bias, the random sampling error, and the diurnal sampling error. The mean absolute error between the GPCC and SSM/I data over land is $69.9 \%$ which compares well with the $63 \%$ calculated theoretically. The mean absolute error between the L/W and SSM/I data over ocean is $49.5 \%$ and also agrees with the $46 \%$ calculated theoretically. It is reasonable to assume that the rms between the SSM/I mean estimates and the raingauge estimates would be comparable to the rms between the SSM/I and the true mean as long as the raingauges exhibit negligible bias relative to the true mean. 


\section{CHAPTER 5}

\section{CLIMATE SCALE RAINFALL ANALYSIS}

The passive microwave rainfall algorithm is used to estimate global rainfall for the time series of SSM/I F8 data over the period August, 1987, through December, 1989. The length of the time series is limited by the launch of the satellite and the eventual failure of both the $85 \mathrm{GHz}$ channels. The time series, presented as a seasonal climatology, shows the global distribution and variability of climate-scale rainfall. To demonstrate the usefulness of global rainfall monitoring to the study of the Earth system, the SSM/I rainfall maps are then analyzed in three different ways:

1) Global rainfall maps are compared during different phases of an El Niño Southern Oscillation event in order to detect associated global rainfall changes. Rainfall maps are analyzed for information about the relationship between the decrease of rainfall associated with the Asian monsoon in the western Pacific region and the increase in rainfall associated with enhanced convective activity in the central Pacific.

2) The relationship between monthly oceanic rainfall and sea surface temperatures in the Atlantic Gulf Stream is examined. The relationship between increased sea surface temperature and rainfall is analyzed during 1988 using a singular value decomposition technique to determine the modes of coupled variability.

3) The migration of the rainfall edge in the African Sahel is tracked over the course of a year. The study tracks the latitudinal extent of the the band of intense rainfall associated with the intertropical convergence zone stretching eastward across Africa from the Ivory Coast to the Ethiopian highlands. The latitudinal extent and migration of the ITCZ causes extreme rainfall variability in the African Sahel region resulting in periodic droughts. 


\subsection{Rainfall climatology}

Global rainfall is derived from the F8 SSM/I data for the period August, 1987 - December, 1989, and is presented as a series of four month rainfall accumulation maps. Figures 5.1- 5.9 present the total seasonal rainfall between 60 degrees latitude. The global patterns of rainfall are generally consistent from season to season except for an annual latitudinal shift. The most prominent feature in the global rainfall pattern is the equatorial rainfall band circumnavigating the globe along the intertropical convergence zone. The band is most organized from Eastern Africa to the western Pacific warm pool where it begins to dissipate at the western edge of the Indian ocean through Ethiopia and Somalia in Eastern Africa. Two global rainfall bands occur in the Southern Ocean and in the northern latitudes at about 45 degrees. These are both separated from the equatorial band by the drier subtropics. The next sections will discuss specific features of the rainfall patterns. 


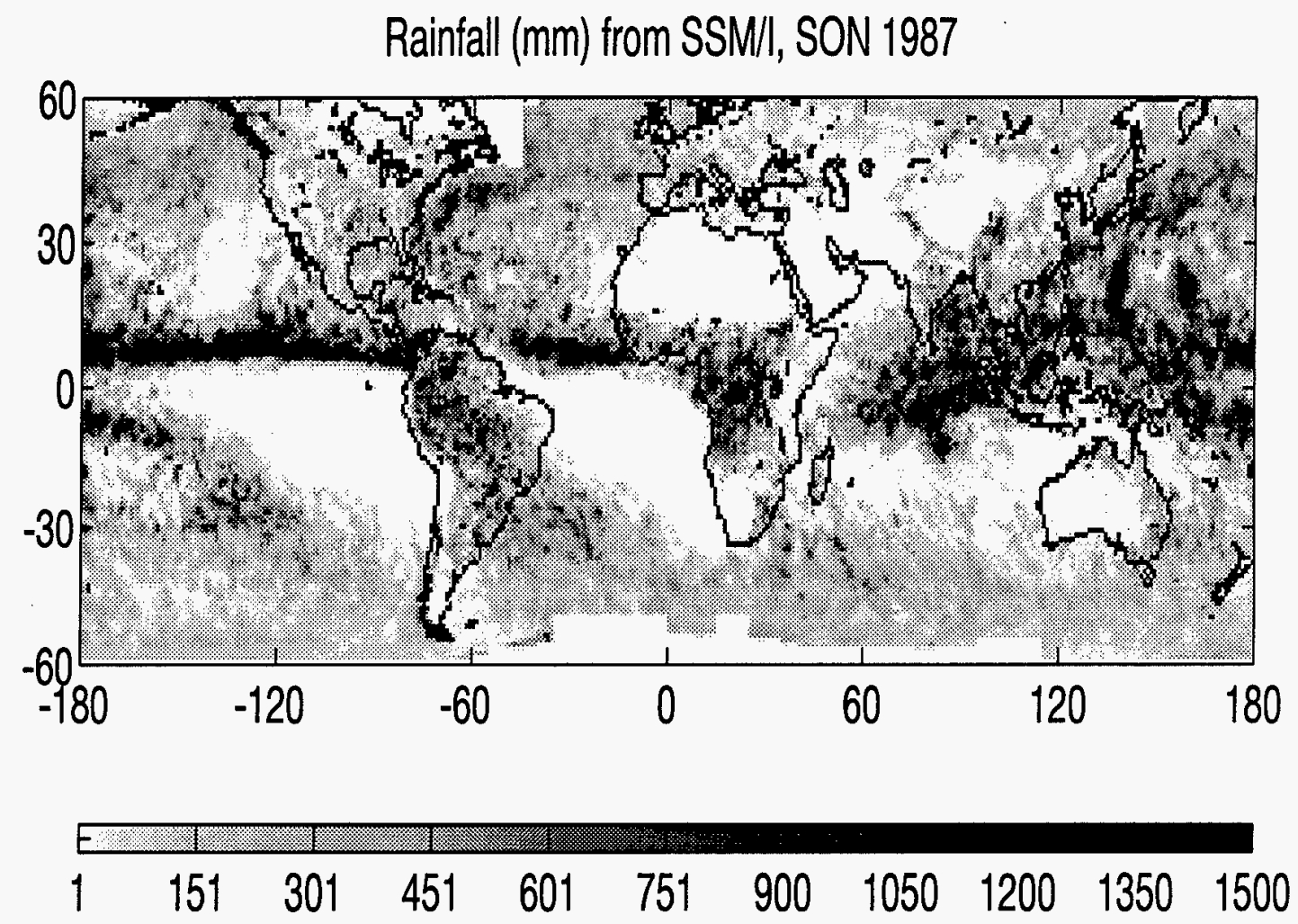

Figure 5.1. Rainfall total for September-October-November, 1987, estimated from SSM/I. 
Rainfall (mm) from SSMII, DJF 1987-88
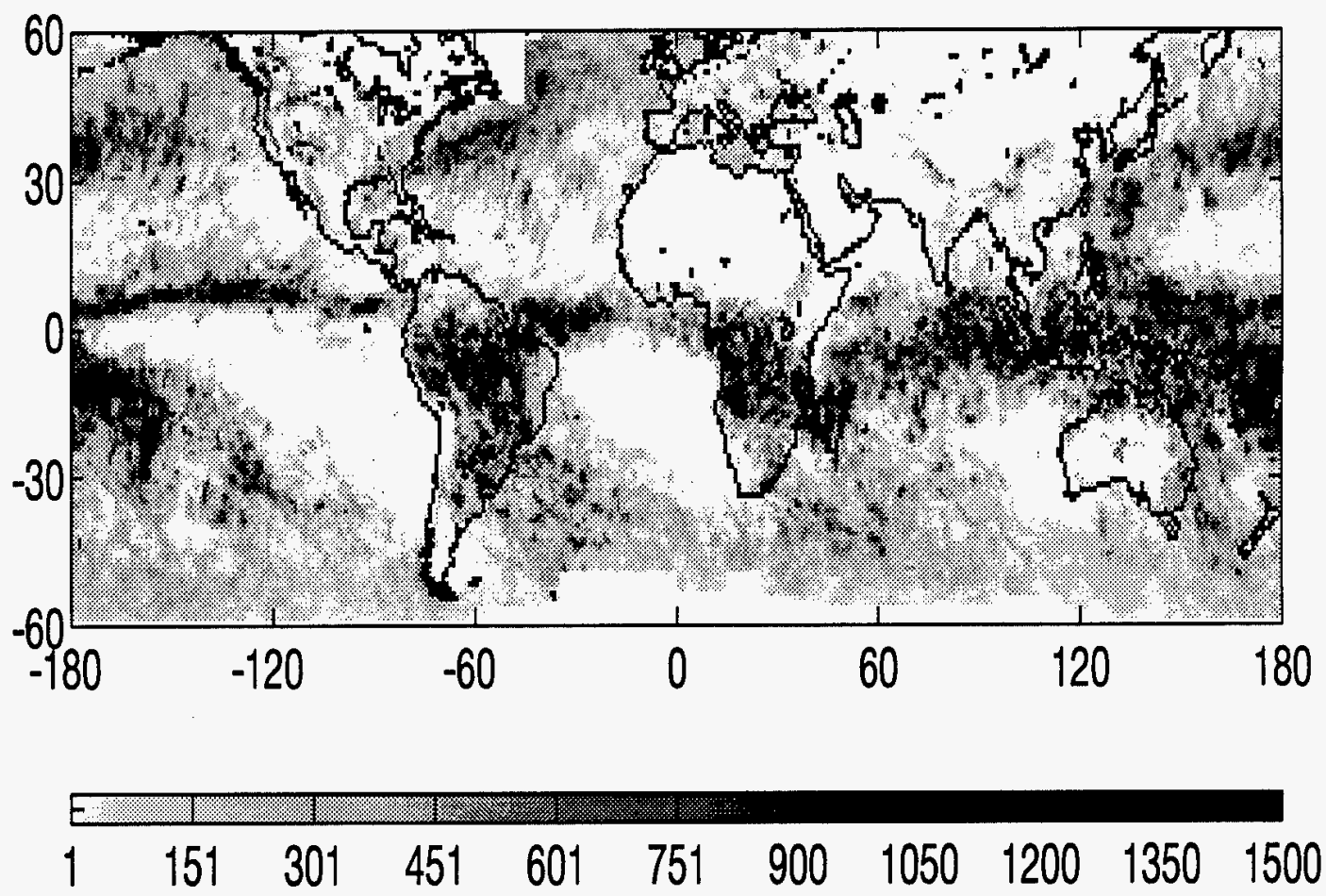

Figure 5.2. Rainfall total for December-January-February, 1987-1988 estimated from SSM/I. 
Rainfall (mm) from SSM/, MAM 1988
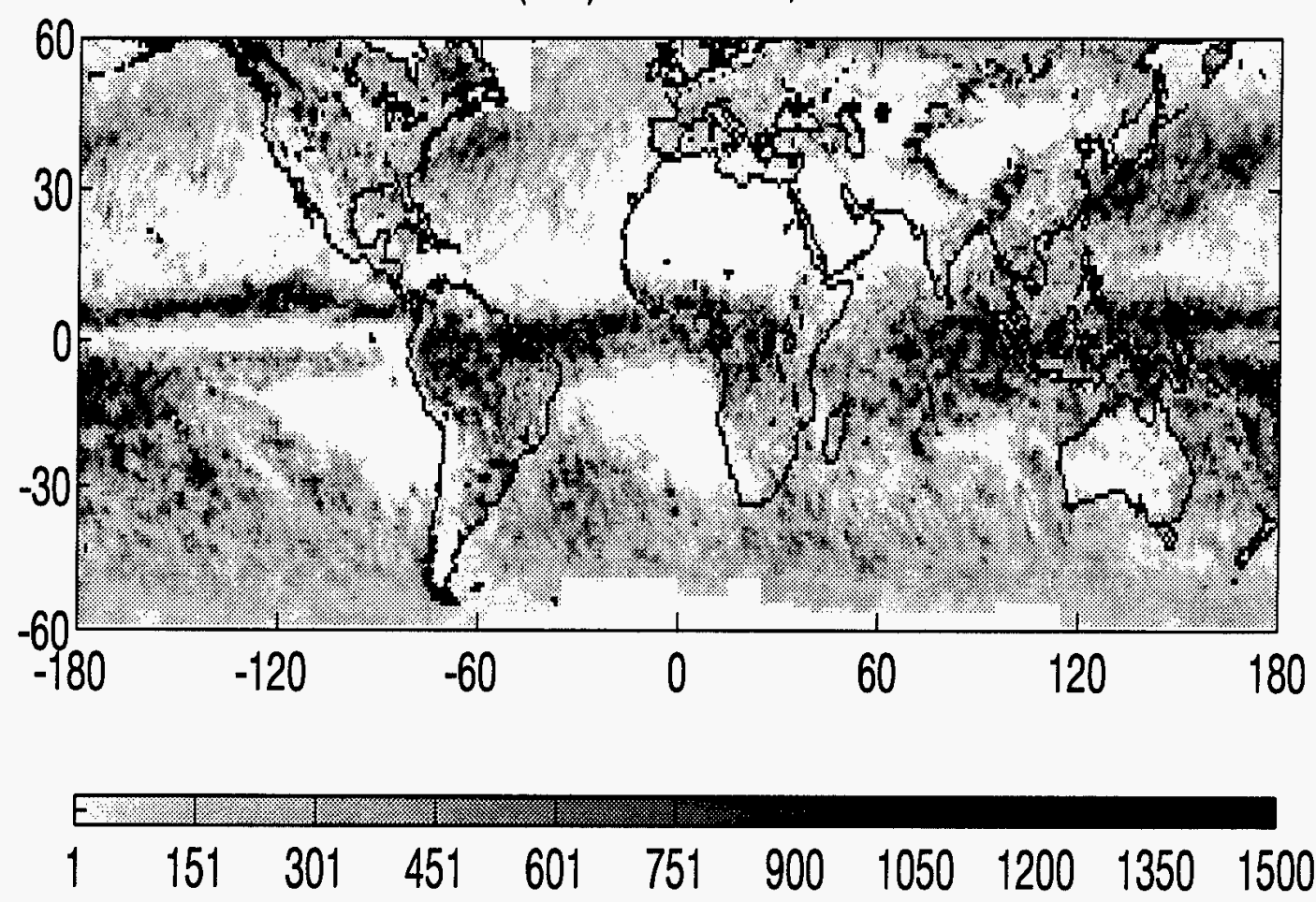

Figure 5.3: Rainfall total for March-April-May, 1988, estimated from SSM/I. 
Rainfall (mm) from SSM/l, JJA 1988
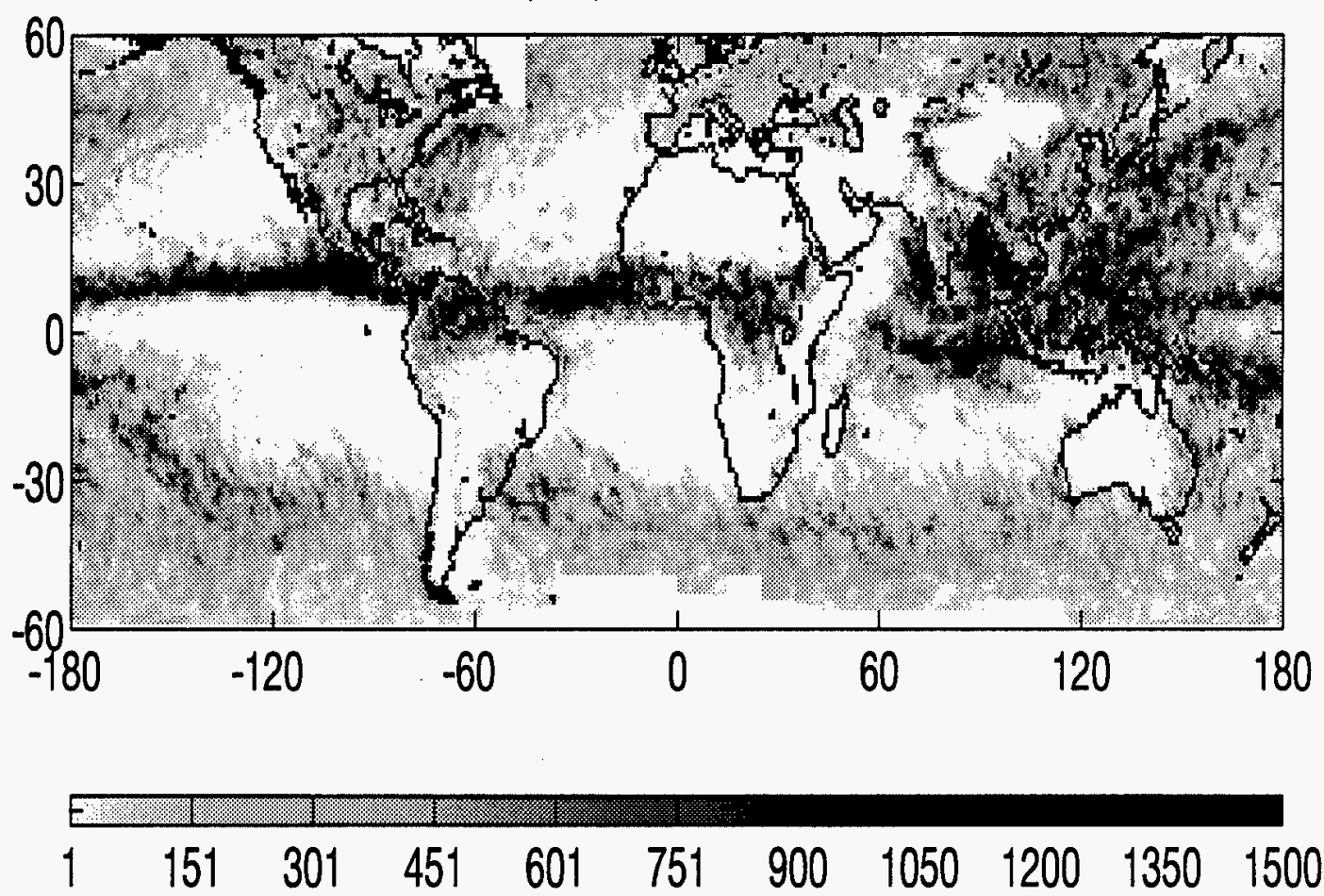

Figure 5.4: Rainfall total for June-July-August, 1988, estimated from SSM/I. 
Rainfall (mm) from SSM/, SON 1988

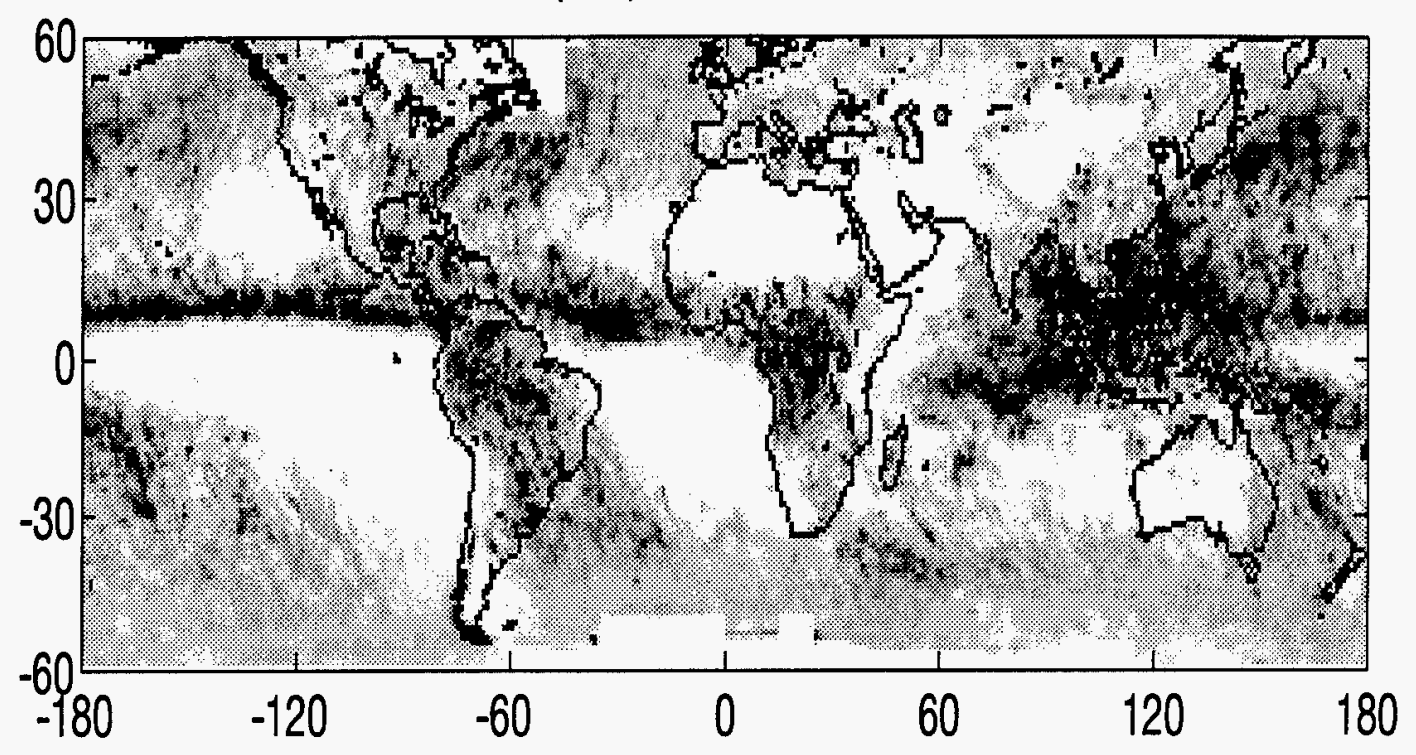

$\begin{array}{lllllllllll}1 & 151 & 301 & 451 & 601 & 751 & 900 & 1050 & 1200 & 1350 & 1500\end{array}$

Figure 5.5. Rainfall total for September-October-November, 1988, estimated from $\mathrm{SSM} / \mathrm{I}$. 


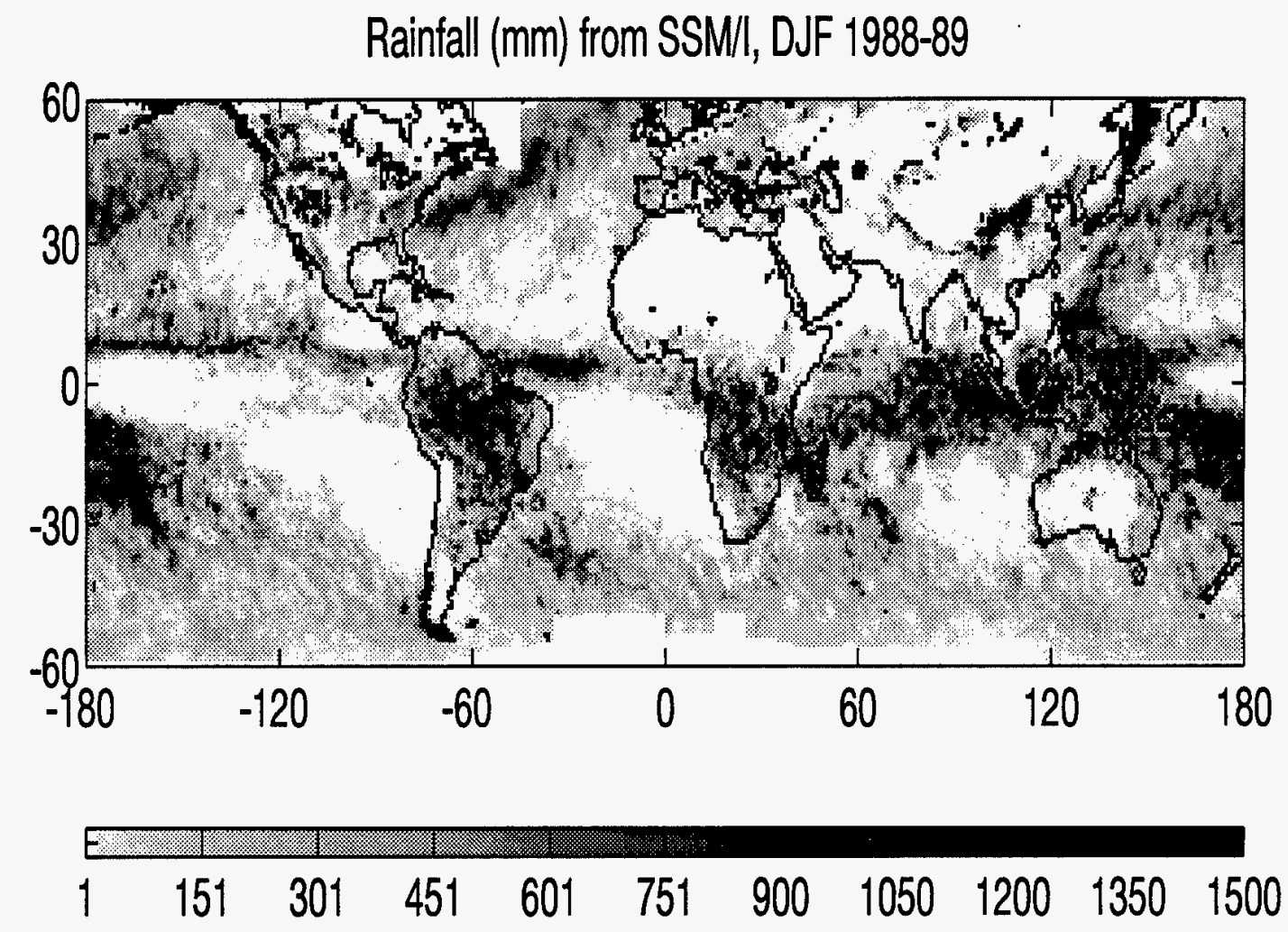

Figure 5.6. Rainfall total for December-January-February, 1988-1989, estimated from SSM/I. 


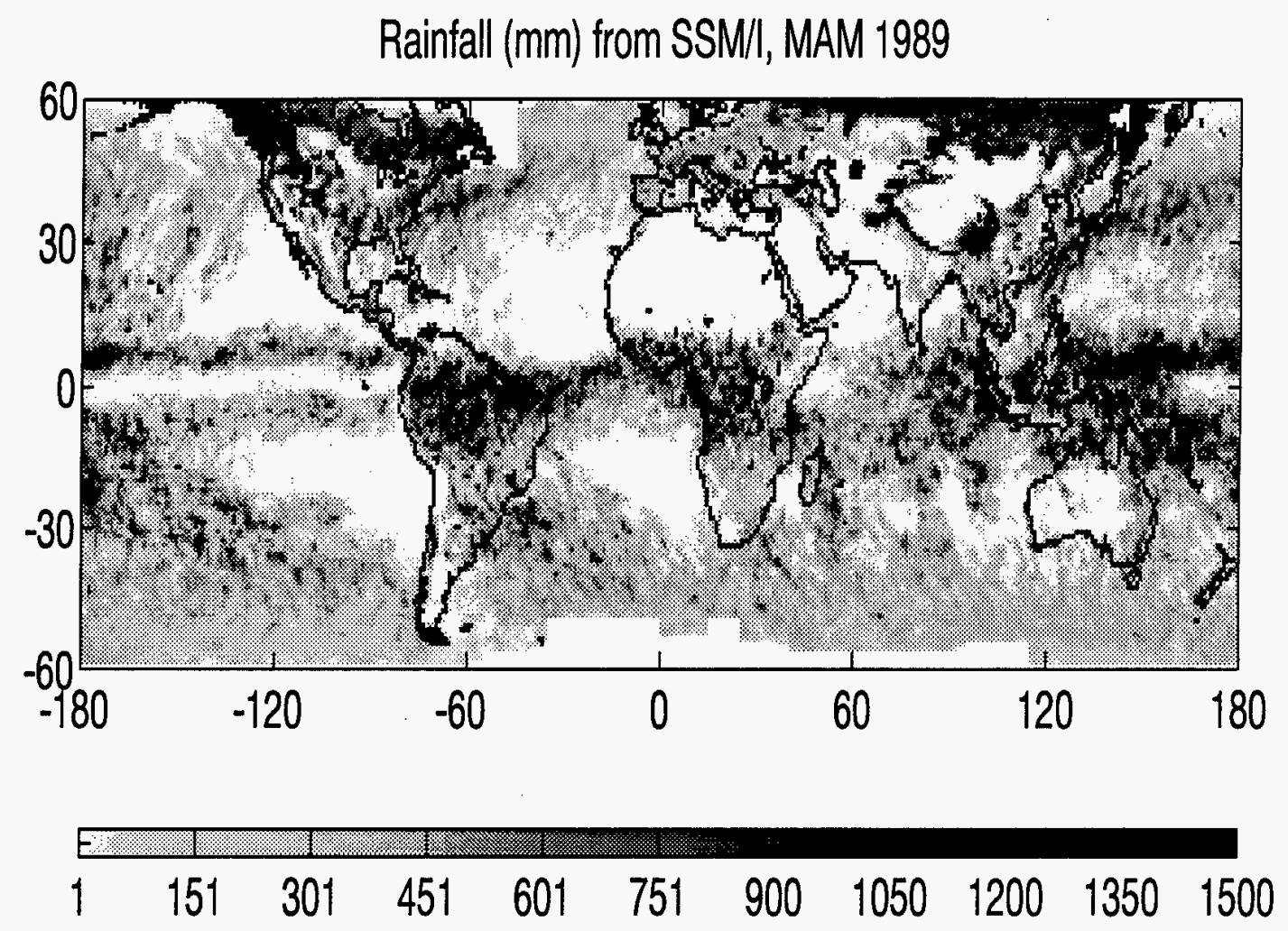

Figure 5.7: Rainfall total for March-April-May, 1989, estimated from SSM/I. 
Rainfall (mm) from SSM/I, JJA 1989

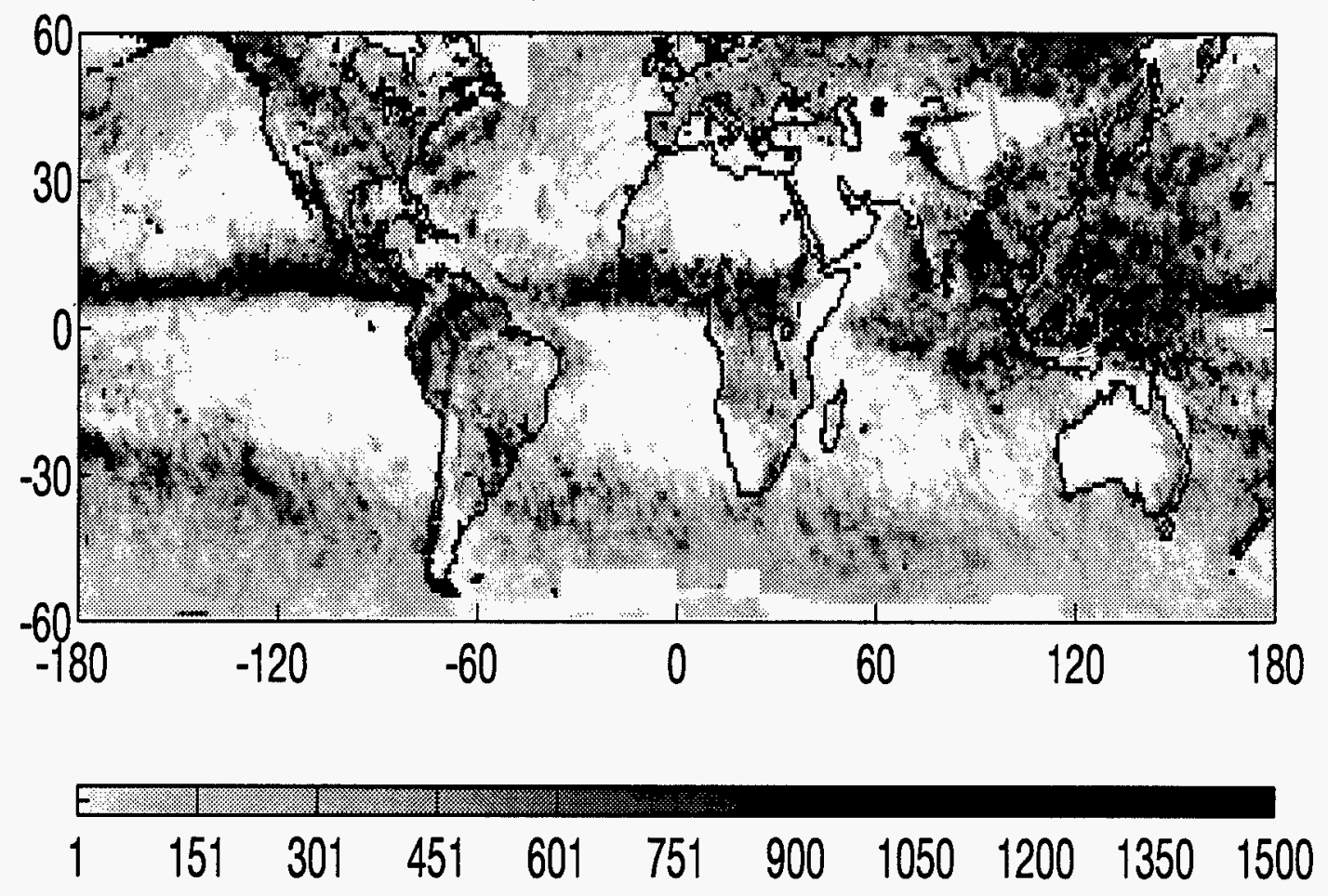

Figure 5.8: Rainfall total for June-July-August, 1989, estimated from SSM/I. 


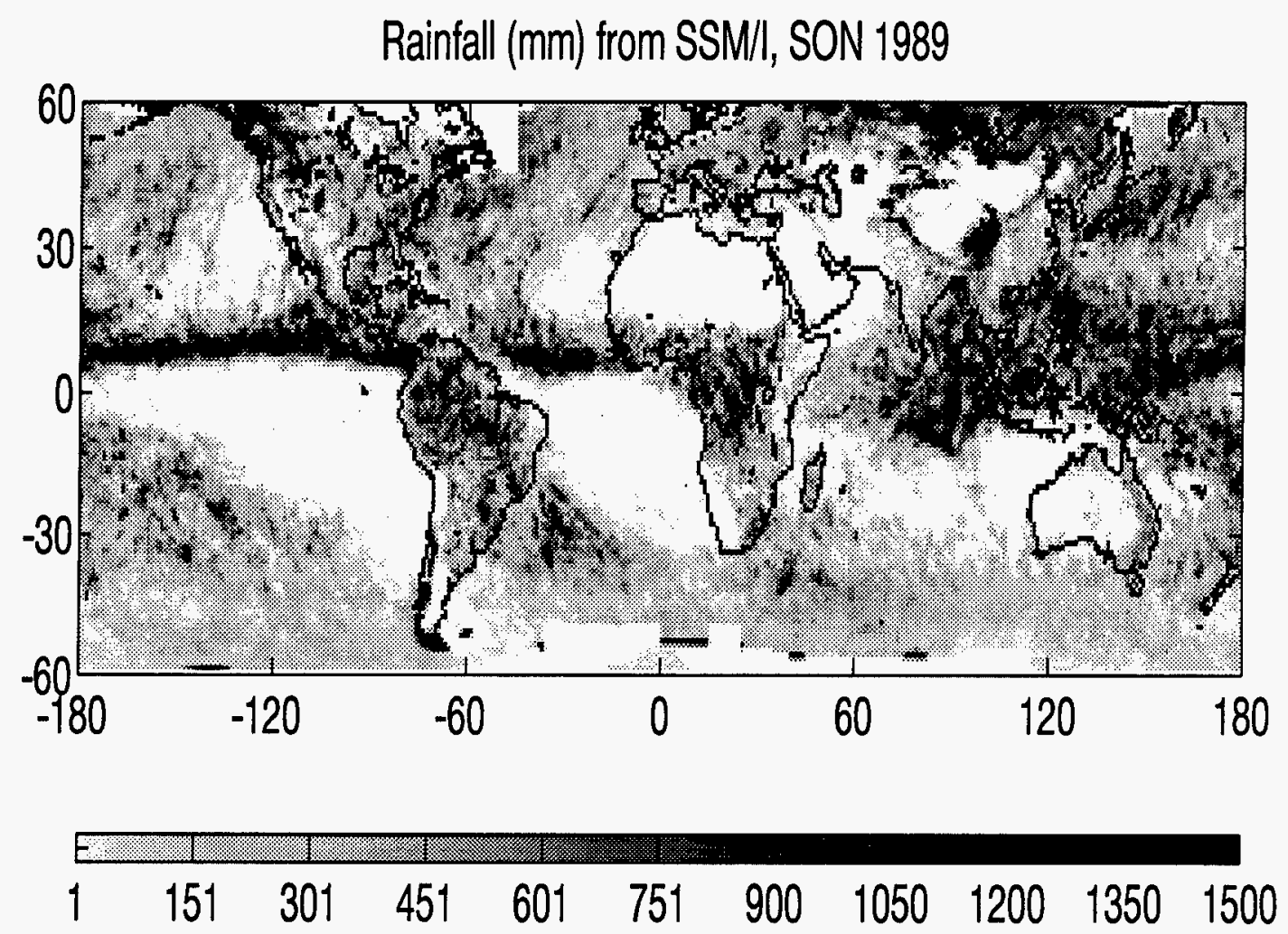

Figure 5.9. Rainfall total for September-October-November, 1989, estimated from $\mathrm{SSM} / \mathrm{I}$. 


\subsection{Global changes in rainfall associated with ENSO}

The rainfall climatology offers an opportunity to study the variations in the global distribution of rainfall and to relate these variations to well known climate anomalies such as the El-Niño/Southern Oscillation (ENSO). The ENSO is characterized by a warming of the eastern Pacific tropical ocean, part of a number of anomalous conditions including a zonal shift in atmospheric pressure and in the Walker circulation (Rasmusson and Wallace 1983; Cane 1983). During El-niño events, the variability of rainfall patterns results in intense drought and severe flooding over large regions of the world. The rainfall anomalies are thought to result from the influence of variations in sea surface temperature and atmospheric circulation. Changes in vertical latent heating in the intertropical convergence zone are thought to cause variability in rainfall and other climate parameters at higher latitudes by affecting the meridional upper atmospheric Hadley circulation (Simpson 1988).

The monsoon rainfall over Eurasia is a climate scale feature of the global distribution of rainfall that is linked to the ENSO. The monsoon is characterized by intense summertime rainfall yielding about $80 \%$ of the annual total in a few events. The monsoon system may be tightly linked to the atmosphere-ocean system in the Pacific (Yasunari 1991), and to the associated large scale atmospheric circulation system, a meridional circulation from the Indian ocean, through India and over the Himilayas and a zonal circulation over the tropical Pacific and Indian Ocean. The monsoon is thought to be linked both to these two atmospheric circulations and to the radiative influences of the Eurasian continent. With an abundance of precipitable water from both the Indian and Pacific ocean, and a positive feedback mechanism between convection induced rainfall and latent heat induced convection, the monsoon is propagated by the resulting meridional and zonal atmospheric circulation. At the onset of an ENSO event, when the warm pool disperses into the central Pacific, and the intense convection associated with the warm pool is not centralized near Eurasia, 
the monsoon rainfall is naturally disrupted. The rainfall climatology may offer a clue to how the rainfall is redistributed during an ENSO event and to what extent this affects the monsoon region.

The period from September, 1987, to November, 1988, represents the end of an El Niño and the onset of anti-El Niño or La Niña. To investigate the changes in global climate scale rainfall patterns associated with this phenomenon, the rainfall total for September, October, November, 1987, is differenced with the same period for 1988. In Figure 5.10, areas with more rainfall in 1987 are depicted with positive rain amount while areas with more rainfall in 1988 are depicted with negative values. The result of differencing the two time periods shows that rainfall is in general higher in the western Pacific during La Niña and greater in the central and eastern Pacific during El Niño. This is expected since the warmer central and eastern Pacific waters during El Niño will initiate more convection rainfall. Another difference is noted in the subtropical central Pacific where more rainfall occurs during La Niña. It appears that during El Niño the ITCZ convection is constrained to a narrow band in the equatorial latitudes and then disperses during La Niña. It also appears that most of the differences occur over the ocean and at lower latitudes. The Atlantic receives more rainfall in the northern midlatitudes but there is little change along the Atlantic equatorial region. The most noticeable global change during El Niño is an eastward shift in global rainfall along the equator from the western to the central and eastern Pacific equal in magnitude to the total rainfall. 
Difference in Seasonal Rainfall (mm) (SON 1987 minus 1988)

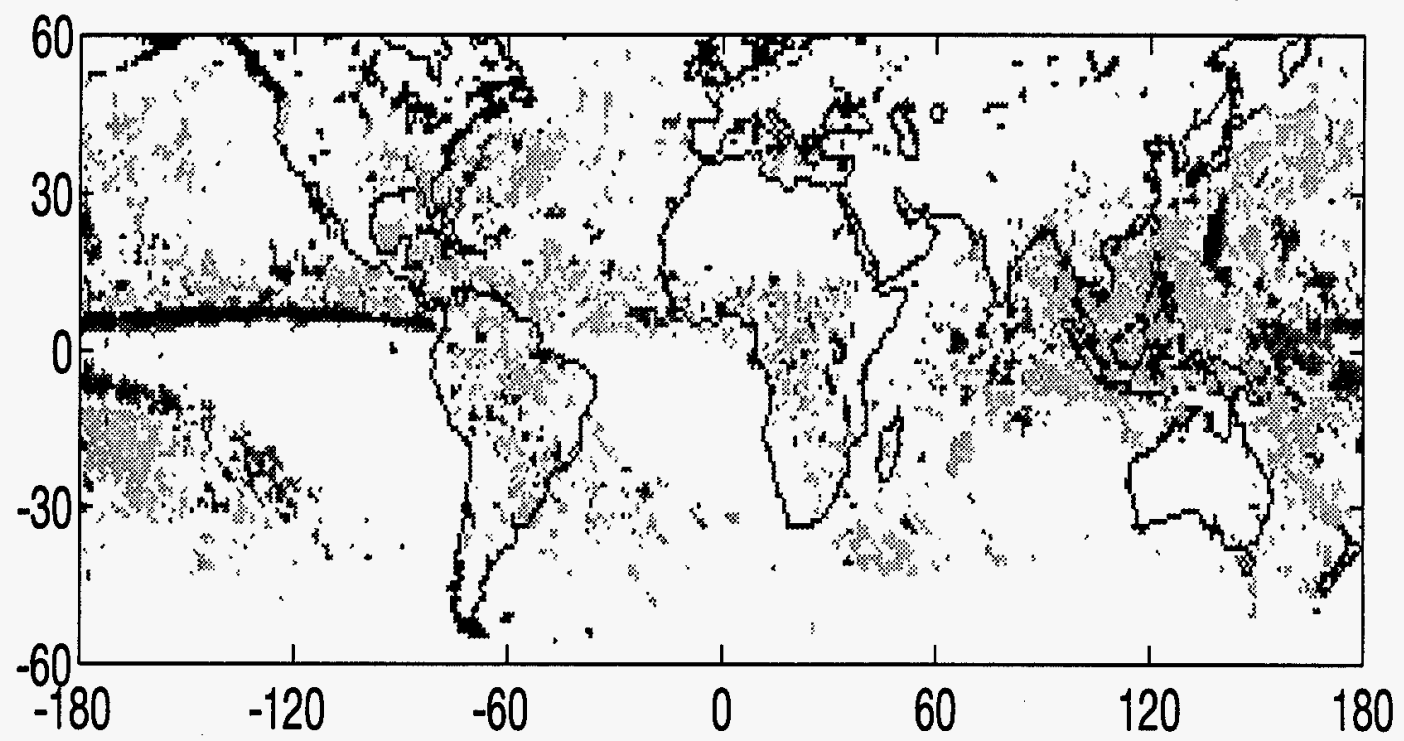

\begin{tabular}{lllllllllll}
\hline 1500 & -1200 & -900 & -600 & -300 & 0 & 300 & 600 & 900 & 1200 & 1500
\end{tabular}

Figure 5.10: Estimated rainfall difference (SON 1987 - SON 1988) 


\subsection{Coupling of rainfall and sea surface temperat ure over the Gulf Stream}

The Gulf Stream is characterized by a warm "river" of water snaking northward just off the coast of the southeastern United States and eventually turning eastward into the north Atlantic (Pickard and Emery 1982). It has long been suggested that the warmer water should produce enhanced convection and initiate heavy rainfall. Evidence such as visible and infrared imagery over the Gulf Stream usually exhibit persistent cloud cover, suggesting the presence of underlying rainfall; however, these sensors are only marginally effective for rainfall detection at these high latitudes over much of the cold season. In order to directly test the validity of this assumption rainfall maps are analyzed over the Gulf Stream in conjunction with sea surface temperatures. The coupled modes of temporal and spatial variability are determined to establish the dependence of rainfall on the position of the Gulf Stream.

Monthly rainfall and sea surface temperature (sst) from 1988 are used in the comparison. The rainfall time series is shown in Figure 5.11 and the sst time series in Figure 5.12. The data are extracted for the region bounded by 80 and 50 degrees west longitude and 30 and 45 degrees north latitude. The rainfall data are rainfall totals over ocean at one degree resolution. The sst data, also at one degree resolution are taken from Reynolds (1988), a blended monthly sea surface temperature analysis using ship, buoy and satellite data. Land and coastline are masked in both data sets.

To examine the coupled modes of variability between the two data sets, singular value decomposition (SVD) is used to determine the eigenvectors and eigenvalues of the cross-covariance matrix. The SVD technique is a well established method for diagonalizing non-square matrices similarly to related techniques such as "principal components" or "empirical orthogonal functions" analysis (Bretherton et al. 1992; Stidd 1967). Each time series is arranged as a matrix with each column 
including all data points for one month and successive columns including data for separate months. The data are normalized by subtracting the yearly mean for each grid point and by subtracting the monthly mean from each of the monthly fields. Each monthly field is then divided by the standard deviation of the entire data set so that neither data sets will dominate the magnitudes of the cross-covariance matrix merely because of the units in which they are expressed. The cross-covariance matrix is obtained by multiplying the rainfall matrix by the transpose of the sst matrix.

The SVD technique produces basis functions of the coupled variability which are new grid fields in which the maximum amount of variability is represented. The amplitude of each of the modes is obtained by multiplying the modal field by the original data. The percent of variance explained by each of the eleven modes from the SVD are plotted in Figure 5.13. Only the first two modes of variability will be examined since the statistical nature of the decomposition means that modes representing only a small fraction of the variance are not expected to represent a physical characteristic of the variability and are usually accounting for the noise in the data. An important difference between the analysis here and more conventional principal component analyses is that because the cross-covariance matrix relates two different data sets rather than just one, there are two resulting eigenvector sets, one for each of the original data sets. Corresponding modes are related to one another because they share the same temporal amplitudes.

The first two modes of coupled variability for rainfall are shown in Figure 5.14 and for sst in Figure 5.15. The associated temporal amplitudes governing each of the modes are presented in Figure 5.16. In the first mode of the rainfall data, the pattern shows variability located along both edges of the mean Gulf Stream. This is evident by the diagonal bands of highs and lows in the rainfall mode one image. The variability of the sst data in mode one also shows a high and a low diagonal band flanking the mean Gulf Stream position. This would suggest that the shifts in 
the mean Gulf Stream over the course of a year are shadowed by associated shifts in the rainfall. The wavelengths of the amplitude curves for both the first and second modes correspond to an annual signal. The first and second modes are in quadrature meaning that the temporal amplitude curves are three months out of phase. The second mode corresponds less to the Gulf Stream pattern, especially in the rainfall map. It appears that the primary coupled mode of variability consists of the sst changes along the edges of the Gulf Stream and corresponding variability in rainfall also along the edges of the Gulf Stream. 

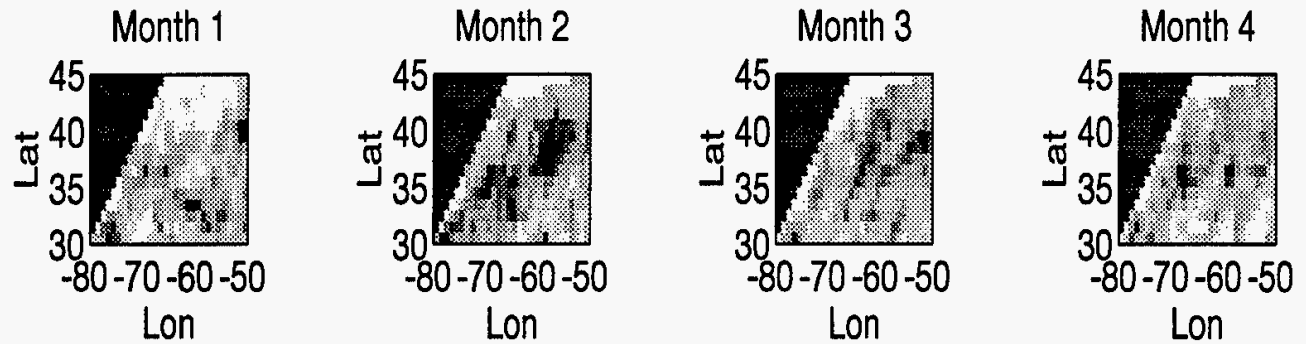

Month 5

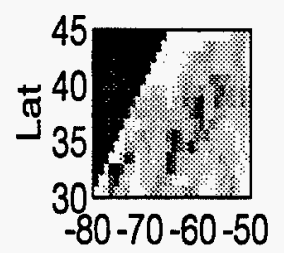

Lon
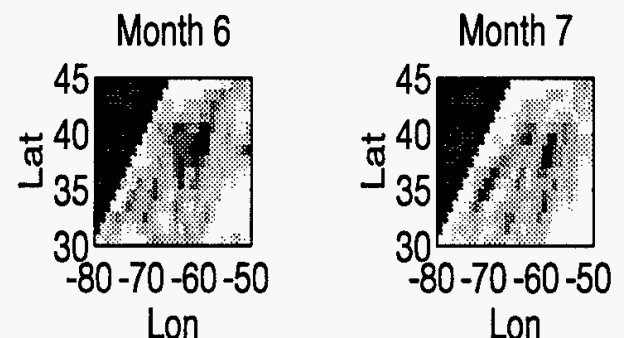

Lon

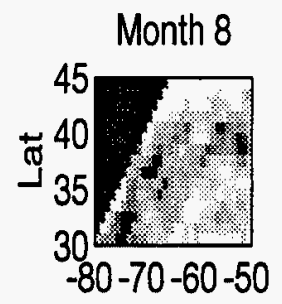

Lon

Lon
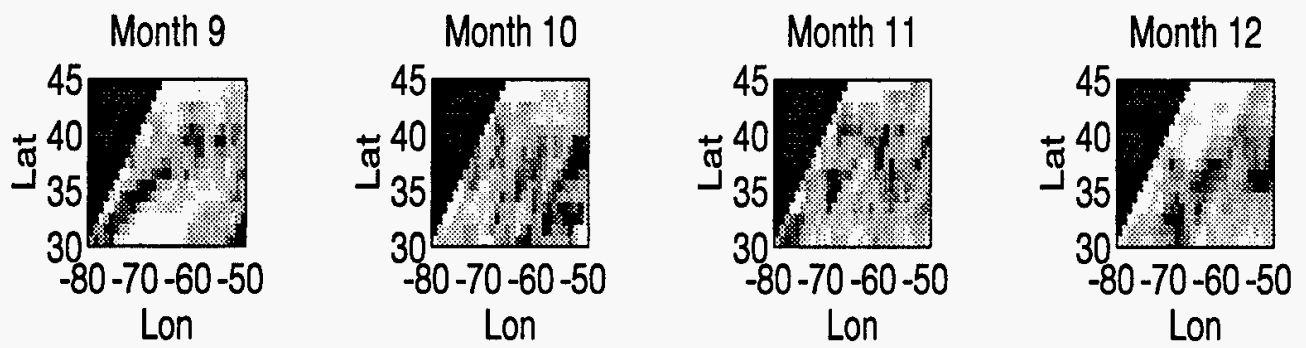

Monthly Rainfall (mm) over the Gulfstream during 1988

151101151201251300350400450500

Figure 5.11: Monthly rainfall over the Gulf Stream derived from SSM/I in 1988. 

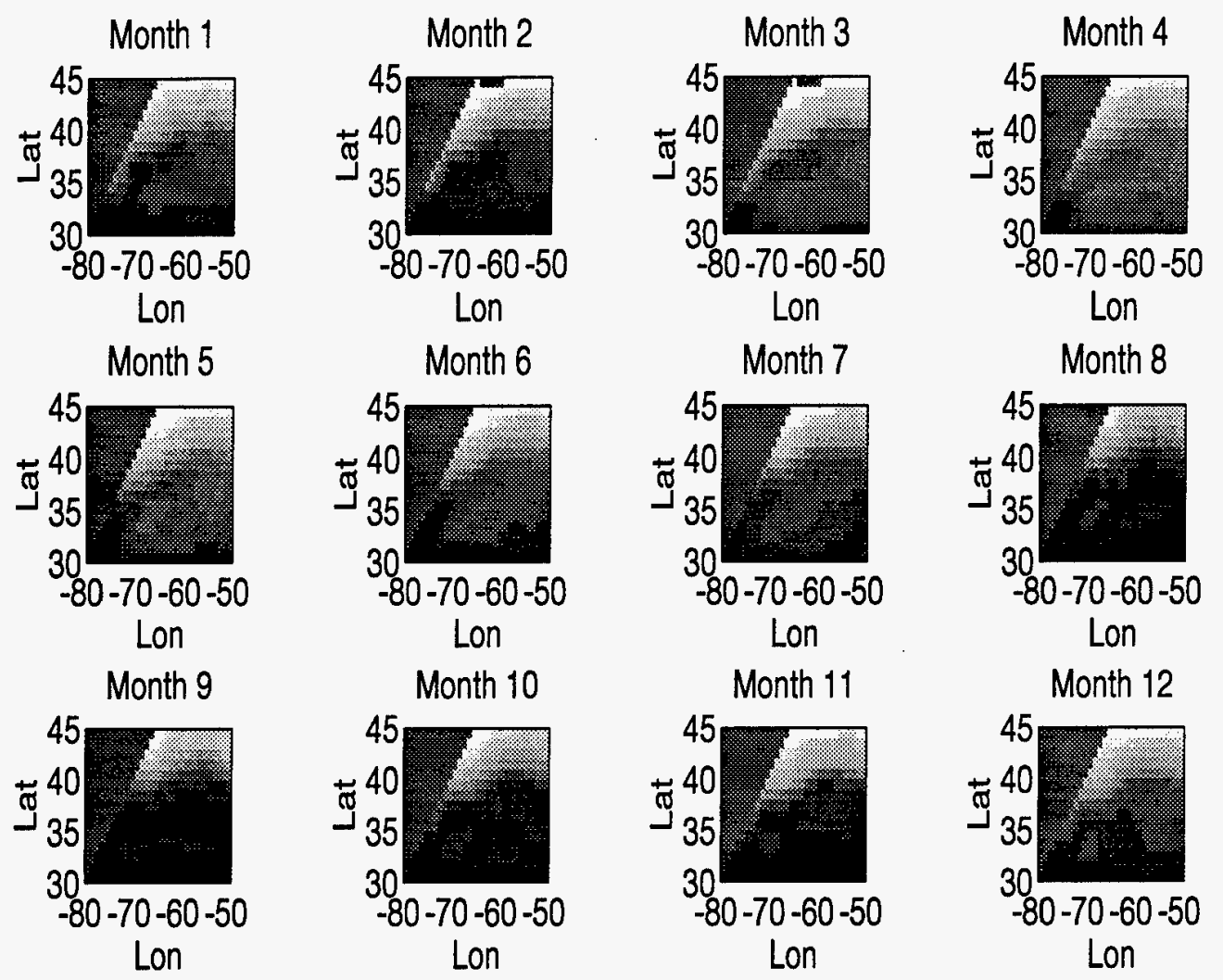

Reynolds 1988 Monthly Sea Surface Temperature (C)

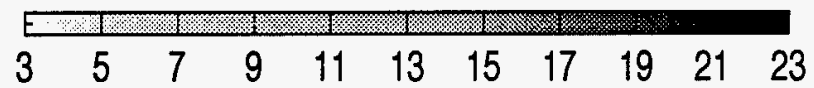

Figure 5.12. Monthly Gulf Stream sea surface temperatures in 1988 after Reynolds. 


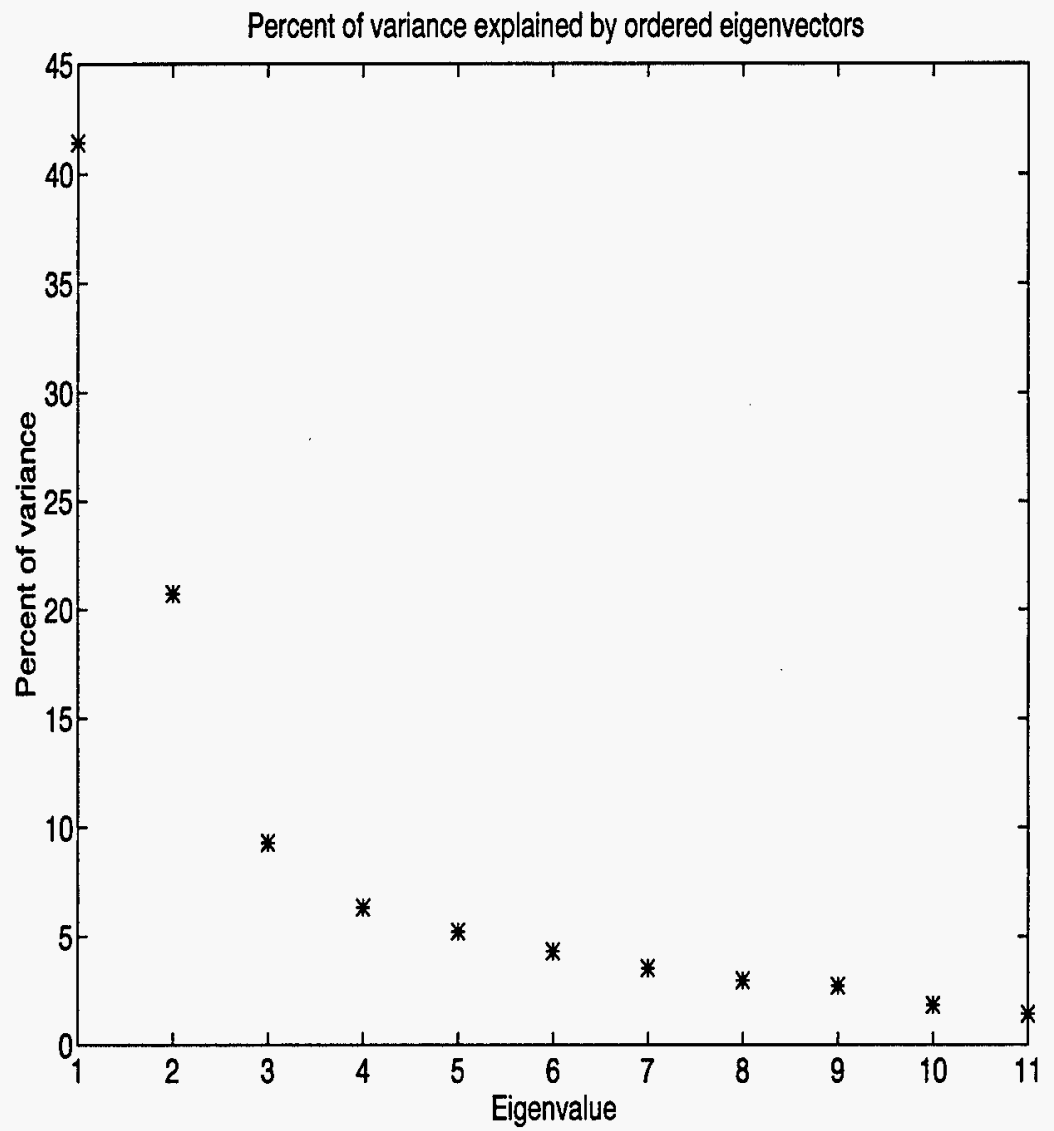

Figure 5.13. Percent of variance explained by the ordered eigenvectors corresponding to the covariance fields of rainfall and sea surface temperature determined from singular value decomposition. 


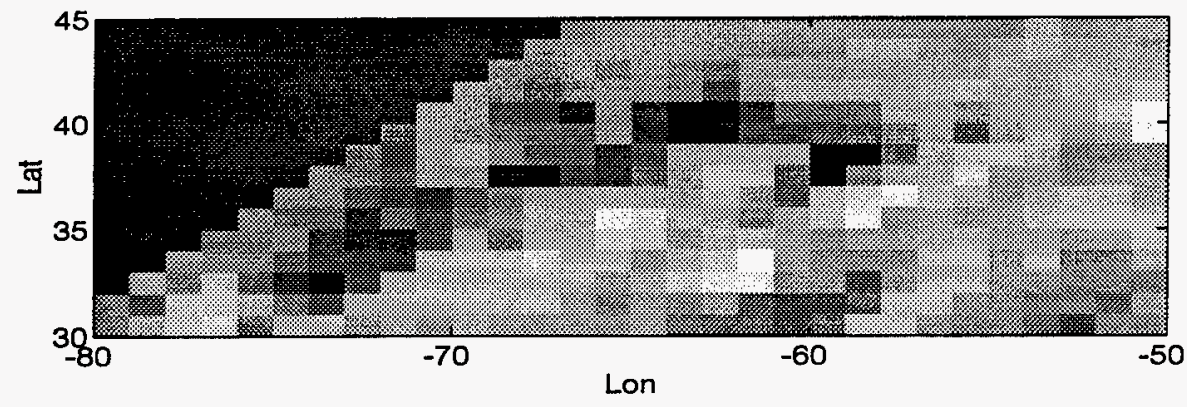

Mode1 ( $\left.{ }^{*} 100\right)$ covariance of rainfall
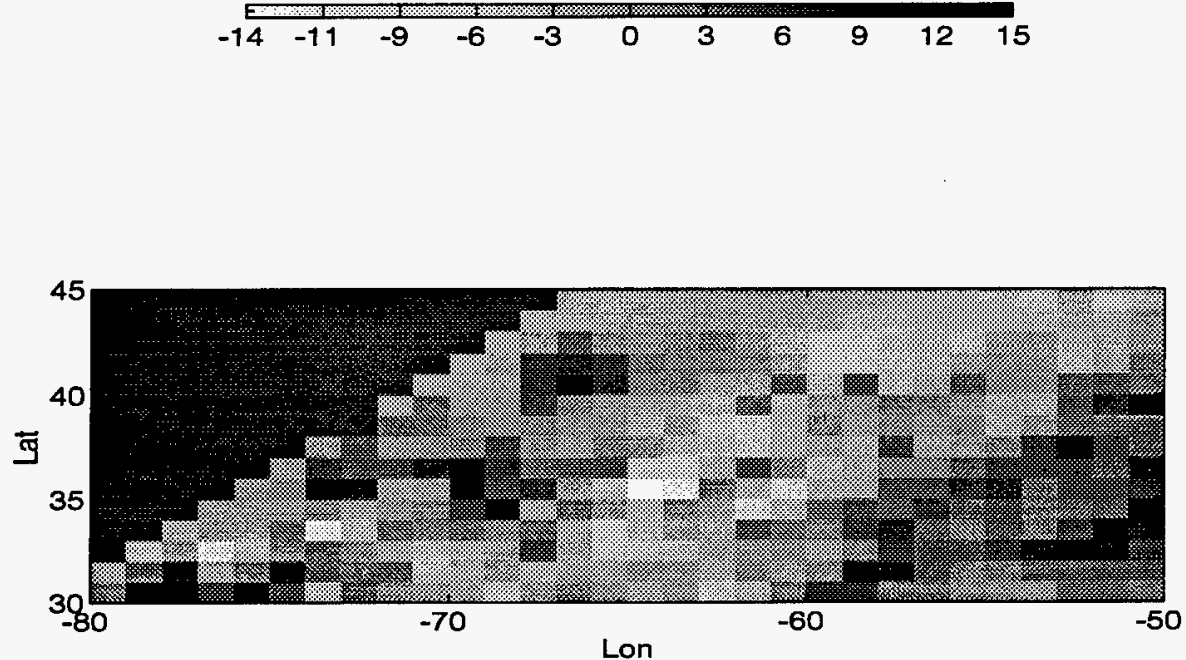

Mode2 (*100) covariance of rainfall

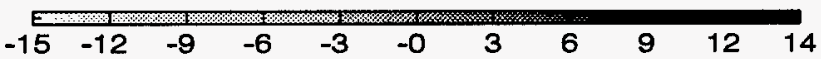

Figure 5.14. Modes one and two of Gulf Stream rainfall variability coupled with sea surface temperature. 


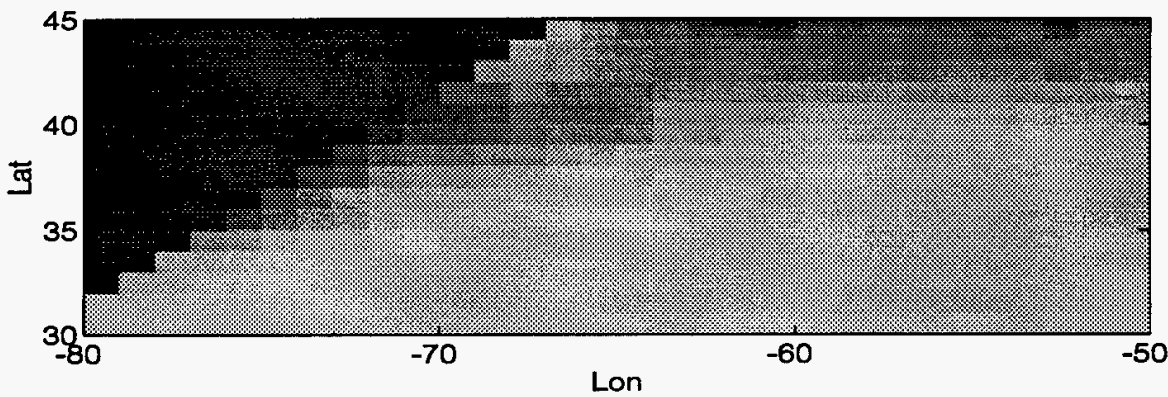

Mode1 ("100) covariance of sst
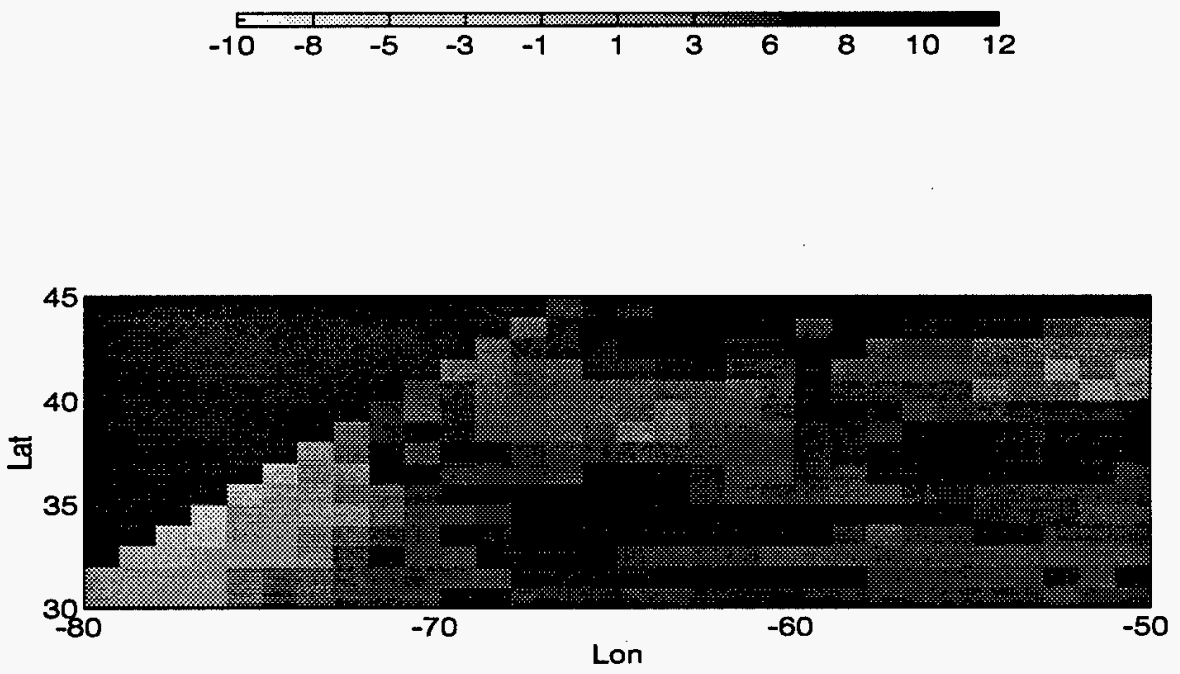

Mode2 (*100) covariance of sst

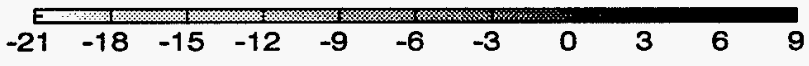

Figure 5.15. Modes one and two of Gulf Stream sea surface temperature variability coupled with rainfall. 

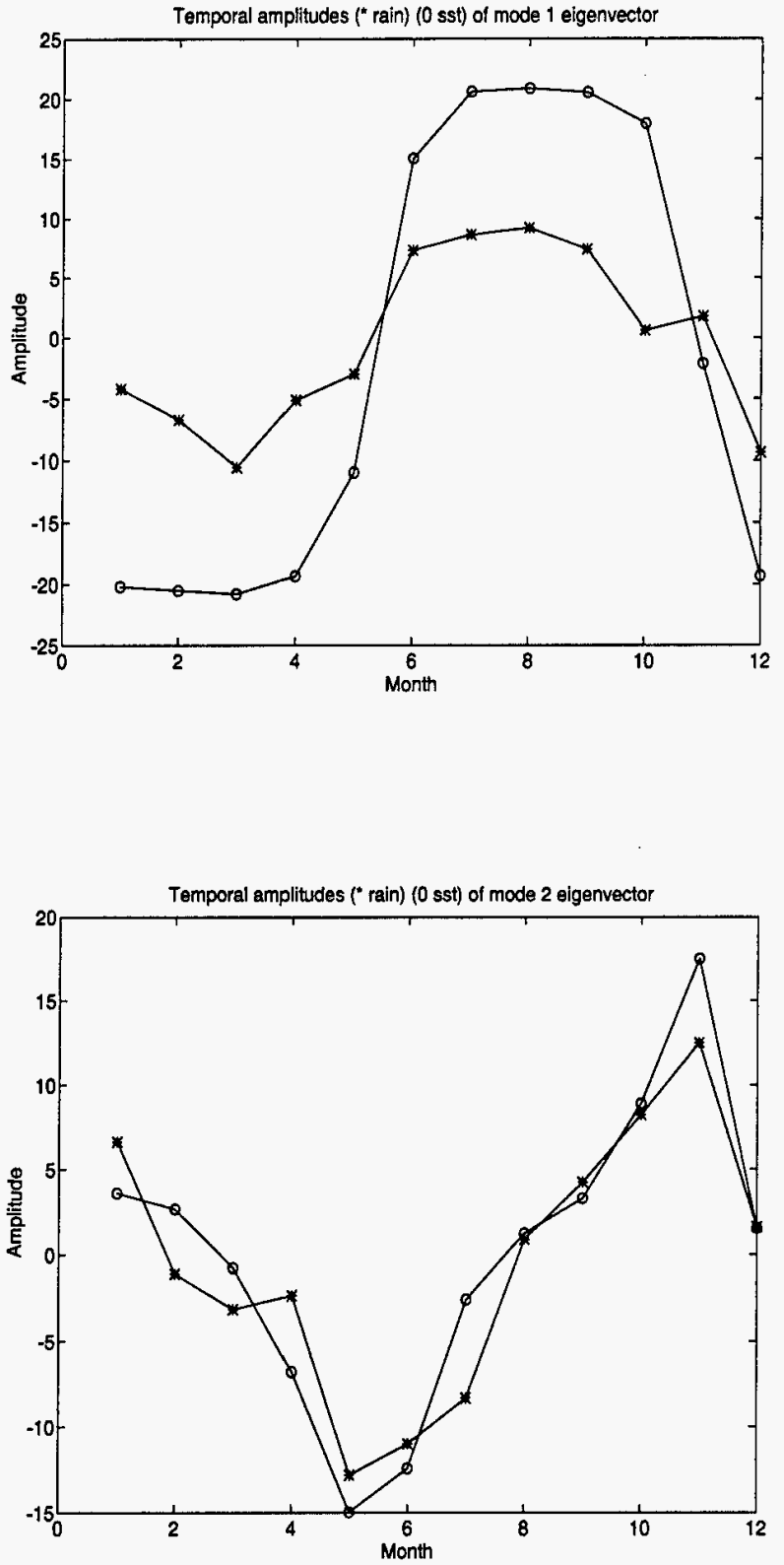

Figure 5.16. Temporal amplitudes of modes one (upper) and two (lower) of the singular value decomposition of rainfall and sea surface temperatures over the Gulf Stream. 


\subsection{Rain edge detection over the African Sahel}

The global rainfall maps in section 5.2 reveal an equatorial band of intense rainfall associated with the intertropical convergence zone (ITCZ). The maps also reveal the annual latitudinal oscillation of the ITCZ rainfall about the equator. In the African Sahel, a region on the edge of the rainfall band connecting the Sahara desert and the equatorial rain forests, the variability of the annual oscillation leaves some areas without rainfall for extended periods of time. In addition to the immediate effects on the people of the Sahel, these droughts are important because they can lead to desertification of fertile grasslands (Bryson 1977).

The SSM/I rainfall maps can be applied to the problem of monitoring the potential droughts and desertification. Figure 5.17 shows the monthly rainfall over northern Africa during 1988 bounded by 20 West and 60 East longitude and -20 and 20 latitude. The stark gradient between the Sahara desert and the rain forests of the Congo region are evident as is the north-south movement of the rainfall band over the course of the year. An edge detection technique is applied to the data to find the northern extent of rainfall greater than $10 \mathrm{~mm} / \mathrm{month}$ as a function of longitude. The technique simply searches from the central Sahara desert down each longitude until the first incidence of rainfall is detected. Figure 5.18 shows the latitude of the rainfall edge as a function of longitude and month. The rain edge diagram can be used in the following way: determine the longitude of the region of interest and then find the latitude of northernmost rainfall for each month of the year. Using the diagram, the time series of rainfall incidence can be determined for any location in the Sahel and the severity of drought inferred.

The pattern of rainfall edge is most stable over the longitudes between 10 West and 40 East. Further east the influence of the Ethiopian mountains disrupts the organization of the ITCZ and consequently the latitudinal consistency of the rainfall band. This may explain why Somalia and Ethiopia are especially vulnerable 
to drought; it may also suggest that the predictability of droughts in these regions is more difficult than in central Africa. In central African regions along the rain edge there is enough variability that adjacent regions may differ in the severity of drought. This diagram could be used to assess the severity of ongoing drought and to direct people to regions of more abundant water. 

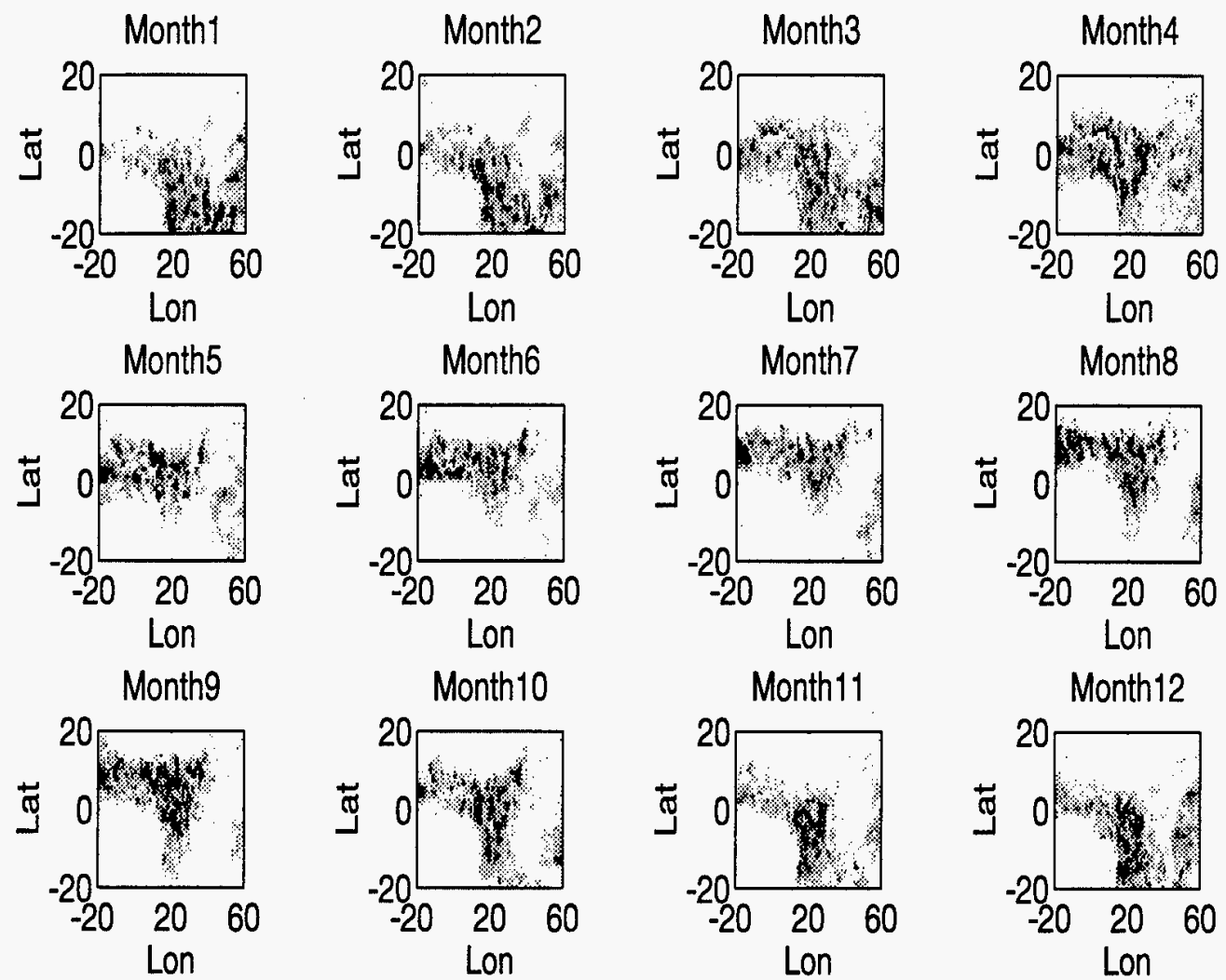

Monthly Central African Rainfall (mm) for 1988

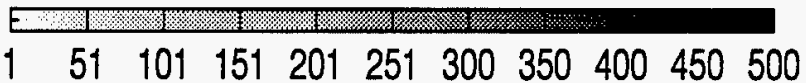

Figure 5.17. Monthly rainfall in Northern Africa estimated from SSM/I during 1988. 


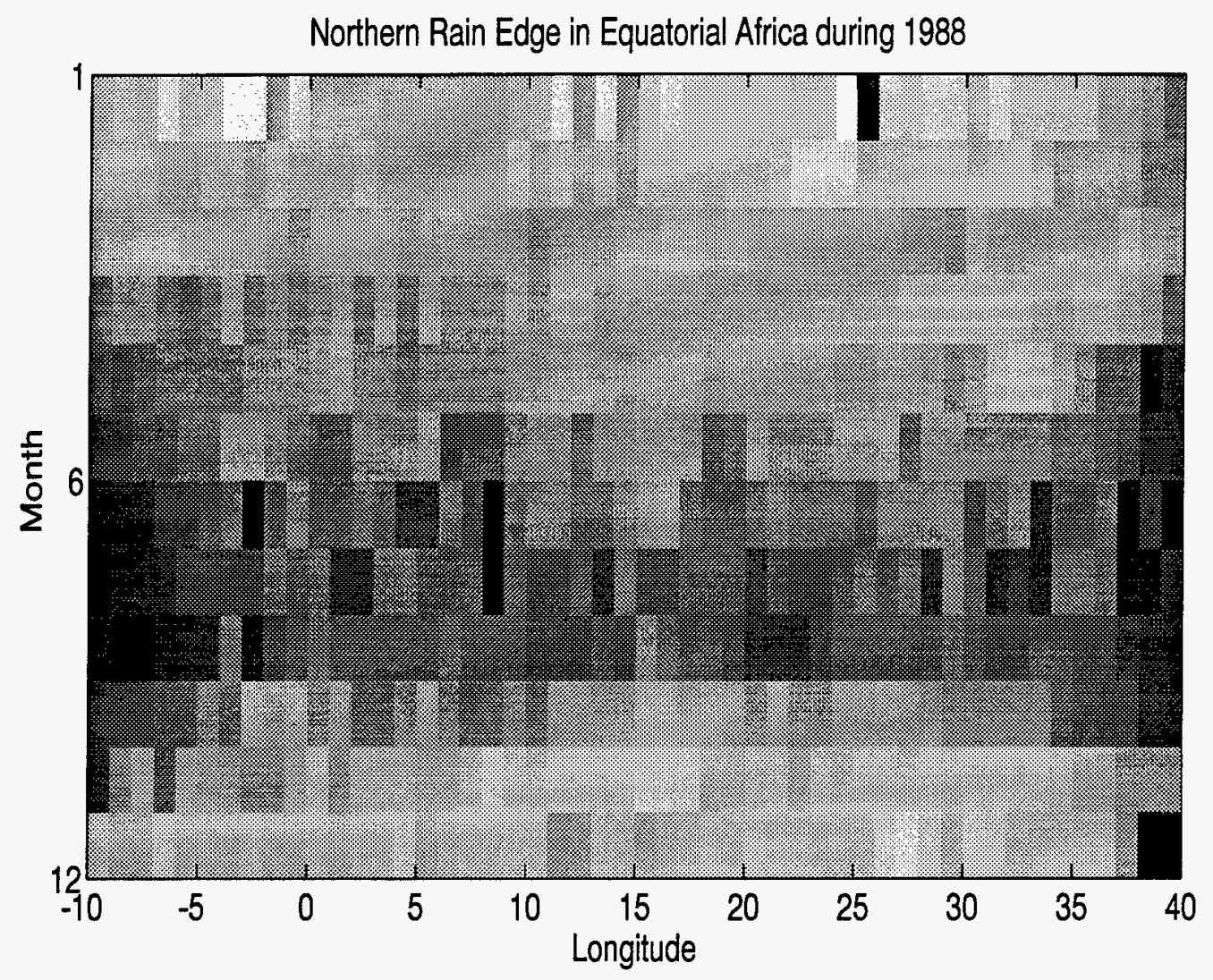

Latitude

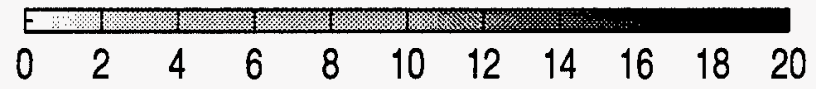

Figure 5.18: Northern boundary of the ITCZ rainfall over Africa during 1988. 


\section{CHAPTER 6}

\section{CONCLUSIONS}

A method for estimating global rainfall using a satellite microwave radiomenter has been presented. Theoretical microwave radiances upwelling through a cloud model are calculated and an algorithm for inverting measured multispectral brightness temperatures to underlying rain rates is constructed for the Special Sensor Microwave/Imager (SSM/I). A combination of checks to screen out non-raining background conditions that exhibit microwave signatures similar to rainfall and a linear inversion formula to estimate rain rate comprise the algorithm. A correction compensates for the non-linear brightness temperature response to inhomogeneous rain rates within the radiometer field-of-view. The rainfall estimation technique is constructed to be relatively insensitive to background conditions by using separate formulations over land and ocean and by using brightness temperature polarization and frequency differences.

$\mathrm{SSM} / \mathrm{I}$ rainfall estimates are compared to a variety of alternative measurements. Instantaneous rainfall estimates are compared to surface radar data from varied climatic regions. Global raingauge climatologies are compared to seasonally averaged rain rates. The validation comparisons are used in a statistical analysis to determine relative rain rate estimate errors. Theoretically modeled sampling scenarios are used to estimate the temporal sampling errors. The error estimates are combined into an error budget for the rainfall algorithm both for instantaneous and climate scale retrievals. The root mean square errors in instantaneous estimates are found to be about $13 \%$ over ocean and about $20 \%$ over land. The root mean square errors in global rainfall are found to range from $46 \%-50 \%$ over ocean and range from 
$63 \%-70 \%$ over land.

A climatology of global rainfall is computed from F8 SSM/I data for the period August, 1987, through December, 1989. Maps of rainfall totals depict the global rainfall distribution including the prominent equatorial band of heavy convective rainfall along the intertropical convergence zone. A difference map calculated from two phases of an El Niño cycle shows a global redistribution of rainfall from the western to the central and eastern Pacific. The variability in the climate scale rainfall is equal to the magnitude of the mean rainfall itself.

The rainfall time series is analyzed over the Gulf Stream for indications of coupling to the sea surface temperature. A singular value decomposition technique shows that there is increased rainfall corresponding to the elevated sea surface temperatures in the Gulf Stream. An edge detection technique is applied to monthly rainfall over northern Africa during 1988. The northern edge of the convective rainfall associated with the intertropical convergence zone is monitored as it migrates latitudinally over the African Sahel. The results indicate that over central Africa the edge is dominated by the seasonal cycle but that variations in drought potential can be identified between areas just $100 \mathrm{~km}$ apart. This would suggest that the effects of drought on people in the Sahel may be reduced by monitoring the evolution of drought and by determining the location of nearby areas of refuge. Over the Ethiopian mountains and Somalia the high variability of the northern rainfall edge indicates that these regions receive sporadic rainfall that is not well defined by the ITCZ.

The rainfall estimation technique using SSM/I brightness temperatures can be readily incorporated into existing processing software. With the current operational stature of the SSM/I instruments on three orbiting spacecraft, a long term climatology of rainfall will be available. The time series will be suitable for rainfall 
predictive studies and for quantifying part of the Earth's hydrologic and energy cycles. There is great potential for integrating global rainfall maps with other climate parameters in order to further our understanding of the interactions governing the Earth system. 


\section{BIBLIOGRAPHY}

Adler, Robert F., and Andrew J. Negri. "A satellite infrared technique to estimate tropical convective and stratiform rainfall". J. Appl. Meteor., 27:30-51, 1988.

Adler, Robert F., Andrew J. Negri, Peter R. Keehn and Ida M. Hakkarinen. "Estimation of monthly rainfall over Japan and surrounding waters from a combination of low-orbit microwave and geosynchronous IR data". J. Appl. Meteor., 32:335-356, February 1993.

Arkin, Phillip A. and Bernard N. Meisner. "The relationship between large-scale convective rainfall and cold cloud over the western hemisphere during 198284". Mon. Wea. Rev., 115:297-316, January 1987.

Arkin, Phillip A. and Philip E. Ardanuy. "Estimating climatic-scale precipitation from space: A review". J. Climate, 2:1229-1238, November 1989.

Atlas, David, Daniel Rosenfield and David A. Short. "The estimation of convective rainfall by area integrals: 1 . The theoretical and empirical basis". J. Geophys. Res., 95:2153-2160, February 28, 1990.

Barrett, E., and R. Adler, K. Arpe, P. Bauer, W. Berg, A. Chang, R. Ferraro, J. Ferriday, S. Goodman, Y. Hong, J. Janowiak, C. Kidd, D. Kniveton, M . Morrissey, W. Olson, G. Petty, B. Rudolf, A. Shibata, E. Smith, R. Spencer. "The First WetNet Precipitation Intercomparison Project (PIP1): Interpretation of results". Remote Sensing Reviews, 1994. In Press.

Bell, Thomas L. "A space-time stochastic model of rainfall for satellite remotesensing studies". J. Geophys. Res., 92:9631-9643, August 20, 1987.

Bell, Thomas L., A. Abdullah, Russell L. Martin and Gerald R. North. "Sampling errors for satellite-derived tropical rainfall: Monte Carlo study using a space-time stochastic model". J. Geophys. Res., 96:2195-2205, February 28, 1990.

Berg, Wesley and Robert Chase. "Determination of mean rainfall from the Special Sensor Microwave/Imager (SSM/I) using a mixed lognormal distribution". J. Atmos. Oceanic Technol., 9:129-141, April 1992.

Berg, Wesley Keith. Estimation and Analysis of Climate-Scale Rainfall over the Tropical Pacific. PhD thesis, University of Colorado, 1993. 
Berg, Wesley and Susan K. Avery. "An evaluation of monthly rainfall estimates derived from SSM/I over the tropical Pacific". submitted to J. Geophys. Res., 1994.

Berg, Wesley and Susan K. Avery. "Rainfall variability over the tropical Pacific from July 1987 through December 1991 as inferred via monthly estimates from SSM/I". J. Appl. Meteor., in press, 1994.

Bretherton, Christopher S., Catherine Smith and John M. Wallace. "An intercomparison of methods for finding coupled patterns in climate data". J. Climate, 5:541-560, June 1992.

Bryson, Reid A. and Thomas J. Murray. Climates of Hunger. The University of Wisconsin Press, 1977.

Cane, Mark A. "Oceanographic events during El Nino". Science, 222:1189-1195, December 16, 1983.

Chang, Alfred T. C., Long S. Chiu, and Thomas T. Wilheit. "Random Errors of Oceanic Monthly Rainfall Derived from SSM/I Using Probability Distribution Functions". Mon. Wea. Rev., 121(8):2351-2354, 1993.

Chiu, Long S., Gerald R. North, David A. Short and Alan McConnell. "Rain estimation from satellites: Effect of finite field of view". J. Geophys. Res., 95:2177-2185, February 28, 1990.

Ferriday, James G. and Christian D. Kummerow. "Estimating instantaneous horizontal rainfall variability from space". In Proceedings of the Specialist Meeting on Microwave Radiometry and Remote Sensing Applications, pages 284-288. NOAA, National Technical Information Service, 1992.

Ferriday, James G. and Susan K. Avery. "Passive microwave remote sensing of rainfall with SSM/I: Algorithm development and implementation". J. Appl. Meteor., December 1994. In Press.

Garcia, Oswaldo. Atlas of Highly Reflective Clouds for the Global Tropics: 1971-1983. U.S. Department of Commerce, National Oceanic and Atmospheric Administration, Environmental Research Laboratories, Boulder, CO, December 1985.

Global Precipitation Climatology Center. Monthly precipitation estimates based on gauge measurements on the continents for the year 1987. Technical Report DWD/K7/WZN-1992/08-1, World Meteorological Organization, August 1992.

Grody, Norman C. "Classification of snow cover and precipitation using the Special Sensor Microwave Imager (SSM/I)". J. Geophys. Res., 96:7423-7435, April 20, 1991. 
Hendon, Harry H. and Karen Woodberry. "The diurnal cycle of precipitation". submitted to J. Geophys. Res., 1992.

Hollinger, J., R. Lo and G. Poe. Special Sensor Microwave/Imager User's Guide. Naval Research Laboratory, Washington, D.C., September 14, 1987.

Hollinger, James P., James L. Pierce and Gene A. Poe. "SSM/I instrument evaluation". IEEE Trans. Geosci. Remote Sensing, 28:781-790, September 1990.

Hollinger, J. DMSP Special Sensor Microwave/Imager Calibration/Validation. Naval Research Laboratory, Washington, D.C., May 20, 1991.

Kniveton, D.R., C. Kidd, E.C. Barrett, B. Motta, M. Smith, M. Goodman. WetNet First Precipitation Intercomparison Project Results. Technical report, Earth Scences and Applications Division, G.C. Marshall Space Flight Center, NASA, April 1993.

Kummerow, Christian, Robert A. Mack and Ida M. Hakkarinen. "A self-consistency approach to improve microwave rainfall rate estimation from space". J. Appl. Meteor., 28:869-884, September 1989.

Laughlin, Charles R. "On the effect of temporal sampling on the observation of mean rainfall". In D. Atlas and O. Thiele, editors, Precipitation Measurements from Space, pages D59-D66, Greenbelt, MD, 1981. NASA: Goddard Space Flight Center. Workshop Report.

Lee, Tim H., John E. Janowiak and Phillip A. Arkin. Atlas of Products from the Algorithm Intercomparison Project 1: Japan and Surrounding Oceanic Regions (June - August 1989). Technical report, The University Corporation for Atmospheric Research, 1991. 131 pages.

Legates, David R. and Cort J. Willmott. "Mean seasonal and spatial variability in gauge-corrected, global precipitation". Int. J. Climatol., 10:111-127, 1990.

Liou, Kuo-Nan. An Introduction to Atmospheric Radiation. Academic Press, San Diego, CA, 1980. International Geophysical Series, Volume 26.

Liu, Guosheng and Judith A. Curry. "Retrieval of precipitation from satellite microwave measurement using both emission and scattering". J. Geophys. Res., 97(D9):9959-9974, June 1992.

Marshall, J.S. and W. McK. Palmer. "The distribution of raindrops with size". J. Meteor., 5:165-166, August 1948.

McConnell, Alan and Gerald R. North. "Sampling errors in satellite estimates of tropical rain". J. Geophys. Res., 92:9567-9570, August 20, 1987. 
Mitchell, J.F.B., S. Manabe, V. Meleshko and T. Tokioka. "Equilibrium climate change - and its implications for the future". Climate Change: The IPCC Scientific Assessment, pages 131-172, 1990.

Morrissey, Mark L. and J. Scott Greene. The Pacific Atoll Raingage Data Set. Technical report, University of Hawaii, Manoa, Honolulu, Hawaii 96822, 1991.

Morrissey, Mark L. and J. Scott Greene. "Comparison of two satellite-based rainfall algorithms using Pacific atoll raingage data". J. Appl. Meteor., 32:411425, February 1993.

Mugnai, Alberto and Eric A. Smith. "Radiative transfer to space through a precipitating cloud at multiple microwave frequencies. Part I: Model description". J. Appl. Meteor., 27:1055-1073, September 1988.

Negri, Andrew J. and Robert F. Adler. "The addition of visible channel data to satellite infrared rain estimation schemes". In Third Conference on Satellite Meteorology and Oceanography, pages 325-330. American Meteorological Society, January 31 - February 51988.

North, Gerald R. and Shoichiro Nakamoto. "Formalism for comparing rain estimation designs". J. Atmos. Oceanic Technol., 6:985-992, December 1989.

Olson, William S. "Physical retrieval of rainfall rates over the ocean by multispectral microwave radiometry: Application to tropical cyclones". J. Geophys. Res., 94:2267-2279, February 20, 1989.

Pickard, George L. and William J. Emery. Descriptive Physical Oceanography. Pergamon Press, New York, fourth edition, 1982.

Prabhakara, C., G. Dalu, R. Suhansini, J. J. Nucciarone, and G. L. Liberti. "Rainfall over oceans: remote sensing from satellite microwave radiometers". Meteorol. Atmos. Phys., 47:177-199, 1992.

Rasmusson, Eugene M. and John M. Wallace. "Meteorological aspects of the El Nino/Southern Oscillation". Science, 222:1195-1202, December 16, 1983.

Reynolds, Richard W. "A real-time global sea surface temperature analysis". J. Climate, 1(1), Jan 1988.

Short, David A. and Gerald R. North. "The beam filling error in the Nimbus 5 Electronically Scanning Microwave Radiometer observations of Global Atlantic Tropical Experiment rainfall". J. Geophys. Res., 95:2187-2193, February 28, 1990.

Simpson, Joanne. "Tropical rainfall from space". In John S. Theon and Nobuyoshi Fugono, editors, Tropical Rainfall Measurements, pages 1-7. A. Deepak, 1988. 
Smith, Eric A. and Alberto Mugnai. "Radiative transfer to space through a precipitating cloud at multiple microwave frequencies. Part II: Results and analysis". J. Appl. Meteor., 27:1074-1091, September 1988.

Spencer, Roy W., Barry B. Hinton and William S. Olson. "Nimbus-7 $37 \mathrm{GHz}$ radiances correlated with radar rain rates over the Gulf of Mexico". J. Climate Appl. Meteor., 22:2095-2099, December 1983.

Spencer, Roy W. "A satellite passive 37-GHz scattering-based method for measuring oceanic rain rates". J. Climate Appl. Meteor., 25:754-766, June 1986.

Spencer, Roy W., Michael H. Goodman and Robbie E. Hood. "Precipitation retrieval over land and ocean with the SSM/I: Identification and characteristics of the scattering signal". J. Atmos. Ocean. Technol., 6:254-273, 1989.

Stidd, Charles K. "The use of eigenvectors for climatic estimates". J. Appl. Meteor., 6:255-264, April 1967.

Tao, W. -K., J. Simpson, and S. -Y. Soong. "The Statistical Properties of a Cloud Ensemble: A Numerical Study". J. Atmos. Sci., 44:3175-3187, 1987.

Wentz, Frank J. User's Manual SSM/I Geophysical Tapes. Technical Report 060989, Remote Sensing Systems, Santa Rosa, CA, June 9, 1989.

Wentz, Frank J. User's Manual SSM/I Antenna Temperature Tapes, Revision 1. Technical Report 120191, Remote Sensing Systems, Santa Rosa, CA, December 1, 1991.

Weng, Fuzhong, Ralph R. Ferraro and Norman C. Grody. "Global precipitation estimations using DMSP F-10 and F-11 Special Sensor Microwave Imager (SSM/I) Data". October 1993.

Wilheit, T.T. and A.T.C. Chang. "An algorithm for retrieval of ocean surface and atmospheric parameters from the observations of the scanning multichannel microwave radiometer". Rad. Sci., 15:525-544, May-June 1980.

Wilheit, Thomas T. "Some comments on passive microwave measurement of rain". Bull. Amer. Meteor. Soc., 67:1226-1232, October 1986.

Wilheit, Thomas T., Alfred T.C. Chang and Long S. Chiu. "Retrieval of monthly rainfall indices from microwave radiometric measurements using probability distribution functions". J. Atmos. Oceanic Technol., 8:118-136, 1989.

Wilheit, T., and R. Adler, S. Avery, E. Barrett, P. Bauer, W. Berg, A. Chang, J. Ferriday, N. Grody, S. Goodman, C. Kidd, D. Kniveton, C. Kummerow, A. Mugnai, W. Olson, G. Petty, A. Shibata, E. Smith, R Spencer. "Algorithms for the retrieval of rainfall from passive microwave measurements". Remote Sensing Reviews, 1994. In Press. 
Wu, Rongzhang and J.A. Weinman. "Microwave radiances from precipitating clouds containing aspherical ice, combined phase, and liquid hydrometeors". J. Geophys. Res., 89:7170-7178, August 201984.

Yasunari, Tetsuzo. The Global Role of Tropical Rainfall, chapter "Role of Monsoon on global climate", pages 129-143. A. Deepak, 1991. 
M97053794

Report Number (14)DOE/OR/00033- T T62

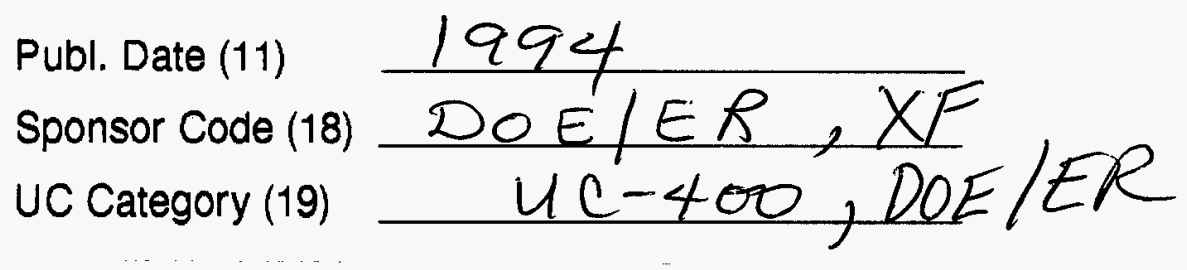

DOE 